\title{
ASSOCIAÇÃO ENTRE POLIMORFISMOS GENÉTICOS E PARÂMETROS DA CURVA DE CRESCIMENTO EM BOVINOS DE CORTE
}

\author{
CLAUDIA CRISTINA PARO DE PAZ
}

\author{
Tese apresentada à Escola Superior de \\ Agricultura "Luiz de Queiroz", Universidade de \\ São Paulo, para obtenção do título de Doutor em \\ Agronomia, Área de Concentração: Ciência \\ Animal e Pastagens.
}

\author{
P I R A C I C A B A \\ Estado de São Paulo - Brasil \\ Outubro - 2002
}




\title{
ASSOCIAÇÃO ENTRE POLIMORFISMOS GENÉTICOS E PARÂMETROS DA CURVA DE CRESCIMENTO EM BOVINOS DE CORTE
}

\author{
CLAUDIA CRISTINA PARO DE PAZ \\ Zootecnista
}

Orientador: Prof. Dr. IRINEU UMBERTO PACKER

\begin{abstract}
Tese apresentada à Escola Superior de Agricultura "Luiz de Queiroz", Universidade de São Paulo, para obtenção do título de Doutor em Agronomia, Área de Concentração: Ciência Animal e Pastagens.
\end{abstract}

P I R A C I C A B A

Estado de São Paulo - Brasil

Outubro - 2002 
Dados Internacionais de Catalogação na Publicação (CIP) DIVISÃO DE BIBLIOTECA E DOCUMENTAÇÃO - ESALQ/USP

Paz, Claudia Cristina Paro de

Associação entre polimorfismos genéticose parâmetros da curva de crescimento em bovinos de corte / Claudia Cristina Paro de Paz. - -

Piracicaba, 2002.

$107 \mathrm{p}$.

Tese (doutorado) - Escola Superior de Agricultura Luiz de Queiroz, 2002. Bibliografia.

1. Bovino de corte 2. Crescimento a nimal 3. Marcador genético 4. Melhoramento genético a nimal 5. Polimorfismo I. Título

CDD 636.213

"Permitida a cópia total ou parcial deste documento, desde que citada a fonte - $\mathrm{O}$ autor" 


\title{
DEDICO
}

\author{
Ao Eduardo, \\ pelo amor, carinho, incentivo, compreensão e paciência \\ durante a edição deste trabalho e concretização deste título.
}

OFEREÇO aos meus pais, Antonio

e Maria Luiza, aos meus irmãos, Fábio $e$ Fabrícia, aos meus cunhados, Leandro $e$ Elisa, às minhas sobrinhas Mariana e Ana Carolina, à minha tia Cida, e a todos, que pela dedicação à ciência, empenharam-se no desenvolvimento deste trabalho. 


\section{As Virtudes Recomendadas}

\section{Romanos 12: 9-21}

“O amor seja sem hipocrisia. Detestai o mal, apegando-vos ao bem. Amai-vos cordialmente uns aos outros com amor fraternal, preferindo-vos em honra uns aos outros. Regozijai-vos na esperança, sede pacientes na tribulação, na oração perseverantes. Compartilhai as necessidades do próximo, praticai a hospitalidade. Abençoai aos que vos perseguem, abençoai e não amaldiçoeis. Alegrai-vos com os que se alegram, e chorai com os que choram. Tende o mesmo sentimento uns para com os outros; em lugar de serdes orgulhosos, condescendei com o que é humilde; não sejais sábios aos vossos próprios olhos. Não torneis a ninguém mal por mal; esforçai-vos por fazer o bem perante todos os homens. Se possível quando depender de vós, tende paz com todos os homens. Não vos vingueis a vós mesmos, por a Deus pertence a justiça. Pelo contrário, se o teu inimigo tiver fome, dá-lhe de comer; se tiver sede, dá-lhe de beber; porque fazendo isto, amontoarás brasas vivas sobre a tua cabeça. Não te deixes vencer do mal, mas vence o mal com o bem."

\section{O Amor é o Dom Supremo \\ 1 Coríntios 13: 1-13}

"Ainda que eu fale as línguas dos homens e dos anjos, se eu não tiver amor, serei como bronze que soa, ou como o címbalo que retine. Ainda que eu tenha o dom de profetizar e conheça todos os mistérios e toda a ciência; ainda que eu tenha tamanha fé ao ponto de transpor montes, se eu não tiver amor nada serei. E ainda que eu distribua todos os meus bens entre os pobres, e ainda que entregue meu próprio corpo para ser queimado, se não tiver amor nada disso se aproveitará. O amor é paciente, é benigno, o amor não arde em ciúmes, não se ufana, não se ensoberbece, não conduz inconvenientemente, não procura seus interesses, não se exaspera, não se ressente do mal, não se alegra com a injustiça, mas regozija-se com a verdade; tudo sofre, tudo crê, tudo espera, tudo suporta. $O$ amor jamais acaba, mas havendo profecias desaparecerão; havendo ciência, passará. Porque em parte conhecemos e em parte profetizamos. Quando, porém, vier o que é perfeito, então o que é em parte será aniquilado. Porque agora vemos com em espelho, obscuramente, então veremos face a face; agora conheço em parte, então conhecerei como também sou conhecido. Agora, pois, permanecem a fé, a esperança e o amor, estes três: porém o maior destes é o amor." 


\section{AGRADECIMENTOS}

À Deus, pela minha vida, pelas graças e bênçãos concedidas e por nunca ter me desamparado, mesmos nos momentos mais difíceis eu sentia Tua presença, Teus cuidados e Teu grande e infinito Amor.

Ao grande "Mestre" e estimado orientador, Dr. Irineu Umberto Packer, Professor Titular do Departamento de Zootecnia, da Escola Superior de Agricultura "Luiz de Queiroz", Universidade de São Paulo, pela orientação, confiança, ensinamentos, amizade apoio e incentivo concedidos na execução deste trabalho.

Ao pesquisador da Embrapa Pecuária Sudeste, Dr. Alfredo Ribeiro de Freitas, pelas conversas, discussões, paciência e principalmente pela co-orientação não oficial deste trabalho.

Ao Dr. Maurício Mello de Alencar e à Dr. ${ }^{a}$ Luciana Corrêa de Almeida Regitano, pesquisadores da Embrapa Pecuária Sudeste, pelo apoio e por terem cedido os conjuntos de dados fenotípicos e genotípicos dos animais utilizados neste estudo.

À Daniela Tambasco-Talhari, doutoranda da Universidade Federal de São Carlos, por ter executado todo trabalho de laboratório referente aos genótipos dos animais utilizados neste trabalho.

À amiga Lenira, pela paciência de ler este trabalho e pelas valiosas sugestões apresentadas.

Ao estimado professor Dr. Eduardo Delgado, pela leitura deste trabalho, e à sua família pelas orações e carinho.

Aos professores Dr. Valdomiro, Dr. Fernando Menten, Dr. José Eurico, Dr.

Luciano e Dr. Luiz Coutinho, do Departamento de Zootecnia, da Escola Superior de Agricultura “Luiz de Queiroz”, Universidade de São Paulo, pela convivência agradável. 
Às secretárias Cláudia e Vera, e ao funcionário José Henrique, do Departamento de Zootecnia da ESALQ-USP, pela atenção dispensada.

À bibliotecária da ESALQ-USP, Eliana Maria Garcia, pela revisão da tese.

Aos amigos Maria Gristina, Sueli e Silvano, do curso de pós-graduação em "Estatística e Experimentação Agronômica" da ESALQ-USP, pela amizade, incentivo e sugestões no decorrer do período do doutoramento.

Aos amigos Carla Nússio, Sarah, Paulo, Daniela, José Otávio, Adriana, Flávio, Aline, Juliano, Carlos Eduardo, Liliana, Cláudio, Juliana e Itiberê, do curso de pós-graduação em "Ciência Animal e Pastagens" da ESALQ-USP, pela convivência e amizade.

À Escola Superior de Agricultura "Luiz de Queiroz", Universidade de São Paulo (ESALQ-USP), e à Embrapa Pecuária Sudeste, São Carlos-SP, pela confiança e apoio demostrando neste trabalho.

Ao Instituto de Zootecnia e à Agência Paulista de Tecnologia dos Agronegócios, pelo afastamento concedido sem o qual não seria possível a obtenção deste título.

Ao suporte financeiro concedido pelo Conselho Nacional de Desenvolvimento Científico e Tecnológico ( $\mathrm{CNPq}$ ), para o aprimoramento de meus conhecimentos e obtenção do título de Doutor. 


\section{SUMÁRIO}

Página

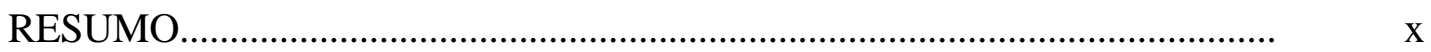

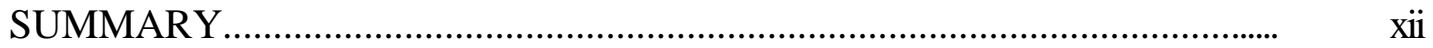

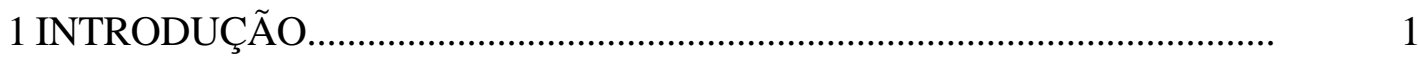

2 REVISÃO DE LITERATURA .............................................................. 4

2.1 Análise genômica ..................................................................................

2.1.1 Marcadores e o melhoramento animal........................................................

2.1.2 Associação entre os polimorfismos dos genes da kappa-caseína, do hormônio do crescimento e da $\beta$-lactoglobulina e características produtivas............................................................................ 10

2.2 Utilização dos modelos não lineares para descrever o crescimento............... 12

2.2.1 Regressão do peso em função da idade............................................... 12

2.2.2 Considerações sobre modelos de crescimento ....................................... 16

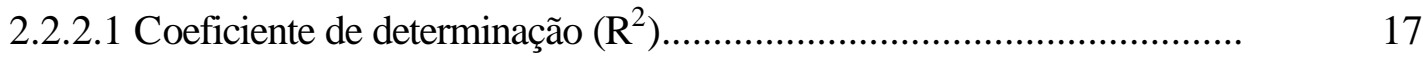

2.2.2.2 Comparação entre funções de crescimento....................................... 18

3 AJUSTE DOS MODELOS NÃO LINEARES NO ESTUDO DA ASSOCIAÇÃO ENTRE POLIMORFISMOS GENÉTICOS E CRESCIMENTO EM BOVINOS DE CORTE. ................................... 21

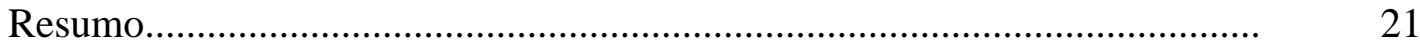

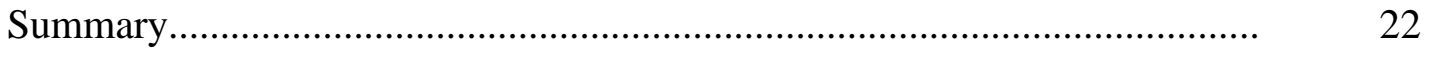

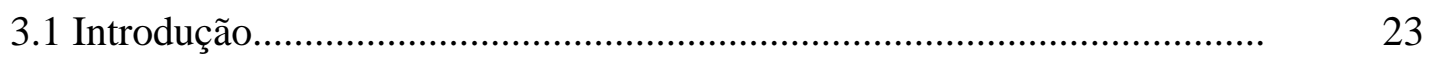

3.2 Material e Métodos........................................................................... 25 


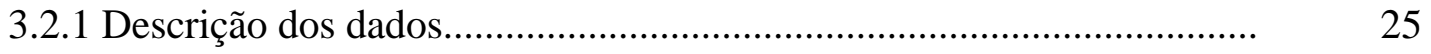

3.2.2 Análises estatísticas........................................................................... 26

3.2.2.1 Ajuste dos modelos nãolineares........................................................ 26

3.2.2.2 Escolha do modelo............................................................................ 28

3.3 Resultados e Discussão.......................................................................... 29

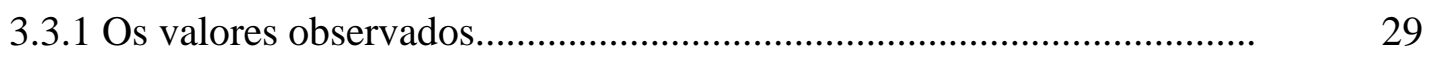

3.3.2 Pré-correção dos dados......................................................................... 31

3.3.3 Ajuste dos modelos.....................................................................

3.3.3.1 Grupos genéticos........................................................................

3.3.3.2 Genótipos.......................................................................................

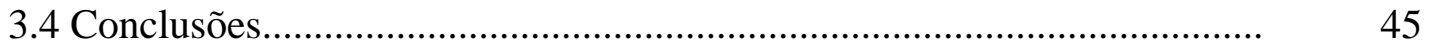

4 INFLUÊNCIA DOS POLIMORFISMOS GENÉTICOS SOBRE OS PARÂMETROS DA CURVA DE CRESCIMENTO EM BOVINOS DE

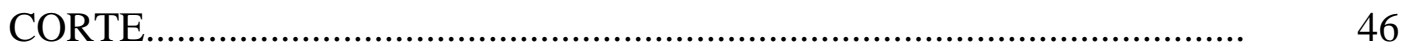

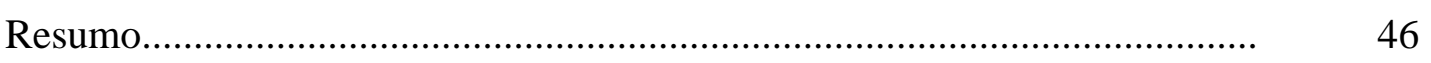

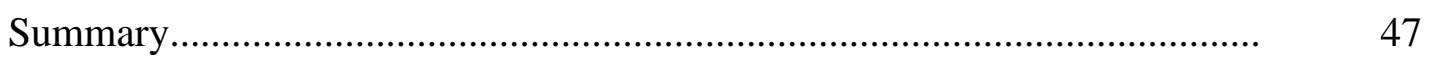

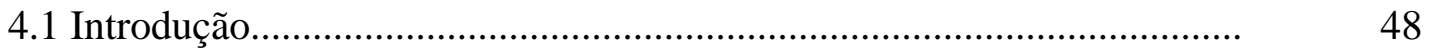

4.2 Material e Métodos............................................................................. 50

4.2.1 Descrição dos dados............................................................................

4.2.2 Análises estatísticas........................................................................

4.2.2.1 Erro de predição..............................................................................

4.2.2.2 Comparação entre os genótipos.......................................................... 52

4.3 Resultados e Discussão............................................................................

4.3.1 Frequências alélica e genotípica.............................................................

4.3.2 Análises estatísticas - modelos não lineares...........................................

4.3.2.1 Erro de predição..................................................................................

4.3.2.2 Efeito dos polimorfismos genéticos sobre a curva de crescimento..... $\quad 59$

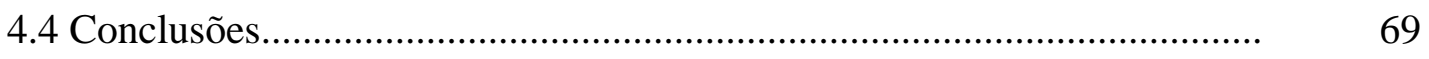

5 CONCLUSÕES GERAIS.................................................................... 


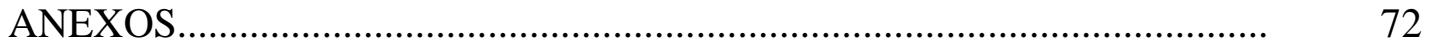

REFERÊNCIAS BIBLIOGRÁFICAS.................................................. 76

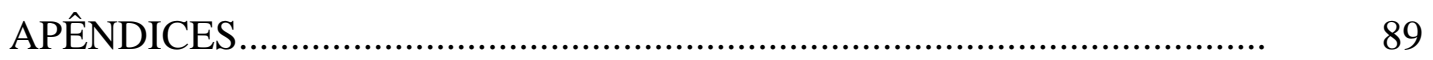




\title{
ASSOCIAÇÃO ENTRE POLIMORFISMOS GENÉTICOS E PARÂMETROS DA CURVA DE CRESCIMENTO EM BOVINOS DE CORTE
}

\author{
Autora: CLAUDIA CRISTINA PARO DE PAZ \\ Orientador: Prof. Dr. IRINEU UMBERTO PACKER
}

\section{RESUMO}

Foram analisadas informações provenientes de um experimento de avaliação de sistemas cruzamento entre raças bovinas de corte, executado na Embrapa Pecuária Sudeste, com o objetivo de avaliar o efeito dos polimorfismos genéticos da kappa-caseína-HinfI (CSN3): AA e AB, do hormônio do crescimento-AluI (GH): LL e LV e da $\beta$-lactoglobulina-HaeIII (LGB): AA, AB e BB sobre a curva de crescimento de bovinos de três grupos genéticos, 1/Nelore+1/Eanchim (NC), 1/2elore+1/20erdeenAngus (NA) e 12telore+1Simental (NS), nascidos nos anos de 1998 e 1999. Os pesos foram medidos ao nascimento, ao desmame e mensalmente dos 8 aos 19 meses de idade. As análises foram realizadas por meio de duas abordagens. Na primeira, as estimativas dos parâmetros $A$ (valor assintótico), $k$ (taxa de maturação) e $m$ (ponto de inflexão) obtidas do modelo Logístico, ajustado para descrever o crescimento de cada animal, foram analisados usando um modelo linear, que incluiu além do efeito do genótipo, o qual foi formado pela concatenação dos polimorfismos genéticos de CSN3, GH e LGB $\left(\mathrm{G}_{1}=\mathrm{AALLAA}, \quad \mathrm{G}_{2}=\mathrm{AALLAB}, \quad \mathrm{G}_{3}=\mathrm{AALLBB}, \quad \mathrm{G}_{4}=\mathrm{AALVAB}, \quad \mathrm{G}_{5}=\mathrm{AALVBB}\right.$, 
$\mathrm{G}_{6}=\mathrm{ABLLAA}, \quad \mathrm{G}_{7}=\mathrm{ABLLAB}, \quad \mathrm{G}_{8}=\mathrm{ABLLBB}, \quad \mathrm{G}_{9}=\mathrm{ABLVAA}, \quad \mathrm{G}_{10}=\mathrm{ABLVAB} \quad \mathrm{e}$ $\mathrm{G}_{11}=\mathrm{ABLVBB}$ ), o ano de nascimento, o sexo e o manejo alimentar. Para os animais do grupo genético $\mathrm{NC}$, os genótipos influenciaram significativamente as estimativas dos parâmetros $A$ e $k$ da curva de crescimento. $\mathrm{O}$ genótipo $\mathrm{G}_{3}$ apresentou valor inferior de $A$ e superior de $k$ em relação aos genótipos $\mathrm{G}_{7}$ e $\mathrm{G}_{8}$. Na segunda abordagem, os dados foram analisados por modelos não lineares, incluindo no modelo, os efeitos fixos de grupo contemporâneo e de genótipo dos genes CSN3 GH e LGB, com o objetivo de verificar a influência destes genes sobre a curva de crescimento destes animais e estimar os parâmetros da função Logística, simultaneamente. Os resultados deste estudo sugerem que a função Logística utilizada para descrever o crescimento dos grupos genéticos NC, NA e NS, foi influenciada pelos genótipos dos genes CSN3, GH e LGB. As maiores diferenças entre os genótipos dos genes CSN3, GH e LGB foram encontradas a partir dos 12-13 meses de idade. O genótipo AA para CSN3 apresentou maior taxa de maturação $(k)$ que o genótipo $\mathrm{AB}$ nos grupos genéticos $\mathrm{NC}$, NA e NS. Quanto ao valor assintótico $(A)$, diferença entre $\mathrm{AA}$ e $\mathrm{AB}$, foi pequena nos grupos genéticos NC e NS. Para o polimorfismo do GH no grupo genético NA, a curva que descreve o crescimento dos animais do genótipo LL mostrou-se mais desejável, do ponto de vista de produção de bovinos de corte. Entretanto, ocorreu uma inversão desta tendência no grupo genético NS. O mesmo ocorreu para o LGB, em que os genótipos AA e $\mathrm{AB}$ apresentaram estimativas do parâmetro $k$ superiores em relação ao genótipo $\mathrm{BB}$ no grupo genético NA, enquanto o genótipo $\mathrm{AB}$ apresentou estimativa de $k$ inferior em relação ao genótipo $\mathrm{BB}$, no grupo genético NS. Evidências de que os polimorfismos dos genes CSN3, GH e LGB estejam ligado a QTL influenciando a curva de crescimento de bovinos, indicam que no futuro os genótipos destes genes podem ser usados em programas de seleção assistida por marcadores. 


\section{ASSOCIATION BETWEEN GENETIC POLYMORPHISMS AND GROWTH CURVE PARAMETERS IN BEEF CATTLE}

Author: CLAUDIA CRISTINA PARO DE PAZ Adviser: Prof. Dr. IRINEU UMBERTO PACKER

\section{SUMMARY}

Data from a crossbreeding experiment, carried out at Embrapa Southeast Cattle Research Center, State of São Paulo, Brazil, were analyzed in order to evaluate the effects of kappa-casein-HinfI (CSN3): $\mathrm{AA}$ and AB, growth hormone-AluI (GH): LL and LV, and $\beta$-lactoglobulin-HaeIII (LGB): $\mathrm{AA}, \mathrm{AB}$ and $\mathrm{BB}$, polymorphism on the growth curve of three beef cattle crosses, 1/2ellore + 1/Eanchim (NC), 1/20llore + 1/2 Aberdeen Angus (NA) and 1/Nellore + 1 Simmental (NS). Animals were born in the years 1998 and 1999. Weight measurements were collected at birth, weaning (7 months of age) and monthly from 8 to 19 months of age. The effect these genetic polymorphisms were analyzed by two approaches. In the first one, the parameters $A$ (asymptotic value), $k$ (maturing rate) and $m$ (inflection point) estimated by Logistic model for each animal, were analyzed by least squares, fitting a linear model which included the fixed effects of the genotype, which was identified by combination of polymorphic RFLP's of the genes CSN3, GH e LGB $\left(\mathrm{G}_{1}=\mathrm{AALLAA}, \mathrm{G}_{2}=\mathrm{AALLAB}\right.$, $\mathrm{G}_{3}=\mathrm{AALLBB}, \quad \mathrm{G}_{4}=\mathrm{AALVAB}, \quad \mathrm{G}_{5}=\mathrm{AALVBB}, \quad \mathrm{G}_{6}=\mathrm{ABLLAA}, \quad \mathrm{G}_{7}=\mathrm{ABLLAB}$, $\mathrm{G}_{8}=\mathrm{ABLLBB}, \mathrm{G}_{9}=\mathrm{ABLVAA}, \mathrm{G}_{10}=\mathrm{ABLVAB}$ e $\mathrm{G}_{11}=\mathrm{ABLVBB}$ ), year of birth, sex and 
feed management. For the NC genetic groups, was detected significant effect of genotypes groups for $A$ and $k$ parameters estimates. The genotypes $\mathrm{G}$ presented inferior value of $A$ and superior of $k$ in relation to $\mathrm{G}_{7}$ and $\mathrm{G}_{8}$. In the second approach, it was fitted a Logistic non linear model which included the fixed effects of the contemporary group and genotype of the genes CSN3, GH and LGB, to examine the effect of these markers on growth curve parameters and to obtain the parameters estimates of the Logistic function, simultaneously. The growth curve used to explain the growth of the NC, NA and NS genetic groups, was influenced by genotypes of the CSN3, GH e LGB markers The major differences started at 12-13 months of age. The value of the maturing rate $(k)$ of the $\mathrm{AA}$ genotype for $\mathrm{CSN} 3$ was superior in relation to $\mathrm{AB}$ genotype in the NC, NA and NS genetic groups. However, there was observed small difference in estimate of the asymptotic value $(A)$ for the $\mathrm{AA}$ and $\mathrm{AB}$ genotypes in $\mathrm{NC}$ and NS genetic groups. For the GH polymorphism in NA genetic group the growth curve of the LL genotype showed more desirable to production of the beef cattle. The same was observed for the LGB, there were superior values of the parameter $k$ of the $\mathrm{AA}$ and $\mathrm{AB}$ genotypes in relation to the $\mathrm{BB}$ for the NA genetic group, however there was inferior value of the parameter $k$ of the $\mathrm{AB}$ genotype in relation to the $\mathrm{BB}$, for the NS genetic group. Evidences that CSN3, GH and LGB polymorphism are linked to QTL influencing growth curve in beef cattle, indicates these genotypes may be a useful marker in future maker-assisted selection programs. 


\section{INTRODUÇÃO}

A genética, conhecida como ciência da hereditariedade, está ramificada em áreas distintas como genética quantitativa e genética molecular, dentre muitas outras.

A genética quantitativa estuda a herança das diferenças entre os indivíduos, as quais são os recursos da seleção natural e artificial (Falconer \& Mackay, 1996). Há muito tempo, a seleção das diferentes espécies de animais domésticos, tem sido praticada com sucesso. Em bovinos de corte, por exemplo, tem sido feita com base na seleção de indivíduos que possuam um valor genético superior para as características de crescimento, os quais são usados como reprodutores na geração seguinte, alterando-se a constituição genética do rebanho, obtendo-se assim um incremento na produtividade.

Outra maneira de promover o melhoramento genético é por meio de sistemas de cruzamentos. Comparativamente, a seleção em populações puras pelo método tradicional explora apenas a variação genética aditiva, enquanto os sistemas de cruzamento exploram a variação genética aditiva e não aditiva. Nos cruzamentos que visam a exploração da heterose, existe grande dificuldade para manutenção dos benefícios da mesma ao longo das gerações, ou seja, a probabilidade de recuperação do melhor genótipo por meio das abordagens convencionais de seleção diminui ao longo das gerações. A seleção de parentais usando marcadores moleculares, por outro lado, pode auxiliar os sistemas de cruzamento, e com isso maximizar a probabilidade de recuperar os genótipos de interesse na progênie.

Desta forma, o desenvolvimento da genética molecular, que iniciou-se na primeira metade do século XX, com a identificação da molécula de DNA tornou-se ferramenta importante para o melhoramento genético.

Até meados dos anos de 1960, os marcadores utilizados em estudos de genética e melhoramento eram controlados por genes associados a caracteres 
morfológicos, em geral, fenótipos de fácil identificação visual. Entretanto, estes são limitados principalmente pelo pequeno número de marcadores morfológicos distintos, ou seja, baixo nível de polimorfismos (Ferreira \& Grattaplagia, 1998; Griffiths et al., 1998).

Com o desenvolvimento dos marcadores isoenzimáticos ampliou-se o número de marcadores genéticos. As novas tecnologias desenvolvidas, possibilitaram a localização de pontos de referência nos cromossomos, denominados de marcadores moleculares. Nos anos de 1980, o uso de enzimas de restrição permitiu a análise de polimorfismo de comprimento de fragmentos de restrição (RFLP) de DNA e posteriormente, com a descoberta da técnica do PCR (Reação em Cadeia de Polimerase), foram descritas outras classes de marcadores moleculares.

Assim, a visão convencional de herança poligênica dos caracteres mudou fundamentalmente com o avanço destas técnicas, permitindo a identificação de locos de características quantitativas (QTL). Os novos métodos de genética quantitativa, que têm por base as análises de marcadores moleculares e simulações computacionais, fornecem suporte no desenvolvimento de novas tecnologias para assistir programas de melhoramento genético animal e vegetal, por meio de análises minuciosas dos caracteres poligênicos, identificando regiões de regulação com importantes funções biológicas.

Os marcadores moleculares podem auxiliar melhoristas e criadores na seleção de reprodutores e em estratégias de acasalamento com o objetivo de maximizar o ganho genético, no curto prazo, e preservar a diversidade genética da população, no longo prazo.

Diversos estudos têm sido conduzidos com o objetivo de associação entre polimorfismos genéticos e características de importância econômica. Em bovinos de corte, características de composição da carcaça, pesos nas diferentes idades, ganho de peso em determinado período e caracteres de ípo como circunferência torácica, foram associadas aos polimorfismos dos genes do hormônio do crescimento, da kappa-caseína; da $\beta$-lactoglobulina e da miostatina (Lin et al., 1987; Rocha et al., 1992; Pilla et al., 1994; Moody et al., 1996; Casas et al., 1998; Casas et al., 2000; Sartore \& Di Stasio, 2000). 
Entretanto, na literatura, praticamente não existem estudos de associação entre polimorfismos genéticos e a curva de crescimento de bovinos. Até o momento, foi relatado apenas o trabalho de Unanian et al. (2000) que verificou o efeito dos polimorfismos do hormônio do crescimento (GH-AluI e GH-MspI) sobre da curva de crescimento de bovinos da raça Nelore.

Fatores inerentes a esta área de pesquisa, como o custo de obtenção das análises laboratoriais destes polimorfismos, a correlação entre os pesos obtidos ao longo da vida do animal, a estrutura incompleta dos dados e a variância crescente do peso em função da idade, devem ser considerados nos estudos de associação entre polimorfismos genéticos e o crescimento. Alternativamente, o ajuste de curvas de crescimento por meio dos modelos não lineares, pode ser minimizar estes problemas. Os objetivos principais do ajuste de funções de crescimento são descrever e predizer o crescimento dos animais além de fazer inferências com base nas interpretações dos parâmetros destas curvas (Ratkoswsky, 1983).

Os objetivos deste estudo foram investigar possíveis associações entre polimorfismos dos genes da kappa-caseína-Hinf $\mathrm{I}$ (CSN3), do hormônio do crescimentoAluI (GH) e da $\beta$-lactoglobulina-HaeIII (LGB) e a curva de crescimento de bovinos

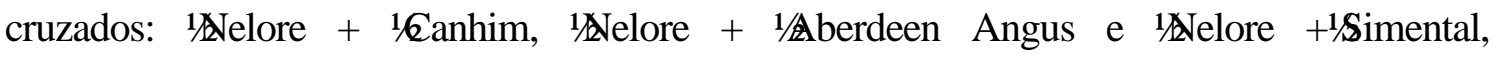
empregando-se duas abordagens de análise por meio dos modelos não lineares, e verificar a possibilidade de utilização destes polimorfismos em programas de seleção assistida por marcadores (MAS).

Para estes fins, o trabalho de tese é apresentado em dois capítulos (Capítulos 3 e 4) referentes a dois artigos científicos distintos, os quais foram enviados para o periódico Revista Brasileira de Zootecnia. No Apêndice 1, apresenta-se o terceiro artigo, que será enviado para um periódico internacional, cujo o objetivo foi estimar o número de animais necessário para se detectar diferenças mínimas significativas entre as médias, considerando-se avaliações mensais do peso dos bovinos dos três grupos genéticos. 


\section{REVISÃO DE LITERATURA}

\subsection{Análise Genômica}

A maioria das características de importância econômica em bovinos, resulta da ação conjunta de genes e ambiente, e são denominadas poligênicas, quantitativas ou de herança múltipla. O fenótipo resultante, apresenta variação contínua ao invés de classes fenotípicas discretas. Caracteres de produção, precocidade, dentre outros, são exemplos de herança quantitativa. Para a maioria destes existem poucas informações sobre o número, posição cromossômica, magnitude do efeito e interações dos locos que controlam sua expressão. Estes locos são denominados, QTL (“Quantitative Trait Locus"), ou seja locos que controlam a expressão de características quantitativas.

Progressos contínuos da genética molecular têm permitido a localização de marcadores genéticos (RFLP, isoenzimas, microssatélites, etc.) ao longo do genoma de interesse. Com a utilização destes marcadores inicia-se o trabalho de inferência sobre locos de características quantitativas (QTL). Estas características podem ser afetadas por muitos genes, entretanto, a localização (Loco) associada à característica quantitativa não pode ser descrita em um simples contexto de um mapa genético típico. A representação estatística das características quantitativas serve para dizer o quanto da variação genética nas linhas parentais contribui para a progênie, em cada região que é identificada por meio de marcadores genéticos. 
O uso de marcadores genéticos para localizar QTL está bem estabelecido (Sax, 1923; Thoday, 1961; Soller \& Brody, 1976; Edwards et al., 1987).

O primeiro e um dos principais estudos na demonstração de ligação entre diferenças dos genes de efeito maior e determinantes da variação quantitativa foi realizado por Sax (1923), que ao estudar a associação entre a pigmentação e o padrão da coloração da casca com o tamanho da planta de feijão, demonstrou a existência de segregação conjunta dos marcadores (pigmentação e padrão da coloração da casca marcadores qualitativos) com os locos que controlam a expressão da característica quantitativa (tamanho da planta). Estes resultados não foram interpretados como sendo evidência final de ligação.

Posteriormente, os resultados encontrados por Sax (1923) foram confirmados por Rasmusson (1933), que associou a cor de flores (coloridas e brancas), consideradas como marcador, com o tempo de florescimento, considerado como característica quantitativa.

Thoday (1961) e Neimann-Sorensem \& Robertson (1961), em trabalhos considerados clássicos em plantas e animais, respectivamente, estudaram o efeito das diferentes contribuições alélicas sobre a variação fenotípica.

A maioria dos estudos dos anos de 1960 usavam enzimas, proteínas ou grupos sanguíneos polimórficos como marcadores genéticos. Nestes trabalhos, as associações entre marcadores genotípicos e características quantitativas foram estudadas em população exogâmica, com indivíduos selecionados aleatoriamente e baseando-se no fato de que quando o marcador genotípico apresentava efeito direto sobre a característica (atualmente - QTL), as diferenças entre os marcadores genotípicos refletiam em diferenças nos efeitos do QTL. Em geral, estes estudos foram insuficientes na detecção de QTL, devido ao uso de marcadores genéticos morfológicos e às interações entre os marcadores. 
Nos estudos de Thoday (1961) e Neimann-Sorensem \& Robertson (1961) foi demonstrado que as dificuldade em encontrar evidências de que alguns locos gênicos estavam associados com determinado caracter quantitativo, estava relacionada com as deficiências na precisão quanto à localização dos marcadores.

$\mathrm{O}$ pequeno número de marcadores morfológicos distintos em uma mesma raça ou linhagem reduz a probabilidade de se encontrar associações significativas entre estes e os caracteres de importância econômica. Isto se deve ao fato de que a probabilidade de que um polimorfismo selecionado aleatoriamente tenha efeito direto sobre uma característica é pequena, apesar do loco estar bem ligado ao QTL (Edwards et al., 1987).

A grande mudança neste contexto iniciou-se com o desenvolvimento dos marcadores isoenzimáticos. As novas técnicas desenvolvidas na área de genética molecular, possibilitaram a localização de pontos de referência nos cromossomos, denominados de marcadores moleculares. Nos anos de 1980 o uso de enzimas de restrição permitiu a análise de polimorfismo de comprimento de fragmentos de restrição (RFLP) de DNA, e posteriormente, com a descoberta da técnica do PCR (Reação em Cadeia de Polimerase), foram descritas outras classes de marcadores moleculares.

Locos polimórficos (locos com vários alelos segregando em uma população) podem ser identificados por RFLP ou microssatélites. A técnica do RFLP é trabalhosa e necessita da pré-existência de uma biblioteca de sondas. Os microssatélites, que são regiões densas e de diferentes classes de sequências repetidas do genoma (pequenas sequências com 1 a 4 nucleotídeos de comprimento repetidas em tandem), são mais utilizados por proporcionarem maiores possibilidades de gerar grandes quantidades de segmentos específicos do genoma. Esta técnica, no entanto, necessita de conhecimento prévio das sequências de nucleotídeos.

Com a descoberta da técnica do PCR, surgiu a opção de converter marcadores RFLP em marcadores baseados em PCR e foi possível empregar os microssatélites, usando-se "primers" específicos que flanqueiam regiões específicas do 
DNA, sendo excelente sistema de genotipagem com rápida construção de mapas de ligação. Estes marcadores, denominados de moleculares (RFLP, microssatélites, etc.) têm o princípio básico de servir como base estrutural para detecção e localização de QTL, com efeitos neutros sobre o fenótipo. Esta abordagem é recente, está centrada no mapeamento do genoma e emprega a técnica de microssatélites (Rapley \& McDonald, 1992); pode ser usada para identificar regiões do genoma ou genes envolvidos com a característica quantitativa. Estes marcadores são então avaliados em estudos de correlação com características de interesse econômico e utilizados na identificação de locos que afetam caracteres quantitativos ou QTL. O sucesso desta estratégia depende da construção de mapas de ligação detalhados, com marcadores dispostos a intervalos de 20cM. Com o desenvolvimentos dos programas de mapeamento do genoma de animais domésticos e com o emprego de marcadores DNA microssatélite, um número suficiente de marcadores é encontrado na literatura, fornecendo em torno de $90 \%$ de cobertura do genoma de bovinos (Barendse et al., 1994; Bishop et al., 1994; Barendse et al., 1997).

Bishop et al. (1994) apresentaram discussão excelente sobre o desenvolvimento e o uso de marcadores na seleção animal. O mapa de ligação e posição totalizando muitas centenas de microssatélites (MS), associados ao polimorfismo no comprimento de fragmentos de restrição (RFLP), são tipos de marcadores que vem sendo desenvolvidos para cada cromossomo do genoma bovino. O uso destes marcadores combinado aos avanços nas biotécnicas de reprodução (inseminação artificial, maturação e fertilização in vitro, sexagem, etc.) oferecem perspectivas promissoras no melhoramento, devido ao aumento da intensidade e acurácia de seleção e redução no intervalo de geração. 


\subsubsection{Marcadores e o melhoramento animal}

A meta principal das análises genômicas atuais, em animais e também plantas, é encontrar genes (denominados locos de características quantitativas - QTL) responsáveis pela variação genética nas características de interesse. As análises genômicas podem ser realizadas de diferentes formas. No caso do melhoramento animal, as duas principais abordagens são a identificação de QTL por meio de estudos de associações envolvendo genes candidatos, e por mapas de ligação com marcadores. No último caso, existem duas situações em que o mapeamento de QTL conduz a resultados diretamente aplicáveis na seleção assistida por marcadores (MAS), tornando o mapeamento por ligação tão atrativo quanto a abordagem de gene candidato (Soller \& Medjugorac, 1999).

A primeira, o mapeamento de QTL, é realizado em experimentos de famílias de meio-irmãos ou irmãos completos, cada uma podendo ter centenas de indivíduos, que constituem a população na qual será implementada a MAS. Este é o caso de gado de leite. As informações sobre o mapeamento do QTL que são obtidas pelas médias de famílias muito grandes são suficientes para serem usadas na MAS, dentro das próprias famílias.

A segunda, ocorre quando se cria alto grau de desequilíbrio de ligação como o retrocuzamento ou o $\mathrm{F}_{2}$, usando-se o cruzamento de animais de raças distintas, como por exemplo, o cruzamento entre zebuínos e taurinos, que pode gerar análises estatísticas com poder equivalente à análise de genes candidatos, e os resultados podem ser usados na população proveniente do cruzamento. Estas duas situações requerem investimentos altos para avaliação dos animais em seleção, principalmente por necessitar de tamanho amostral elevado.

Em revisão apresentada por Soller (1994), verifica-se que só se consegue detectar diferenças médias entre marcadores genotípicos, considerando-se uma população, quando houver desequilíbrio de ligação entre o marcador e o QTL, e que a probabilidade de detecção de QTL depende da quantidade de desequilíbrio de ligação 
entre este e o marcador, e ainda que em população exogâmica, espera-se apreciável quantidade de desequilíbrio de ligação entre marcador e QTL, apenas quando estes estiverem intimamente associados e o tamanho efetivo da população for pequeno.

As sequências de genes de ação biológica conhecida que estão envolvidas no desenvolvimento ou fisiologia de determinada característica, são denominadas de genes candidatos. No caso de utilização destes marcadores, o poder de detecção é muito grande, comparado ao mapeamento por ligação.

Os genes candidatados podem ser estruturais, reguladores ou intermediários, no caminho bioquímico, afetando a expressão da característica (Bryne \& McMullen, 1996). A seleção destes genes é realizada de acordo com a sua importância para a característica que se pretende estudar (Coutinho \& Regitano, 1995). Esta escolha pode ser baseada no efeito maior, ocasionado por mutação sobre uma característica em humanos ou camundongos, sugerindo uma função para o gene na característica correspondente em outras espécies animais. Os genes candidatos têm sido utilizados para diversos propósitos como, identificação de animais portadores de doenças genéticas, determinação de paternidade, além da associação com características de produção. Devido à sua importância, têm proporcionado vários estudos com a finalidade de oferecer uma tecnologia molecular que, no futuro, permitirá selecionar com maior precisão os animais mais produtivos (Rothschild \& Soller, 1999).

Genes candidatos têm sido utilizados com estes propósitos em função de sua ligação à compostos, como hormônios de função fisiológica conhecida. Fazem parte desta categoria de marcadores, o gene do hormônio de crescimento $(\mathrm{GH})$, o fator de crescimento semelhante à insulina (IGF), a kappa-caseína (CSN3) e a $\beta$-lactoglobulina (LGB), dentre outros. Pelas atividades biológicas que o hormônio de crescimento exerce no organismo, como a regulação do crescimento, função galactopoiética, gliconeogênese, ativação da lipólise, incorporação de aminoácidos nas proteínas dos músculos (Gluckman et al., 1987) e a ativação de processos imunes envolvidos na resistência de doenças (Arkins et al., 1993), acredita-se que este gene esteja associado a uma ou mais caraterísticas de produção. 
A hipótese testada no caso desta abordagem, é que uma proporção significativa do QTL afetando a variação da característica em dada população, está de fato associada à genes candidatos ligados à característica. A alternativa aceita por estatísticos, geneticistas e biométricos, é a hipótese do efeito pleiotrópico, ou seja, a expressão fenotípica do gene pode envolver mais do que um caracter. Ocasionalmente o efeito do gene sobre uma característica é mais evidente (efeito principal) e em outras menos (efeito secundário). Assim, a variação genética quantitativa de uma determinada característica pode ser atribuída ao efeito pleiotrópico (isto é, secundário) dos genes, nos quais os efeitos principais não são relacionados com a característica em questão (Rothschild \& Soller, 1999).

A abordagem de gene candidato para identificação de QTL pode ser aplicada em indivíduos de populações acasaladas ao acaso, que possam ser medidos fenotipicamente e genotipicamente. Esta é a grande vantagem da abordagem de gene candidato sobre a identificação de QTL por meio dos mapas de ligação com marcadores e a razão da grande aplicação destes na área animal, para detecção de genótipos superiores e detecção de doenças.

\subsubsection{Associação entre os polimorfismos dos genes da kappa-caseína, do hormônio do crescimento e da $\boldsymbol{\beta}$-lactoglobulina e características produtivas}

A principal meta dos cientistas da área de genética molecular é construir mapas de ligação suficientemente densos que forneçam suporte para os estudos de características de importância econômica, cuja expressão está associada à genes simples ou à locos de características quantitativas (QTL), os quais contribuem para a variação observada em algumas destas características. Estes mapas de ligação podem ser usados para desenvolver estratégias para a seleção assistida por marcadores - MAS (Rothschild \& Soller, 1999) . 
Desta forma, alguns estudos sobre associação entre os polimorfismos genéticos dos genes do hormônio do crescimento bovino, kappa-caseína e da $\beta$ lactoglobulina, e algumas características de importância econômica, têm sido relatados na literatura.

A estrutura do gene do hormônio do crescimento bovino, descrita por Woychic (1982) e Gordon et al. (1983), possui alto grau de polimorfismo e vários sítios polimórficos (Kirkpatric, 1992; Hoj et al., 1993; Lucy et al., 1991; Zhang et al., 1992 e 1993 e Unanian et al., 1994).

Os estudos sobre a estrutura do hormônio do crescimento foram seguidos de pesquisas que procuraram associar os polimorfismos encontrados à produção (Hoj et al., 1993), à quantidade de gordura do leite (Yao et al., 1996), ao peso ao nascimento (Rocha et al., 1992) e, à composição e qualidade da carcaça (Taylor et al., 1998). Estes polimorfismos também foram associados à características de tipo, como circunferência torácica em animais cruzados Piemontês x Chianina (Pilla et al., 1994).

Da mesma maneira que para o gene do hormônio do crescimento, Moody et al. (1996) encontraram associação da kappa-caseína, descrita por Medrano \& AguilarCordova (1990a) e da $\beta$-lactoglobulina, descrita por Medrano \& Aguilar-Cordova (1990b), com características de crescimento (valor genético direto do peso ao nascimento, ganho do nascimento ao desmame, ganho do desmame ao ano e valor genético materno do peso ao nascimento e ganho do nascimento ao desmame). Os genes da kappa-caseína e a $\beta$-lactoglobulina que codificam estas proteínas do leite foram associados com os pesos ao nascimento, aos 350 dias de idade e ao primeiro parto, por Lin et al. (1987). 


\subsection{Utilização dos modelos não lineares para descrever o crescimento}

A associação de polimorfismos genéticos à características de interesse econômico, como por exemplo o peso, tem sido relatada em diversos estudos, com o objetivo principal de associar marcadores moleculares aos pesos em diferentes idades, analisados separadamente. No entanto, o peso corporal avaliado nas diferentes idades do animal, pode ser considerado como uma única característica e analisado como medida repetida ou dados longitudinais. Neste caso, o objetivo é descrever o crescimento do animal por meio de uma função, que associa o peso (y) e idade (X).

A modelagem de dados longitudinais envolve caracterizar a relação entre a variável resposta em função do tempo denominada medida repetida. Em muitas situações, a função que descreve esta relação é não linear nos parâmetros, como no caso da função que relaciona peso e idade. O modelo não linear é mais adequado que o linear, principalmente porque os parâmetros possuem interpretação biológica, que é muito importante do ponto de vista de aplicação. Assim, a associação de polimorfismos de genes candidatos com a característica peso medida ao longo da vida do animal, pode ser melhor compreendida por meio do ajuste dos modelos não lineares.

\subsubsection{Regressão do peso em função da idade}

A análise de dados longitudinais ou medidas repetidas por meio de ajustamento de uma função que descreva todo o período de vida do animal relacionando peso (y) e idade $(\mathrm{X})$, tem sido objetivo de inúmeros estudos em diversas áreas da pesquisa.

Segundo Ratkoswsky (1983), os objetivos principais do ajuste de curvas de crescimento são descrever e predizer o crescimento dos animais além de fazer inferências com base nas interpretações dos parâmetros destas curvas. Os parâmetros podem ser utilizados separadamente, ou em conjunto, para predizer taxas de 
crescimento, requerimentos nutricionais, resposta à seleção e outros aspectos de interesse.

Uma característica comum dos modelos de crescimento é que estes, dreta ou indiretamente, utilizam dois parâmetros biologicamente relevantes. O primeiro, estabelece a posição do indivíduo (ou grupo) para determinada idade, usualmente a maturidade, sendo que as correlações entre as diferentes medidas de tamanho para o mesmo indivíduo em diferentes idades, tendem a ser altas (Brinks et al., 1964; Taylor \& Craig 1965 e Brown et al., 1973a e 1973b). O segundo, é denominado de taxa de maturação, define o tempo médio de maturidade do animal e foi relatado por Blaxter (1968) e Taylor \& Young (1996), como eficiência intrínseca do crescimento.

Considerando-se o crescimento dos animais como processo contínuo de acumulação de massa, a taxa de crescimento relativa (ganho por unidade de tempo) aumenta em função do tempo, entre o nascimento até atingir o crescimento máximo e a partir deste ponto, a taxa decresce até atingir valores próximos de zero, quando então o tamanho máximo do indivíduo é atingido.

Brody (1945) usou o tempo de maturidade como base para converter a idade cronológica em idade fisiológica, para comparação entre as espécies. Em adição à estes dois parâmetros, definiu-se um terceiro, o qual é usado para particionar a curva de crescimento em dois estágios: crescimento exponencial crescente e decrescente, relativo ao ponto em que taxa é máxima.

Os modelos mais usados para descrever o crescimento dos animais, como as funções Brody (Brody, 1945), Von Bertalanffy (Bertalanffy,1957), Richards (Richards, 1959), Logística (Nelder, 1961) e Gompertz (Laird, 1965), são funções não lineares nos parâmetros, e tem apresentado resultados desejáveis.

Como forma geral destas, pode-se considerar o modelo de Richards (1959): $\mathbf{y}_{\mathbf{t}}=\mathbf{A}\left(\mathbf{1}-\mathbf{B} \mathbf{e}^{-\mathbf{k t}}\right)^{\mathbf{m}}+\boldsymbol{\varepsilon}_{\mathbf{t}}$, em que $\mathbf{y}_{\mathbf{t}}$ é o peso à idade $\mathbf{t} ; \mathbf{A}$ é o valor assintótico de $\mathbf{y}_{\mathbf{t}}$, atingido quando $\mathbf{t}$ tende ao infinito e que é interpretado como o peso do animal adulto; $\mathbf{k}$ é a taxa de maturação; e é a base do logaritmo natural; B é a constante de integração relacionada aos pesos iniciais; $\mathbf{m}$ é a constante que define a forma da curva; e $\boldsymbol{\varepsilon}_{\mathbf{t}}$ é o erro aleatório associado a cada pesagem (Brown et al., 1976). 
$\mathrm{O}$ ajuste de funções não lineares à sequência de pontos peso-idade dos animais tem sido usado como técnica analítica para resumir informações contidas nesta sequência em alguns parâmetros que permitam interpretação biológica, os quais podem ser usados na derivação de características relevantes para o estudo do crescimento (Fitzhugh Junior, 1976).

Os modelos habitualmente usados para descrever o crescimento animal são:

Modelo Brody (Brody, 1945):

$$
y_{t}=A\left(1-B e^{-k t}\right)+\varepsilon
$$

Modelo Von Bertalanffy (Bertalanffy, 1957):

$$
y_{t}=A\left(1-B e^{-k t}\right)^{3}+\varepsilon
$$

Modelo Richards (Richards, 1959):

$$
y_{t}=A\left(1-B e^{-k t}\right)^{m}+\varepsilon
$$

Modelo Logístico (Nelder, 1961):

$$
y_{t}=A\left(1+e^{-k t}\right)^{-m}+\varepsilon
$$

Modelo Gompertz (Laird, 1965):

$$
\mathrm{y}_{\mathrm{t}}=A \mathrm{e}^{\mathrm{Be}(-\mathrm{kt})}+\varepsilon
$$

No modelo Brody (Brody, 1945) o parâmetro $m$ assume o valor 1. Este modelo foi proposto para descrever o crescimento que ocorre após o ponto de inflexão ou "fase de auto-inibição do crescimento". A maioria dos trabalhos que utilizam este 
modelo, consideram o nascimento como o ponto de inflexão, portanto pode ser utilizado para descrever o crescimento pós-natal.

Outro modelo utilizado baseia-se na suposição de que o crescimento é a diferença entre as taxas de anabolismo e catabolismo dos tecidos. Este é o modelo proposto por Bertalanffy (1957), em que $m$, o ponto de inflexão, é fixo em aproximadamente 0,30 do valor de $A$.

O modelo proposto por Richards possui quatro parâmetros, porém com ponto de inflexão variável. Segundo Brown et al. (1976), existe dificuldade em se ajustar este modelo, devido a não convergência do processo iterativo, causada principalmente pela alta correlação negativa entre $B$ e $m$. Para esta função, o ponto de inflexão é dado por:

$$
\mathrm{t}_{\mathrm{i}}=\mathrm{A}\left(\frac{\mathrm{m}}{\mathrm{m}+1}\right)^{\mathrm{m}}
$$

No modelo Logístico (Nelder, 1961), o parâmetro $B$ é fixo e igual a 1. Brown et al. (1976), parametrizou este modelo incluindo o parâmetro $m$, o que permitiu o ponto de inflexão variável para a curva Logística (Nelder, 1961), entretanto, devido a $B$ ser fixo em 1, o ponto de inflexão fica limitado entre 0,41 e 0,44 do valor de $A$, sendo dado por:

$$
\mathrm{t}_{\mathrm{i}}=\mathrm{A}\left(\frac{\mathrm{m}-1}{\mathrm{~m}}\right)^{\mathrm{m}}
$$

O modelo Gompertz (Laird, 1965), foi desenvolvido sob a suposição de que a taxa de crescimento específico cai exponencialmente com o tempo. O ponto de inflexão neste modelo é fixo em 0,37do valor de $A$ (Duarte, 1975). 
As funções descritas anteriormente contêm diversos parâmetros em comum e embora existam variações quanto à sua interpretação e conteúdo, é possível associar significado biológico a cada um deles.

$A=$ Peso a maturidade - cada modelo apresenta uma estimativa do peso assintótico. Este peso, não é o máximo que o animal atinge, e sim o peso médio à maturidade livre das variações sazonais (Brown et al., 1976 e Fitzhugh Junior, 1976).

$k=$ Taxa de maturação - tem interpretações diferentes nos diversos modelos, apesar de significar sempre variações na velocidade de crescimento. A maturação de um indivíduo em determinada idade é a fração do peso adulto atingida pelo indivíduo nesta idade.

$B=$ Constante de integração - está relacionada com os pesos iniciais do animal; reflete o grau de maturação do animal ao nascimento $(t=0)$.

$m=$ Define a forma da curva nos modelos, e consequentemente determina em que proporção do valor assintótico $(A)$ ocorre o ponto de inflexão da curva.

O peso à maturidade ou peso assintótico e a taxa de maturação são os dois parâmetros de maior importância zootécnica. Por exemplo, fêmeas mais pesadas geralmente criam bezerros que crescem mais rapidamente, o que é desejável em gado de corte. Por outro lado, o acréscimo em gastos para a manutenção de vacas de maior porte pode não compensar a vantagem do crescimento mais rápido dos bezerros (Cartwright, 1970).

\subsubsection{Considerações sobre modelos de crescimento}

A escolha do modelo que melhor descreva o processo de crescimento geralmente é feita com base na qualidade de seu ajustamento aos dados, na interpretação biológica dos parâmetros e nas dificuldades computacionais para obtenção do ajustamento.

A dificuldade computacional baseia-se no número de iterações necessárias para atingir o critério de convergência e no número de animais que não atingiram o 
critério de convergência, enquanto a variância residual obtida no ajuste dos modelos de cada animal, determina a qualidade do ajuste do modelo pelo coeficiente de determinação. O ajustamento dos modelos não lineares aos dados peso-idade em bovinos, depende do número de avaliações feitas no animal, desde o seu nascimento até a idade adulta (Brown et al., 1976).

\subsubsection{Coeficiente de determinação $\left(\mathbf{R}^{2}\right)$}

No uso dos modelos de regressão linear, a qualidade do ajuste é expressa em termos de coeficiente de determinação $\left(\mathrm{R}^{2}\right)$. Em regressão não linear, o parâmetro mais utilizado para avaliação da qualidade do ajuste é o coeficiente de determinação, critério que não é facilmente definido, nestes modelos. Um dos problemas com a definição de $\mathrm{R}^{2}$ é que este requer a presença de intercepto no modelo, parâmetro que nem sempre compõe os modelos não lineares.

De acordo com Schabenberger (2001), uma medida, relativamente próxima ao $\mathrm{R}^{2}$ no caso dos modelos não lineares é:

$$
\mathrm{R}^{2}=1-\left(\frac{\mathrm{SQ}_{\text {resíduo }}}{\mathrm{SQ}_{\text {TotalCorrigida }}}\right)
$$

em que:

$\mathrm{SQ}_{\text {resíduo }}=$ Soma de quadrados do resíduo; e

$\mathrm{SQ}_{\text {Total }}$ Corrigida $=$ Soma de quadrados total corrigida para o número de parâmetros do modelo. 


\subsubsection{Comparação entre funções de crescimento}

A comparação dos modelos que descrevem o crescimento de animais foi feita em diversos estudos científicos.

Analisando-se dados de animais da raça Nelore, Cortarelli (1973), utilizou as funções Brody, Von Bertalanffy, Logística e Gompertz, tendo selecionado a última, pois apresentava ajuste mais adequados à estes dados.

Segundo Brown et al. (1976), os modelos de Brody e Richards são os mais comuns para descrição do crescimento de bovinos, devido à facilidade computacional no ajustamento de dados de animais de raças taurinas. Estes autores ajustaram cinco modelos não lineares em dados de peso em função da idade, para vacas de diversas raças e manejo. As comparações foram feitas com base na qualidade do ajuste, interpretação biológica de parâmetros e facilidade computacional.

Os modelos Von Bertalanffy, Gompertz e Logístico superestimaram o peso nas idades iniciais e o Logístico subestimou o peso adulto. O modelo Richards foi o que descreveu melhor o crescimento destes animais, porém foi computacionalmente mais difícil do que os demais. Segundo os autores, este modelo tem ponto de inflexão variável, que é mais apropriado para ajustar dados antes dos 10 meses de idade, quando o ajuste é crítico. O modelo Brody ajustou-se aos dados para idades após 6 meses, tão bem quanto o modelo Richards, sendo o ajuste computacionalmente mais fácil. Os autores também concluíram que apesar dos parâmetros terem a mesma interpretação biológica nos diferentes modelos, as suas estimativas não são perfeitamente correlacionadas.

DeNise \& Brinks (1985) ajustaram dados peso-idade de 233 vacas usando as funções Brody e Richards, na qual a primeira apresentou menor soma de quadrados dos resíduos e maior facilidade computacional, sendo portanto melhor ajustada. Segundo os autores, a curva apropriada para descrever o crescimento ao longo do tempo deve ser escolhida com base na sua habilidade de responder questões específicas e de interesse do pesquisador. 
Para vacas leiteiras, os modelos Brody e Richards apresentaram variância residual menor que os modelos Logístico e de Gompertz (Perotto et al., 1992).

Castanho (1994) usou a função Logística para descrever as curvas de crescimento de animais da raça Gir. Da mesma forma, Freitas et al., (1995 e 1997) ajustaram a função Logística, a qual apresentou melhor ajuste que as funções Brody e Richards, em 85 vacas Holandesas com mensurações mensais de pesos do nascimento aos 24 meses de idade. Entretanto, Perotto et al. (1997) utilizaram 203 fêmeas, zebuínas puras e mestiças e da raça Holandesa, sendo que parte destes animais foram utilizados no estudo de Castanho (1994), e ajustaram o modelo Richards para descrever o crescimento destes animais.

Oliveira (1995) ajustou cinco funções não lineares para fêmeas da raça Guzerá, e observou que o modelo Richards, apesar de ajustar bem às séries de dados peso-idade, apresentou dificuldades computacionais, não sendo indicado seu uso para representar a curva de crescimento. Os outros modelos testados (Brody, Gompertz, Von Bertalanffy e Logístico) apresentaram boa qualidade do ajuste, sendo o modelo Von Bertalanffy escolhido para representar o crescimento destes animais, por apresentar ajustamento médio superior aos demais modelos, considerando-se o conjunto de critérios utilizados.

De forma geral, os modelos Brody, Logístico, Von Bertalanffy, Gompertz e Richards apresentaram bom ajuste aos dados de 629 fêmeas Nelore, 358 Guzerá e 176 Gir, no entanto foi escolhido o modelo Brody para descrever o crescimento destes animais, por apresentar o melhor ajuste (Elias, 1998).

Em estudos efetuados com dados peso-idade de animais Canchim pertencentes à Embrapa Pecuária Sudeste, Freitas et al. (1998a; 1998b), compararam os modelos Gompertz, Logístico e Von Bertalanffy. Os autores concluíram que os dois últimos proporcionaram boa qualidade do ajuste aos pesos observados, para ambos os sexos, com certa superioridade do modelo Logístico em relação aos demais.

Para 211 machos da raça Nelore pesados ao nascimento, ao desmame e mensalmente dos 10 aos 16 meses de idade, o modelo Von Bertalanffy apresentou melhor ajuste (Unanian et al., 2000). 
Conclui-se destes estudos que há grande divergência com relação a escolha de um ou dois modelos que sejam mais adequados para descrever o crescimento de bovinos, entretanto existe tendência de melhor adequação dos modelos Brody e Richards para raças taurinas, e dos modelos Von Bertalanffy e Logístico para raças zebuínas. Nadarajah et al. (1984) afirmaram que o ponto de inflexão não é detectado em raças muito precoces, quando as pesagens na fase inicial do processo de crescimento não são realizadas com grande frequência. Contudo, se o ponto de inflexão ocorrer mais tardiamente, como é esperado em raças menos precoces, é possível que os modelos com ponto de inflexão variável (Richards e Logístico) sejam mais adequados Além de que, a alta correlação negativa entre os parâmetros $m$ e $B$ no modelo Richards, geralmente dificulta o ajustamento deste modelo (Brown et al., 1976). 


\section{AJUSTE DOS MODELOS NÃO LINEARES NO ESTUDO DA ASSOCIAÇÃO ENTRE POLIMORFISMOS GENÉTICOS E CRESCIMENTO EM BOVINOS DE CORTE}

\section{Resumo}

Foram utilizados dados de peso ao nascimento, ao desmame e mensais dos 8 aos 19 meses de idade de 11 classes de genótipos formadas pela concatenação dos polimorfismos genéticos da kappa-caseína-HinfI (CSN3): AA e AB, do hormônio do crescimento-AluI (GH): LL e LV e da $\beta$-lactoglobulina-HaeIII (LGB): AA, AB e BB $\left(\mathrm{G}_{1}=\mathrm{AALLAA}, \quad \mathrm{G}_{2}=\mathrm{A} A L L A B, \quad \mathrm{G}_{3}=\mathrm{AALLBB}, \quad \mathrm{G}_{4}=\mathrm{AALVAB}, \quad \mathrm{G}_{5}=A A L V B B\right.$, $\mathrm{G}_{6}=\mathrm{ABLLAA}, \quad \mathrm{G}_{7}=\mathrm{ABLLAB}, \quad \mathrm{G}_{8}=\mathrm{ABLLBB}, \quad \mathrm{G}_{9}=\mathrm{ABLVAA}, \quad \mathrm{G}_{10}=\mathrm{ABLVAB} \quad \mathrm{e}$ $\mathrm{G}_{11}=\mathrm{ABLVBB}$ ). As informações foram obtidas de animais de três grupos genéticos:

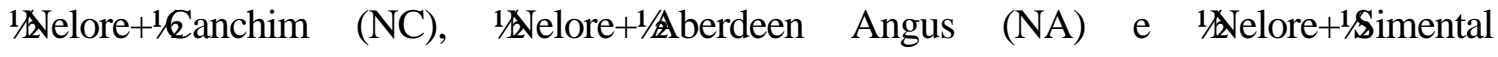
(NS), nascidos em 1998 e 1999 e pertencentes à Embrapa Pecuária Sudeste, São Carlos, SP. Dos cinco modelos estudados: Brody, Von Bertalanffy, Richards, Gompertz e Logístico, o último apresentou melhor qualidade do ajuste. As estimativas dos parâmetros $A$ (valor assintótico), $k$ (taxa de maturação) e $m$ (ponto de inflexão) obtidas do modelo Logístico, ajustado para descrever o crescimento de cada animal, foram analisadas pelo método dos quadrados mínimos, por meio de um modelo linear, que incluiu, além da média geral, o efeito do genótipo, o ano de nascimento, o sexo e o manejo alimentar. Para os animais do grupo genético NC, os genótipos influenciaram significativamente $(\mathrm{P}<0,05)$ as estimativas dos parâmetros $A$ e $k$ da curva de crescimento. $\mathrm{O}$ genótipo $\mathrm{G}_{3}$ apresentou valor inferior de $A$ e superior de $k$ em relação aos genótipos $\mathrm{G}_{7}$ e $\mathrm{G}_{8}$. Quanto aos grupos genéticos NA e NS, não foi observado efeito 
significativo do genótipo sobre nenhum dos três parâmetros. A aplicação da técnica dos modelos não lineares em estudos de associação entre polimorfismos genéticos e o crescimento animal, proporcionou uma análise detalhada do desenvolvimento dos animais de diferentes genótipos (genes: CSN3, GH e LGB). No entanto, mais estudos são necessários para confirmar a possível associação destes e outros genes com o crescimento de bovinos de corte e as possíveis interações entre genes.

Palavras-chaves: Bos indicus x Bos taurus, curvas de crescimento, desenvolvimento ponderal, modelo Logístico, polimorfismos genéticos.

\section{Summary}

In this study were weights at birth, weaning and monthly from 8 to 19 months of age of 11 genotype groups identified by combination of polymorphic RFLP's of the genes kappa-casein-HinfI (CSN3): $\mathrm{AA}$ and $\mathrm{AB}$, growth hormone-AluI (GH): LL and LV, and $\beta$-lactoglobulin-HaeIII (LGB): AA, AB and BB $\left(\mathrm{G}_{1}=\mathrm{AALLAA}\right.$, $\mathrm{G}_{2}=\mathrm{AALLAB}, \quad \mathrm{G}_{3}=\mathrm{AALLBB}, \quad \mathrm{G}_{4}=\mathrm{AALVAB}, \quad \mathrm{G}_{5}=\mathrm{AALVBB}, \quad \mathrm{G}_{6}=\mathrm{ABLLAA}$, $\mathrm{G}_{7}=\mathrm{ABLLAB}, \mathrm{G}_{8}=\mathrm{ABLLBB}, \mathrm{G}_{9}=\mathrm{ABLVAA}, \mathrm{G}_{10}=\mathrm{ABLVAB}$ e $\left.\mathrm{G}_{11}=\mathrm{ABLVBB}\right)$. The data were obtained from three genetic groups: 1-Nelore+16anchim (NC),

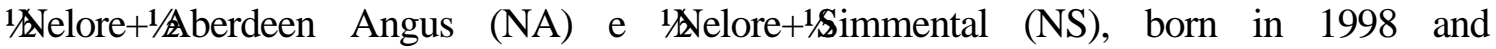
1999 in Southeast Brazil. From five nonlinear models studied: Brody, Von Bertalanffy, Richards, Gompertz and Logistic, the more adequate was the last one. The parameters $A$ (asymptotic value), $k$ (maturing rate) and $m$ (inflection point) estimated by Logistic model for each animal, were analyzed by ordinary least squares, by a linear model that included, besides the overall mean, the fixed effects of the genotype, year of birth, sex and feed management. For the NC genetic groups, was detected significant effect of genotype for $A$ and $k$ parameters estimates. The genotypes $\mathrm{G}_{3}$ presented inferior value of $A$ and superior of $k$ in relation to $\mathrm{G}$ and $\mathrm{G}_{8}$. Considering the NA and NS genetic groups, the effects of genotype on $A, k$ and $m$ parameters was not significant. Nonlinear model application in this study of association between genetic marker and weight trait in beef 
cattle, provided a analysis of the shape of the growth curve regarding the genotype for the CSN3, GH and LGB genes. However, more investigations are necessary for studying possible association of these and other genes with the body weight in beef cattle, and the possible interactions between them.

Key-words: Bos indicus x Bos taurus, growth curves, genetic polymorphisms, Logistic model, ponderal performance.

\subsection{Introdução}

Os polimorfismos genéticos têm sido associados à características de interesse econômico, como por exemplo o peso em determinada idade do animal. Fatores inerentes a esta área de pesquisa, como o custo de obtenção das análises laboratoriais para determinação destes polimorfismos, têm determinado o pequeno tamanho de amostras destes experimentos. Outro fator relevante é que os pesos obtidos ao longo da vida do animal são correlacionados entre si, pois os genes que influenciam o peso em determinada idade podem influenciá-lo nas demais idades (pleiotropia). Além da estrutura dos dados, que geralmente não é completa e a variância do peso em função da idade, que é crescente.

Alternativamente, o ajuste de curvas de crescimento por meio dos modelos não lineares, pode minimizar estes problemas. As funções não lineares utilizadas para descrever o desenvolvimento dos animais, contém informações biológicas relevantes, resumidas em um pequeno número de parâmetros. Estas funções podem ainda fornecer informações importantes sobre a variação genética e ambiental que ocorre entre as avaliações consecutivas (Mansour et al., 1991).

Modelos não lineares como o Brody (Brody, 1945), o Von Bertalanffy (Bertalanffy,1957), o Richards (Richards, 1959), o Logístico (Nelder, 1961) e o Gompertz (Laird, 1965), são os mais empregados em estudos de desenvolvimento animal. Os objetivos principais do ajuste de curvas de crescimento são descrever e 
predizer o crescimento e fazer inferências com base nas interpretações dos parâmetros (Ratkoswsky,1983).

O desenvolvimento ponderal do animais pode ser visto como processo contínuo, em que a taxa de crescimento relativo em função da idade, aumenta do nascimento até atingir o ponto em que o crescimento é máximo e a partir deste ponto, a taxa decresce até atingir valores próximos a zero quando o tamanho máximo do indivíduo é atingido.

A forma da curva de crescimento é muito influenciada pela correlação negativa entre o tamanho adulto e a precocidade (Fitzhugh Junior \& Taylor, 1971, Fitzhugh Junior, 1976). Deste modo, acredita-se que melhorias na eficiência do processo de crescimento de bovinos de corte, serão possíveis por meio de alterações na taxa de maturação e na composição corporal independentemente do tamanho adulto, apesar das diferenças quanto à eficiência do processo de crescimento dos animais, além da associação entre esta eficiência e parâmetros da curva de crescimento (Webster, 1989; Huges \& Pitchford, 1994) e das diferenças genéticas entre animais e raças, quanto aos parâmetros da curva de crescimento (Mezzadra \& Miquel, 1994; Oliveira et al., 1994).

Estudos envolvendo a associação entre polimorfismos genéticos e a curva de crescimento são praticamente inexistentes na literatura. Foi encontrado um único relato de associação entre polimorfismos do hormônio do crescimento (GH-AluI e GHMspI) e os parâmetros da curva de crescimento de bovinos da raça Nelore (Unanian et al., 2000).

Em vista disto, o presente estudo teve por objetivos ajustar o modelo Logístico a dados de crescimento (originais e pré-corrigidos para efeitos fixos de sexo, ano de nascimento e sistema de manejo alimentar) de bovinos cruzados 1elore + 16anchim (NC), 1/Nelore + 1/Aberdeen Angus (NA) e 1/Delore + 1Simental (NS) e verificar se os genes da kappa-caseína-HinfI (CSN3), do hormônio do crescimento-AluI (GH) e da $\beta$-lactoglobulina-HaeIII (LGB), influenciam a função de crescimento dos animais dos três cruzamentos estudados. 


\subsection{Material e Métodos}

\subsubsection{Descrição dos dados}

As 230 informações utilizadas neste estudo foram provenientes de um experimento de avaliação de sistemas cruzamento entre raças bovinas de corte $^{1}$, pertencentes aos grupos genéticos: 1/20lore + 1/Canchim (83 animais), 1/2velore + 1/20rdeen Angus (76 animais) e 12yelore +1 Simental (71 animais), nascidos nos anos de 1998 e 1999. Foram utilizados 2, 6 e 4 touros respectivamente para a raça Canchim, Aberdeen Angus e Simental, e 57 fêmeas Nelore acasaladas com cada uma das duas primeiras raças de touros (Canchim e Aberdeen Angus) e 53 fêmeas Nelore acasaladas com touros da raça Simental. Foram eliminadas 37 observações do arquivo de dados original, restando 65, 69 e 59 animais dos grupos genéticos 1/Eelore + 1/Eanchim, 1/2elore + 1/Aberdeen Angus e +1 Simental, respectivamente. Os animais da raça Canchim, Nelore e cruzados, e o sêmen dos touros das raças Aberdeen Angus e Simental pertencem àEmbrapa Pecuária Sudeste, São Carlos, SP.

Foram empregados os polimorfismos de restrição dos genes da kappacaseína-HinfI (CSN3) (Barendse et al., 1997), do hormônio do crescimento-AluI (GH) (Taylor et al., 1998), e da $\beta$-lactoglobulina-HaeIII (LGB) (Barendse et al. 1997), os quais são do tipo RFLP-PCR, distribuídos nos cromossomos 19, 6 e 11 de bovinos, às distâncias de 72,7 cM, 103 cM e 150 cM, respectivamente. Foram observadas as classes de genótipos LL e LV para o GH e AA, AB e BB para CSN3 e LGB.

$\mathrm{O}$ arquivo de dados continha as seguintes informações:

- Identificação do animal, da vaca e do touro;

- Data de nascimento do animal e da vaca;

- Peso ao nascimento, ao desmame e pesos mensais no período dos 8 aos 19 meses de idade, em $\mathrm{kg}$ e respectivas datas das pesagens;

\footnotetext{
${ }^{1}$ Projeto financiado pela Fapesp.
} 
- Código de sexo (Macho ou Fêmea);

- Código de manejo (CS = com suplementação ou $\mathbf{S S}=$ sem suplementação);

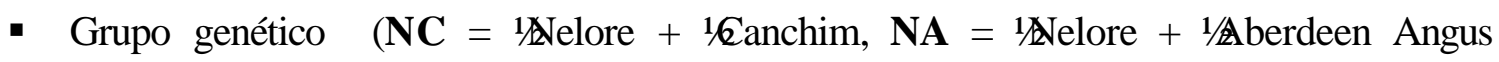
e NS = 12velore $+{ }^{1}$ Simental $) ; \mathrm{e}$

- Código dos genótipos para os polimorfismos do genes da kappa-caseína-HinfI (AA, $\mathrm{AB}$ e $\mathrm{BB}$ ), do hormônio do crescimento-AluI (LL e LV), e $\beta$-lactoglobulina-HaeIII (AA, $\mathrm{AB}$ e $\mathrm{BB})$.

A partir destas informações foram formados os grupos contemporâneos pela concatenação das variáveis sexo, manejo, e ano de nascimento do animal. Inicialmente, foram organizadas 22 classes de genótipos identificadas pela concatenação de CSN3, GH e LGB, entretanto, foram eliminados os animais de genótipos desconhecidos para qualquer um dos genes estudos ou de genótipos que não convergiram na análise realizada pela técnica dos modelos não lineares usando-se o PROC NLIN (SAS, 2001), o que resultou em 11 classes de genótipos $\left(\mathrm{G}_{1}=\right.$ AALLAA, $\mathrm{G}_{2}=\mathrm{AALLAB}, \quad \mathrm{G}_{3}=\mathrm{AALLBB}, \quad \mathrm{G}_{4}=\mathrm{AALVAB}, \quad \mathrm{G}_{5}=\mathrm{AALVBB}, \quad \mathrm{G}_{6}=\mathrm{ABLLAA}$, $\mathrm{G}_{7}=\mathrm{ABLLAB}, \mathrm{G}_{8}=\mathrm{ABLLBB}, \mathrm{G}_{9}=\mathrm{ABLVAA}, \mathrm{G}_{10}=\mathrm{ABLVAB}$ e $\mathrm{G}_{11}=\mathrm{ABLVBB}$ ).

Durante a edição dos dados, foram efetuadas as pré-correções dos dados de peso para o efeitos fixos de sexo, ano de nascimento e sistema de manejo alimentar para os animais dos grupos genéticos NC, NA e NS.

\subsubsection{Análises estatísticas}

\subsubsection{Ajuste dos modelos não lineares}

Foram ajustados os modelos Brody, Von Bertalanffy, Richards, Logístico e Gompertz (Tabela 1), para estimar o crescimento do animal em função da idade e avaliar a influência dos genótipos dos polimorfismos dos genes da kappa-caseína-HinfI, do hormônio do crescimento-AluI e $\beta$-lactoglobulina-HaeIII, sobre crescimento. O método 
utilizado para o ajuste foi o iterativo de Gauss-Newton, descrito por Hartley (1961), por meio da técnica dos modelos não lineares usando-se o procedimento NLIN (SAS, 2001).

Tabela 1. Forma geral de cada modelo não linear utilizado e suas respectivas derivadas

\begin{tabular}{|c|c|c|c|c|}
\hline Modelo & Forma Geral & $\mathrm{dy} / \mathrm{dA}$ & $\mathrm{dy} / \mathrm{dB}$ & dy/dk \\
\hline Brody & $\mathrm{y}_{\mathrm{t}}=\mathrm{A}\left(1-\mathrm{Be}^{-\mathrm{kt}}\right)$ & $\left(1-\mathrm{Be}^{-\mathrm{kt}}\right)$ & $-\mathrm{Ae}^{-\mathrm{kt}}$ & $\mathrm{ABte}^{-\mathrm{kt}}$ \\
\hline Von Bertalanffy & $\mathrm{y}_{\mathrm{t}}=\mathrm{A}\left(1-\mathrm{Be}^{-\mathrm{kt}}\right)^{3}$ & $\left(1-\mathrm{Be}^{-\mathrm{kt}}\right)^{3}$ & $-3^{\mathrm{A}} \mathrm{e}^{-\mathrm{kt}}\left(1-\mathrm{Be}^{-\mathrm{kt}}\right)^{2}$ & $3^{\mathrm{A}} \mathrm{Bte}^{-\mathrm{kt}}\left(1-\mathrm{Be}^{-\mathrm{kt}}\right)^{2}$ \\
\hline Richards * & $\mathrm{y}_{\mathrm{t}}=\mathrm{A}\left(1-\mathrm{Be}^{-\mathrm{kt}}\right)^{\mathrm{m}}$ & $\left(1-\mathrm{Be}^{-\mathrm{kt} t}\right)^{\mathrm{m}}$ & $-\mathrm{Ame}^{-\mathrm{kt}}\left(1-\mathrm{Be}^{-\mathrm{kt}}\right)^{(\mathrm{m}-1)}$ & $\operatorname{Ambte}^{-\mathrm{kt}}\left(1-\mathrm{be}^{-\mathrm{kt}}\right)^{(\mathrm{m}-1)}$ \\
\hline Logístico $* *$ & $\mathrm{y}_{\mathrm{t}}=\mathrm{A}\left(1+\mathrm{e}^{-\mathrm{kt}}\right)^{-\mathrm{m}}$ & $\left(1+\mathrm{Be}^{-\mathrm{kt}}\right)^{-\mathrm{m}}$ & ------ & $\operatorname{Amte}^{-k t}\left(1+e^{-k t}\right)^{(-m-1)}$ \\
\hline Gompertz & $y_{t}=A e^{-B e(-k t)}$ & $e^{-\mathrm{Be}(-\mathrm{kt})}$ & $-\mathrm{Ae}^{-\mathrm{kt}} \mathrm{e}^{(-\mathrm{Be}(-\mathrm{kt}))}$ & $A B t e^{-k t} e^{-B e(-k t)}$ \\
\hline
\end{tabular}

$* \mathbf{d y} / \mathbf{d m}=\mathrm{A} \ln \left(1-\mathrm{Be}^{-\mathrm{kt}}\right)\left(1-\mathrm{Be}^{-\mathrm{kt}}\right)^{\mathrm{m}} \quad * * \mathbf{d y} / \mathbf{d m}=-\mathrm{A} \ln \left(1+\mathrm{e}^{-\mathrm{kt}}\right)\left(1+\mathrm{e}^{-\mathrm{kt}}\right)^{-\mathrm{m}}$

Adaptado de Fitzhugh Junior (1976); Perotto et al.(1992).

$\mathrm{Na}$ análise dos modelos não lineares utiliza-se o processo iterativo para obtenção das soluções do sistema de equações, pois não é possível obter solução analítica dos parâmetros como no caso dos modelos lineares. O processo iterativo requer o fornecimento de valores iniciais aos parâmetros e a partir destes valores é calculada a soma de quadrado do resíduo (SQR). Os parâmetros são continuamente modificados até que a SQR seja minimizada. Os valores iniciais foram considerados a partir da média de cada estimativa de parâmetro obtida da literatura. Foi estabelecido o máximo de 100 iterações para que o critério de convergência fosse atingido. A convergência ocorreu sempre que $\left(\mathrm{SQR}_{\mathrm{j}-1}-\mathrm{SQR}_{\mathrm{j}}\right) /\left(\mathrm{SQR}_{\mathrm{j}}+10^{-6}\right)$ foi menor que $10^{-8}$, em que $\mathrm{SQR}_{\mathrm{j}}$ é a soma de quadrados residual na $j$-ésima iteração. 


\subsubsection{Escolha do modelo}

Para escolher o modelo mais adequado, foram consideradas as dificuldades computacionais (número de animais e de genótipos para os quais a convergência foi atingida e a média de iterações para a convergência), a qualidade do ajuste (coeficiente de determinação, quadrado médio do resíduo e as médias dos desvios e do quadrado dos desvios) e interpretação biológica dos parâmetros.

Análises iniciais mostraram que o modelo Logístico (Nelder, 1961), apresentado abaixo, foi mais apropriado para descrever o crescimento dos animais.

$$
\mathrm{y}_{\mathrm{t}}=\mathrm{A}\left(1+\mathrm{Be}^{-\mathrm{kt}}\right)^{-\mathrm{m}}+\varepsilon
$$

em que:

$y_{t}=$ representa o peso corporal em $\mathrm{kg}$ no tempo $\mathrm{t}$, expresso em dias após o nascimento;

$A=$ valor ou peso assintótico ;

$B=$ constante de integração. No modelo Logístico assume o valor 1.

$k$ = taxa de maturidade pós-natal. É um indicador da velocidade com que o animal atinge o valor assintótico;

$m=$ constante que define a forma da curva nos modelos, e consequentemente, o ponto de inflexão da curva; e

$\varepsilon=$ erro aleatório.

Tais modelos foram ajustados às observações de pesos pré-corrigidos para os fixos de sexo, ano de nascimento e sistema de manejo alimentar, e de pesos originais (não corrigidos para estes efeitos). 


\subsection{Resultados e Discussão}

\subsubsection{Os valores observados}

A amplitude dos valores das idades de cada pesagem foi: 146-253, 175282, 203-311, 238-354, 269-394, 297-425, 325-454, 353-480, 381-512, 409-531, 437549, 464-568 e 495-603 dias, respectivamente para $\mathrm{P}_{\mathrm{D}}, \mathrm{P}_{8}, \mathrm{P}_{9}, \mathrm{P}_{10}, \mathrm{P}_{11}, \mathrm{P}_{12}, \mathrm{P}_{13}, \mathrm{P}_{14}, \mathrm{P}_{15}$, $\mathrm{P}_{16}, \mathrm{P}_{17}, \mathrm{P}_{18}$ e $\mathrm{P}_{19}$ (pesos mensurados mensalmente dos 7 aos 19 meses de idade, em média).

As distribuições dos pesos observados ao desmame ( 7 meses de idade) e mensalmente dos 8 aos 19 meses idade, em função da idade, representadas em gráficos do tipo scatter-plot, estão apresentadas no Anexo A. Estes gráficos, apresentam as distribuições bivariadas envolvendo pesos nos eixos-y e idade nos eixos- $\mathrm{x}$ e as elipses de confiança com 95\% de probabilidade, indicada pelo círculo e fornecem contribuições importantes para compreensão do relacionamento entre o peso e a idade (Freitas et al., 2002). Os pontos situados fora da elipse, por exemplo, podem ser considerados outliers, a forma alongada da elipse evidencia forte correlação entre as duas variáveis (peso e idade). Observa-se que a maior parte das observações estão dentro da elipse de confiança com $95 \%$.

As médias dos pesos, o número de observações de machos $\left(\mathrm{N}_{\mathrm{m}}\right)$ e fêmeas $\left(\mathrm{N}_{\mathrm{f}}\right)$ e o coeficiente de variação $(\mathrm{CV})$, em \%, das 14 mensurações de pesos, ao nascer $\left(\mathrm{P}_{\mathrm{N}}\right)$, ao desmame -7 meses de idade $-\left(\mathrm{P}_{\mathrm{D}}\right)$, e pesos mensais dos 8 aos 19 meses de idade $\left(\mathrm{P}_{8}, \mathrm{P}_{9}, \mathrm{P}_{10}, \mathrm{P}_{11}, \mathrm{P}_{12}, \mathrm{P}_{13}, \mathrm{P}_{14}, \mathrm{P}_{15}, \mathrm{P}_{16}, \mathrm{P}_{17}, \mathrm{P}_{18}\right.$ e $\left.\mathrm{P}_{19}\right)$, de bovinos cruzados NC, NA e NS e dos 3 grupos genéticos em conjunto estão apresentados na Tabela 2. 
Tabela 2. Médias dos pesos $(\mathrm{kg})$, número de observações de machos $\left(\mathrm{N}_{\mathrm{m}}\right)$ e fêmeas $\left(\mathrm{N}_{\mathrm{f}}\right)$ e o coeficiente de variação $(\mathrm{CV})$, em \%, de animais cruzados e dos três grupos genéticos em conjunto.

\begin{tabular}{|c|c|c|c|c|c|c|c|c|c|c|c|c|c|c|c|c|}
\hline \multirow[b]{2}{*}{ Peso* } & \multicolumn{4}{|c|}{ 1/Nelore + 1/Canchim } & \multicolumn{4}{|c|}{ 1/2yelore + 1/:Angus } & \multicolumn{4}{|c|}{ 1/Nelore + ${ }^{1}$ Simental } & \multicolumn{4}{|c|}{3 Grupos Genéticos } \\
\hline & Média & $\mathbf{N}_{\mathbf{m}}$ & $\mathbf{N}_{\mathbf{f}}$ & CV & Média & $\mathbf{N}_{\mathbf{m}}$ & $\mathbf{N}_{\mathbf{f}}$ & $\mathbf{C V}$ & Média & $\mathbf{N}_{\mathbf{m}}$ & $\mathbf{N}_{\mathbf{f}}$ & CV & Média & $\mathbf{N}_{\mathbf{m}}$ & $\mathbf{N}_{\mathbf{f}}$ & CV \\
\hline$\overline{\mathbf{P}_{\mathrm{N}}}$ & 32,46 & 41 & 42 & 11,03 & 33,64 & 39 & 37 & 11,14 & 33,67 & 32 & 39 & 12,90 & 33,23 & 112 & 118 & 11,77 \\
\hline $\mathbf{P}_{\mathbf{D}}$ & 203,78 & 40 & 39 & 1396 & 21782 & 39 & 37 & 333 & 1065 & 32 & 37 & 14,13 & 210,66 & 111 & 113 & 14,01 \\
\hline $\mathbf{P}_{8}$ & 21760 & 39 & 32 & 13,67 & 23420 & 39 & 32 & 1247 & 22708 & 29 & 32 & 14,07 & 226,32 & 107 & 96 & 3,65 \\
\hline $\mathbf{P}_{9}$ & 23450 & 39 & 32 & 13,43 & 25225 & 39 & 32 & 1162 & 24554 & 29 & 32 & 14,20 & 244,02 & 107 & 96 & 3,34 \\
\hline $\mathbf{P}_{10}$ & 263,81 & 39 & 32 & 15,87 & 281,21 & 37 & 32 & 13,88 & 270,77 & 29 & 32 & 16,07 & 271,90 & 105 & 96 & 15,40 \\
\hline $\mathbf{P}_{11}$ & 288,23 & 39 & 32 & 16,94 & 307,26 & 37 & 32 & 14,80 & 293,85 & 29 & 32 & 17,63 & 296,47 & 105 & 96 & 16,56 \\
\hline $\mathbf{P}_{12}$ & 314,76 & 39 & 32 & 17,65 & 338,46 & 37 & 32 & 15,74 & 322,08 & 29 & 32 & 18,81 & 325,11 & 105 & 96 & 17,53 \\
\hline $\mathbf{P}_{13}$ & 339,92 & 31 & 32 & 18,94 & 367,63 & 29 & 32 & 6 & 349,94 & 21 & 32 & 18,74 & 352,47 & 81 & 96 & 18,41 \\
\hline $\mathbf{P}_{14}$ & 362,46 & 31 & 32 & 20,12 & 394,63 & 29 & 32 & 17,66 & 373,22 & 21 & 32 & 19,44 & 376,77 & 81 & 96 & 19,27 \\
\hline $\mathbf{P}_{15}$ & 381,56 & 28 & 32 & 23,09 & 422,47 & 29 & 32 & 19,74 & 395,22 & 21 & 32 & 21,64 & 400,06 & 78 & 96 & 21,73 \\
\hline $\mathbf{P}_{16}$ & 384,30 & 23 & 32 & 22,75 & 422,71 & 21 & 32 & 19,57 & 410,17 & 19 & 32 & 21,33 & 405,40 & 63 & 96 & 21,43 \\
\hline $\mathbf{P}_{17}$ & 363,72 & 8 & 32 & 19,33 & 387,60 & 3 & 32 & 9,64 & 409,52 & 12 & 32 & 18,33 & 387,68 & 23 & 96 & 17,23 \\
\hline $\mathbf{P}_{18}$ & 368,84 & 6 & 32 & 19,27 & 387,06 & 1 & 32 & 9,25 & 414,80 & 10 & 32 & 17,85 & 391,24 & 17 & 96 & 17,00 \\
\hline $\mathbf{P}_{19}$ & 347,50 & 0 & 32 & 8,89 & 395,18 & 0 & 32 & 8,21 & 404,22 & 4 & 32 & 14,17 & 383,18 & 4 & 96 & 12,81 \\
\hline
\end{tabular}

*14 mensurações de pesos, ao nascer $\left(\mathrm{P}_{\mathrm{N}}\right)$, ao desmame - 7 meses de idade $-\left(\mathrm{P}_{\mathrm{D}}\right)$, e pesos mensais dos 8 aos 19 meses de idade $\left(\mathrm{P}_{8}, \mathrm{P}_{9}, \mathrm{P}_{10}, \mathrm{P}_{11}, \mathrm{P}_{12}, \mathrm{P}_{13}, \mathrm{P}_{14}, \mathrm{P}_{15}, \mathrm{P}_{16}, \mathrm{P}_{17}, \mathrm{P}_{18}\right.$ e $\left.\mathrm{P}_{19}\right)$.

No Anexo B estão apresentadas as 193 observações de pesos médios (kg) das 14 mensurações de pesos, ao nascer, ao desmame (7 meses), e pesos mensais dos 8 aos 19 meses de idade, em função dos genótipos dos três grupos genéticos. Considerando-se o critério de qualidade do ajuste do modelo (coeficiente de determinação, quadrado médio do resíduo, número de animais que atingiram a convergência e interpretação biológica dos parâmetros), foram eliminados os animais pertencentes às classes de genótipos que não apresentaram ajuste adequado, para o modelo Logístico. 
Assim, os animais estavam representados nos grupos genéticos e nas classes de genótipos da seguinte maneira: 65 animais NC pertencentes aos genótipos: $\mathrm{G}_{2}=\operatorname{AALLAB}(\mathrm{n}=12), \mathrm{G}_{3}=\operatorname{AALLBB}(\mathrm{n}=33), \mathrm{G}_{7}=\operatorname{ABLLAB}(\mathrm{n}=10), \mathrm{G}_{8}=\operatorname{ABLLBB}(\mathrm{n}=7)$ e $\mathrm{G}_{9}=\operatorname{ABLVAA}(\mathrm{n}=3), 69$ animais NA das classes de genótipos: $\mathrm{G}_{1}=\operatorname{AALLAA}(\mathrm{n}=3)$, $\mathrm{G}_{2}=\operatorname{AALLAB}(\mathrm{n}=15), \mathrm{G}_{3}=\operatorname{AALLBB}(\mathrm{n}=14), \mathrm{G}=\operatorname{AALVAB}(\mathrm{n}=3), \mathrm{G}=\operatorname{AALVBB}(\mathrm{n}=8)$, $\mathrm{G}_{6}=\operatorname{ABLLAA}(\mathrm{n}=8), \mathrm{G}_{7}=\operatorname{ABLLAB}(\mathrm{n}=7), \mathrm{G}_{0}=\operatorname{ABLVAB}(\mathrm{n}=6)$ e $\mathrm{G}_{1}=\operatorname{ABLVBB}(\mathrm{n}=5)$ e 59 animais NS das classes de genótipos: $\mathrm{G}_{2}=\operatorname{AALLAB}(\mathrm{n}=8), \mathrm{G}_{3}=\operatorname{AALLBB}(\mathrm{n}=26)$, $\mathrm{G}_{4}=\mathrm{AALVAB} \quad(\mathrm{n}=11), \mathrm{G}_{5}=\mathrm{AALVBB} \quad(\mathrm{n}=5), \mathrm{G}_{8}=\mathrm{ABLLBB} \quad(\mathrm{n}=6)$ e $\mathrm{G}_{11}=\mathrm{ABLVBB}$ $(\mathrm{n}=3)$, para os genes $\mathrm{CSN} 3, \mathrm{GH}$ e LGB respectivamente.

\subsubsection{Pré-correção dos dados}

Os conjuntos de dados peso-idade $\left(\mathrm{P}_{\mathrm{N}}, \mathrm{P}_{\mathrm{D}}, \mathrm{P}_{8}, \mathrm{P}_{9}, \mathrm{P}_{10}, \mathrm{P}_{11}, \mathrm{P}_{12}, \mathrm{P}_{13}, \mathrm{P}_{14}, \mathrm{P}_{15}\right.$, $\mathrm{P}_{16}, \mathrm{P}_{17}, \mathrm{P}_{18}$ e $\mathrm{P}_{19}$ ) foram corrigidos para os efeitos fixos de ano de nascimento (1998 e 1999), sexo (macho e fêmea) e manejo alimentar (com ou sem suplementação). Para efetuar esta pré-correção utilizou-se a técnica dos modelos lineares, pelo procedimento GLM (SAS, 2001), com a finalidade de estimar os efeitos fixos e obter as médias ajustadas.

Inicialmente, haviam sido formados os grupos contemporâneos (GC) pela concatenação do ano de nascimento (AN), sexo (S) e manejo alimentar (MA) e realizados as pré-correções, para GC. Entretanto, quando os dados corrigidos para GC eram utilizados para o ajuste da função de crescimento Logística, as estimativas obtidas para os parâmetros desta função não eram coerentes. Assim, optou-se por incluir na análise dos modelos lineares, usadas para efetuar as pré-correções das observações, apenas os efeitos principais de AN, $\mathrm{S}$ e MA e suas interações simples, quando significativos ao nível de $5 \%$. 


\subsubsection{Ajuste dos modelos}

Considerando-se a dificuldade de realização das análises, o modelo Logístico foi o mais adequado pois foi o único que convergiu para a maior parte dos animais, tanto para os dados pré-corrigidos como para os dados originais. Provavelmente, o fato dos animais ainda não terem atingido a maturidade quando foram realizadas às últimas mensurações dos pesos (19 meses de idade em média), associado ao fato de que as pesagens nas fases iniciais da vida não foram muito frequentes (peso medido ao nascimento e depois ao desmame por volta dos 7 meses de idade), pode estar ligado com a dificuldade do ajuste dos modelos Brody, Von Bertallanffy, Richards e Gompertz, que não convergiram. Segundo Nadarajah et al. (1984), em raças menos precoces, como é o caso das zebuínas, é possível que os modelos com ponto de inflexão variável (Richards e Logístico), sejam mais adequados, o que pode explicar estes resultados. Além de que, a alta correlação negativa entre os parâmetros $m$ e $B$ no modelo Richards, geralmente dificulta o ajustamento deste modelo (Brown et al., 1976). Em estudos mais recentes, Freitas et al. (1998a; 1998b), compararam os modelos Gompertz, Logístico e Von Bertalanffy, utilizando-se dados de animais da raça Canchim. Os autores concluíram que os dois últimos proporcionaram boa qualidade do ajuste aos pesos observados, para ambos os sexos, com certa superioridade do modelo Logístico em relação aos demais.

As funções não lineares usadas no presente estudo para descrever o crescimento animal apresentam três parâmetros em comum, representados por $A, k$ e $m$, que têm importantes interpretações sob o ponto de vista biológico.

O parâmetro $A$ fornece uma estimativa do valor ou peso assintótico, não sendo, necessariamente, o maior peso que animal atinge, mas sim o peso médio a maturidade livre das variações sazonais (Brown et al., 1976 e Fitzhugh Junior, 1976). Este parâmetro é mais representativo do peso adulto quanto mais constantes forem as condições ambientais. Existem controvérsias sobre o tamanho adulto ótimo, pois depende da raça, da seleção praticada previamente, do sistema de manejo e das condições ambientais. 
Outro parâmetro importante é o $k$, que do ponto de vista biológico é interpretado como índice de maturação e é utilizado como medida da taxa de mudança na velocidade de ganho de peso, ou seja, pode ser um indicador da velocidade com que o animal atinge o valor assintótico, portanto quanto maior o valor do parâmetro $k$, mais precoce é o animal e vice-versa (Brown et al., 1976).

O parâmetro $m$ define a forma da curva nos modelos, e consequentemente determina em que proporção do valor assintótico $(A)$ ocorre o ponto de inflexão da curva.

\subsubsection{Grupos genéticos}

Na Tabela 3 estão apresentados os valores médios dos parâmetros da curva de crescimento estimados pelo modelo Logístico e o número de animais para o qual o critério de convergência foi atingido, dos grupos genéticos NC, NA e NS. Os valores de $m$ variaram muito pouco (de 3,5 a 3,8), com exceção do conjunto de dados précorrigidos, do grupo genético NS, em que o valor foi de aproximadamente 4,5. Neste modelo a variação de $m$ é limitada entre 2 e 4, pela fixação de $B=1$ (Brown et al., 1976).

Com relação a qualidade do ajuste do modelo, baseada no coeficiente de

determinação $\left(\mathrm{R}^{2}\right)$, no número de animais que atingiram a convergência $(\mathrm{N})$ e na interpretação biológica dos parâmetros, o modelo Logístico pode ser utilizado para descrever o crescimento dos animais das três composições genéticas em estudo. Os modelos ajustados para os conjuntos de dados (Tabela 3), apresentaram boa qualidade do ajuste, com coeficiente de determinação superior a 79,5\%. 
Tabela 3. Estimativas dos parâmetros $(A, k$ e $m)$ e respectivos erros-padrão (s), número de animais $(\mathrm{N})$, coeficiente de determinação $\left(\mathrm{R}^{2}\right)$ e número de iterações $(\mathrm{NI})$, dos modelos Logísticos ajustados para os dados de peso pré-corrigidos $\left(\mathrm{P}_{\mathrm{Cor}}\right)$ para ano de nascimento, sexo e manejo e originais $(\mathrm{P})$ de animais cruzados.

\begin{tabular}{ccccccc}
\hline $\begin{array}{c}\text { Grupo } \\
\text { Genético }\end{array}$ & $\begin{array}{c}\mathbf{A} \pm \mathbf{~} \\
(\mathbf{k g})\end{array}$ & $\begin{array}{c}\mathbf{k} \pm \mathbf{~} \\
\left(\mathbf{d i a}^{-\mathbf{1}}\right)\end{array}$ & $\mathbf{m} \pm \mathbf{s}$ & $\begin{array}{c}\mathbf{R}^{2} \\
(\boldsymbol{\%})\end{array}$ & $\mathbf{N I}$ \\
\hline $\mathbf{N C}$ & $\mathbf{P}_{\mathbf{C o r}}$ & $687,7 \pm 45,2$ & $0,00402 \pm 0,000294$ & $3,7877 \pm 0,0922$ & 84,3 & 20 \\
$(\mathbf{N = 6 5})$ & $\mathbf{P}$ & $427,5 \pm 10,3$ & $0,00660 \pm 0,00037$ & $3,5710 \pm 0,1959$ & 79,5 & 5 \\
$\mathbf{N A}$ & $\mathbf{P}_{\text {Cor }}$ & $631,0 \pm 21,2$ & $0,00474 \pm 0,000225$ & $3,7479 \pm 0,0931$ & 89,3 & 10 \\
$\mathbf{( N = 6 9 )}$ & $\mathbf{P}$ & $475,0 \pm 10,1$ & $0,00624 \pm 0,000285$ & $3,5137 \pm 0,1442$ & 84,5 & 4 \\
$\mathbf{N S}$ & $\mathbf{P}_{\text {Cor }}$ & $1602,5 \pm 276,0$ & $0,00225 \pm 0,000216$ & $4,5060 \pm 0,1924$ & 92,5 & 6 \\
$\mathbf{( N = 5 9 )}$ & $\mathbf{P}$ & $489,1 \pm 13,8$ & $0,00599 \pm 0,000346$ & $3,5401 \pm 0,1699$ & 83,7 & 4 \\
\hline
\end{tabular}

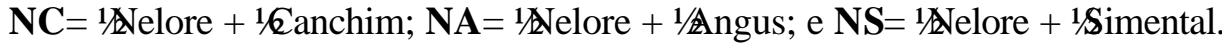

As proporções de animais que atingiram a convergência (considerando-se os genótipos) foram de 78,3\%, 90,8\% e 83,1\% respectivamente para os grupos genéticos NC, NA e NS. Estes resultados concordam com Freitas et al. (1995; 1997; 1998a; 1998b), que também ajustaram a função Logística aos dados de crescimento de animais das raças Holandesa e Canchim.

Considerando-se os dados originais, para os grupos genéticos NA e NS as estimativas do peso assintótico $(A)$ foram superiores às do $\mathrm{NC}$, mostrando que estes animais apresentam tamanho comparável a algumas raças de origem européia.

$\mathrm{Na}$ Figura 1 estão apresentadas as curvas do peso e ganho de peso considerando-se os dados de peso pré-corrigidos $\left(\mathrm{P}_{\mathrm{Cor}}\right)$ para sexo, manejo alimentar e ano de nascimento e originais (P), em função da idade, ajustada pelo modelo Logístico, para animais cruzados NC, NA e NS. 


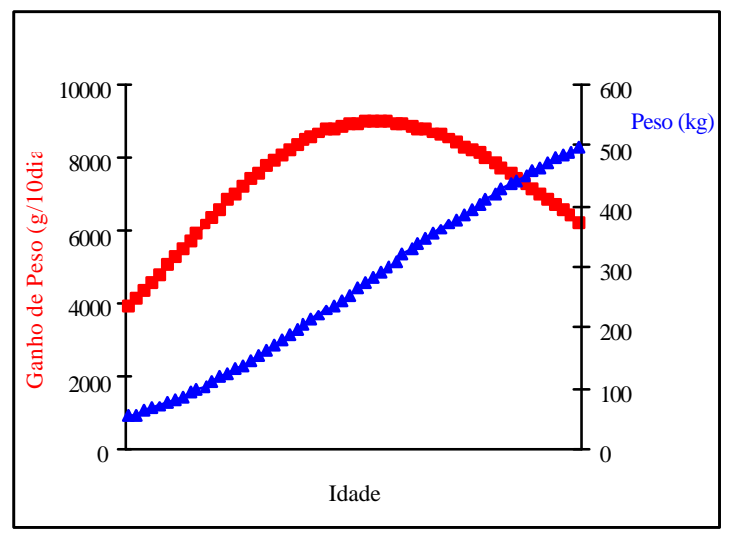

12Eelore + 1/6anchim $\left(\mathrm{P}_{\mathrm{Cor}}\right)$

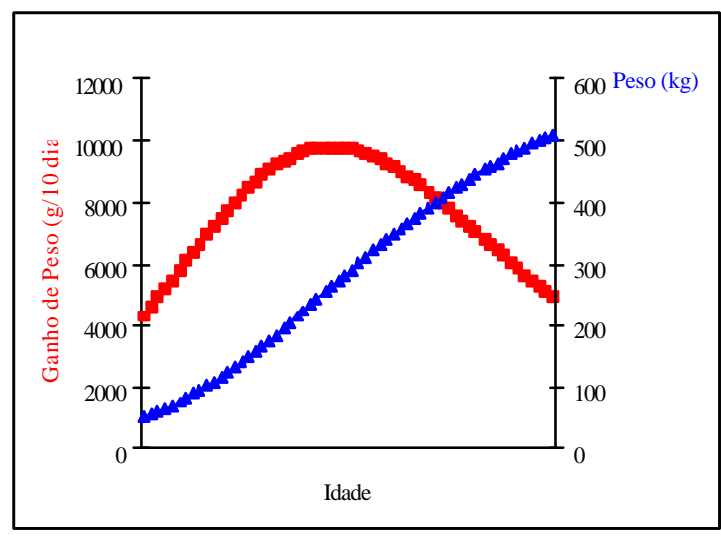

1/2 elore $+1 /$ Angus $\left(\mathrm{P}_{\mathrm{Cor}}\right)$

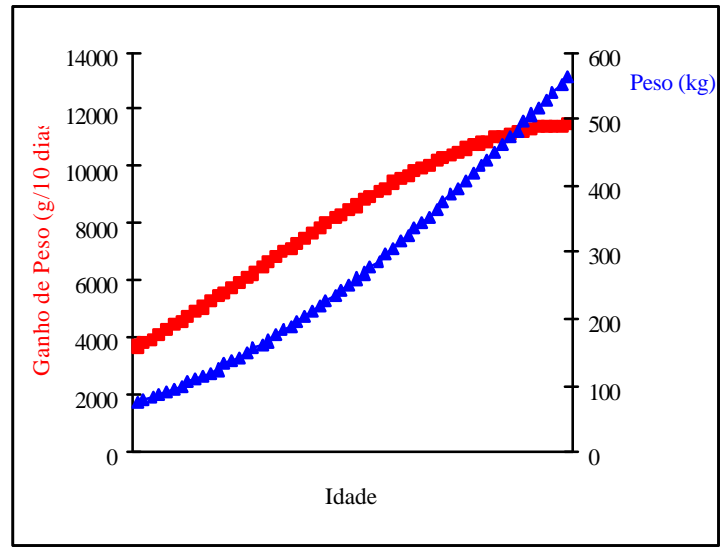

1/2elore $+{ }^{1 / S i m e n t a l}\left(\mathrm{P}_{\mathrm{Cor}}\right)$

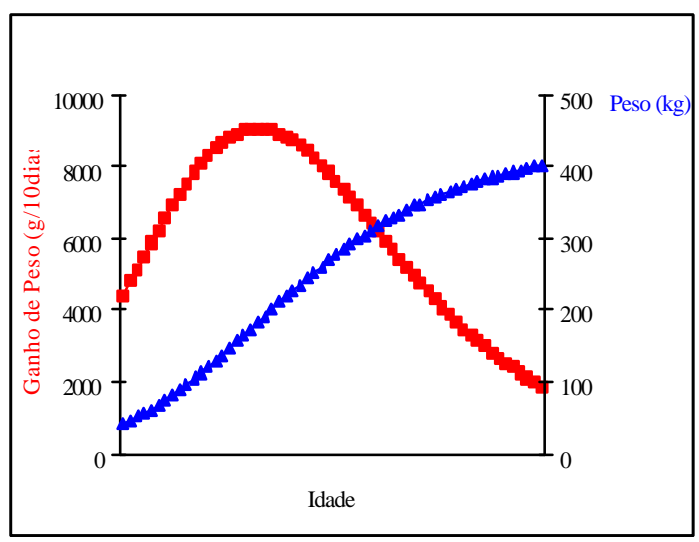

12:-elore + 1/6anchim (P)

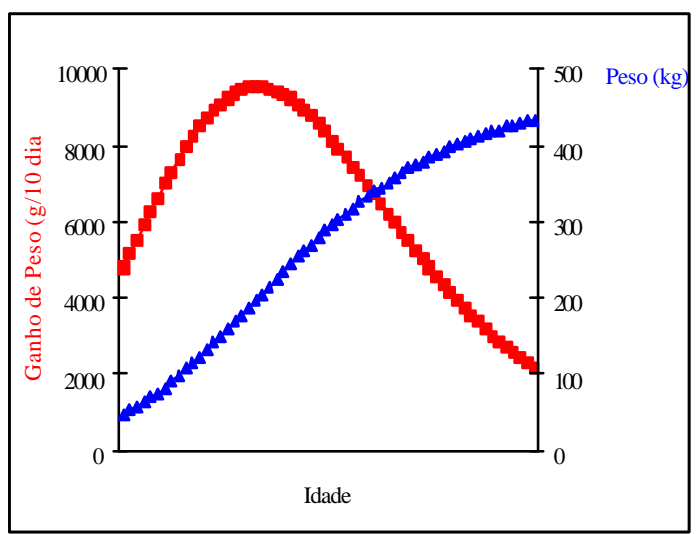

1/2elore + 1/2Angus (P)

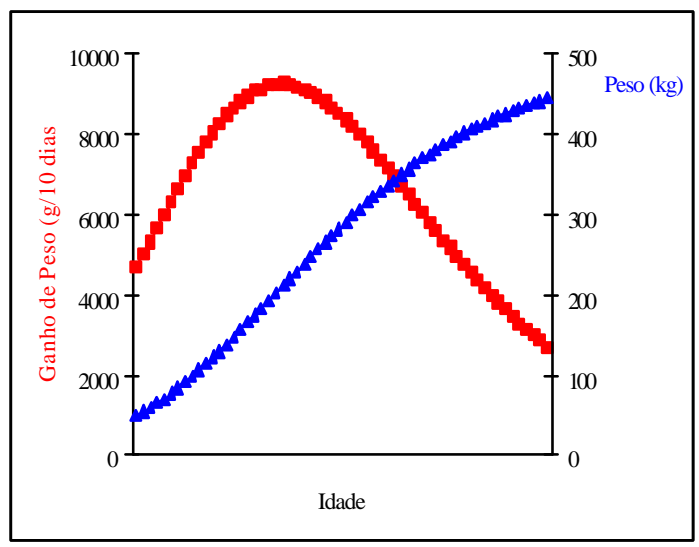

1/Eelore $+{ }^{1}$ Simental (P)

Figura 1 - Estimativa do peso $(\mathrm{kg})$ e ganho de peso (g/10dias) para dados pré-corrigidos $\left(\mathrm{P}_{\mathrm{Cor}}\right)$ para sexo, manejo alimentar e ano de nascimento e originais $(\mathrm{P})$, em função da idade (dias), ajustada pelo modelo Logístico, para animais cruzados. 
A pré-correção, efetuada nos dados para os efeitos fixos, não proporcionou estimativas coerentes para os parâmetros das funções não lineares testadas. Ocorreu superestimação do parâmetro $A$, principalmente para os animais NS. A taxa de maturação $(k)$, apresentou valores menores para os dados pré-corrigidos, comparada com os valores obtidos para os dados originais (Tabela 3 e Figura1).

As estimativas de peso e do ganho de peso (Figura 1) ilustram, de certa forma, o problema causado pela pré-correção dos dados (superestimação do parâmetro $A$ e subestimação do $k$, observado na Tabela 3). O ponto de inflexão das curvas do peso e do ganho de peso é deslocado para a direita, ou seja, ocorre mais tardiamente na vida do animal. Este problema foi mais acentuado no caso dos animais NS, entretanto ocorreu também para os animais NC e NA. Uma provável explicação para esta discrepância, pode ser devida ao fato de que a principal causa de variação sobre o peso, dentre os efeitos fixos usados nas pré-correções, foi o sexo ( $\mathrm{P}<0,0001)$. A frequência de machos em que foram realizadas as pesagens, diminui intensamente com o aumento da idade (chegando a 0 na última pesagem), enquanto a de fêmeas mantêm-se praticamente constante (Tabela 2). Os outros dois efeitos (ano de nascimento e manejo alimentar) apresentaram efeito significativo sobre o peso ao nível de $5 \%$.

O peso assintótico $(A)$ e o índice de maturação $(k)$ são considerados os dois parâmetros de maior importância, do ponto de vista zootécnico, principalmente porque as fêmeas mais pesadas geralmente criam bezerros que crescem mais rapidamente, o que é desejável em gado de corte, mas por outro lado, o acréscimo em gastos para a manutenção de vacas de maior porte, pode não compensar a vantagem do crescimento mais rápido dos bezerros (Cartwright, 1970).

Oliveira (1995) ajustou cinco modelos com o objetivo de descrever o crescimento de 556 fêmeas da raça Guzerá. No modelo de Von Bertalanffy, que apresentou ajuste mais adequado (de acordo com os critérios adotados), foram estimados valores de $453,9 \mathrm{~kg}$ e 0,06936 mês $^{-1}$ para os parâmetros $A$ e $k$ respectivamente. Apenas para fim de comparação com o presente estudo, no modelo Logístico foram estimados para os parâmetros $A, k$ e $m$ os valores de $445,9 \mathrm{~kg}, 0,090459$ mês $^{-1}$ e 2,98837, 
respectivamente. Perotto et al., (1997) usaram o modelo Richards para descrever o crescimento de 53 fêmeas da raça Guzerá e encontraram 441,4 kg, 0,06513 mês ${ }^{-1}$ e 3,8416 para as estimativas de $A, k$ e $m$, respectivamente.

Considerando-se as estimativas médias obtidas para os dados de pesos originais, 427,5 kg, 475,0 kg e 489,1 kg para o peso assintótico (A), 0,00660 dia ${ }^{-1}$, $0,00624 \mathrm{dia}^{-1}$ e $0,00599 \mathrm{dia}^{-1}$ para a taxa de maturação $(k)$ e 3,5710, 3,5137 e 3,5401 para o ponto de inflexão $(m)$, respectivamente, para os grupos genéticos NC, NA e NS, observa-se razoável discordância entre as estimativas dos parâmetros de crescimento obtidas para os animais cruzados e aquelas estimadas para os animais da raça Guzerá (Oliveira, 1995; Perotto et al., 1997), principalmente quanto ao parâmetro $k$.

As curvas ajustadas pelo modelo Logístico, cujas estimativas dos parâmetros estão apresentados na Tabela 3, utilizando-se dados pré-corrigidos e originais, que descrevem o crescimento dos animais NC, NA e NS, estão apresentadas na Figura 2. 

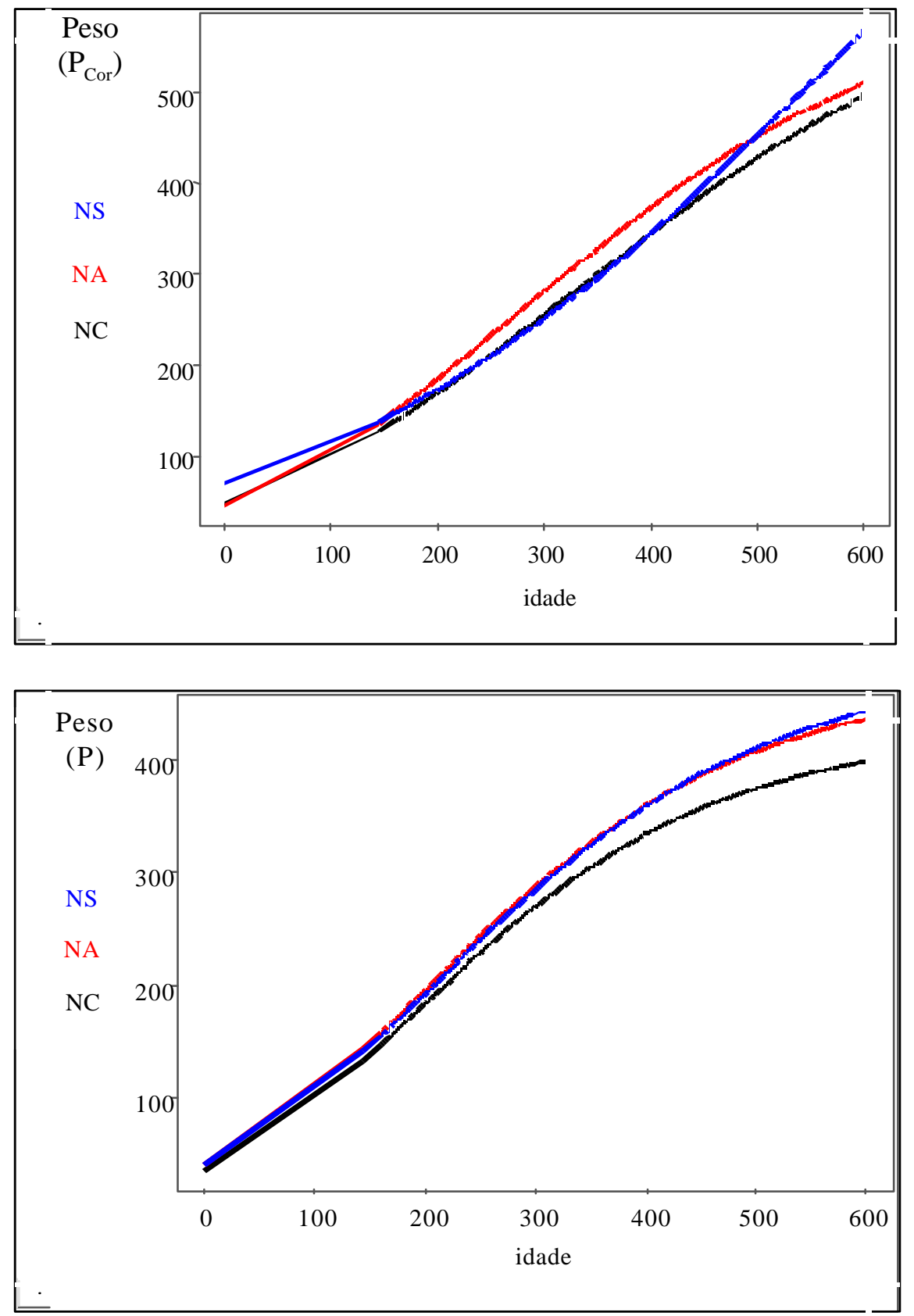

Figura 2 - Estimativa do peso $(\mathrm{kg})$ considerando-se dados pré-corrigidos $\left(\mathrm{P}_{\mathrm{Cor}}\right)$ para sexo, manejo alimentar e ano de nascimento e originais $(\mathrm{P})$ em função da idade (dias), ajustada pelo modelo Logístico para animais 1/20lore + 16anchim (NC), 1/2elore +1/2/Angus (NA) e 1/20lore + 1/Simental (NS). 
Para os dados originais do peso, nota-se que, enquanto o valor do parâmetro $A$ do NC foi $10 \%$ e $12,5 \%$ inferior ao valor do mesmo parâmetro para o NA e NS, respectivamente, o valor de $A$ para o NA foi apenas 3\% inferior em relação ao NS. Quanto ao parâmetro $k$ do NC seu valor foi $5 \%$ superior em relação ao valor do NA, 9\% superior em relação ao valor do NS e o valor de $k$ para NA foi $4 \%$ superior em relação ao NS. Estes resultados corroboram com a sugestão de que certos cruzamentos podem contornar parcialmente o antagonismo biológico entre peso adulto e taxa de maturação em peso existente dentro de raças (Fitzhugh Junior \& Taylor, 1971).

\subsubsection{Genótipos}

Na Tabela 4 estão apresentados as estimativas dos parâmetros $(A, k$ e $m)$, pelo modelo Logístico, o coeficiente de determinação, o número de animais por genótipo, que atingiram a convergência e o número de terações dos modelos utilizandose dados de peso pré-corrigidos para ano de nascimento, sexo e manejo e dados originais, de cada classe de genótipo, de animais cruzados NC, NA e NS.

Em geral, nos conjuntos de dados originais, o modelo Logístico proporcionou boa qualidade do ajuste, com $\mathrm{R}^{2}$ variando de $73,5 \%$ a $98,5 \%$. O peso assintótico também apresentou valores razoáveis, com exceção do genótipo $\mathrm{G}_{11}$ (ABLVBB), cuja estimativa de $A$ foi superior a $700 \mathrm{~kg}$.

Assim como no caso das estimativas médias dos parâmetros para os grupos genéticos, as estimativas de $A$, principalmente para o grupo genético NS, foram superestimadas quando utilizados dados pré-corrigidos para os efeitos fixos, e, consequentemente, a taxa de maturação $(k)$ foi subestimada, considerando-se as curvas ajustadas para os genótipos. 
Tabela 4. Estimativas dos parâmetros $(A, k$ e $m)$, coeficiente de determinação $\left(\mathrm{R}^{2}\right)$, número de animais por grupo genético $(\mathrm{N})$ e genótipo $(\mathrm{NG})$, que atingiram a convergência e número de iterações, obtidos do modelo Logístico ajustado para dados de pesos précorrigidos $\left(\mathrm{P}_{\mathrm{Cor}}\right)$ para ano de nascimento, sexo e manejo alimentar e dados originais $(\mathrm{P})$, de cada genótipo, de bovinos cruzados.

\begin{tabular}{|c|c|c|c|c|c|c|c|c|c|c|}
\hline \multirow{2}{*}{$\begin{array}{c}\text { Grupo } \\
\text { Genético }\end{array}$} & \multirow[b]{2}{*}{ Genótipo } & \multirow[b]{2}{*}{ NG } & \multicolumn{2}{|c|}{ A (kg) } & \multicolumn{2}{|c|}{$k\left(\operatorname{dia}^{-1}\right)$} & \multicolumn{2}{|c|}{$\mathbf{m}$} & \multicolumn{2}{|c|}{$\mathbf{R}^{2}(\%)$} \\
\hline & & & $\mathbf{P}_{\text {Cor }}(*)$ & $\mathbf{P}(*)$ & $\mathbf{P}_{\mathrm{Cor}}$ & $\mathbf{P}$ & $\mathbf{P}_{\text {Cor }}$ & $\mathbf{P}$ & $\mathbf{P}_{\text {Cor }}$ & $\mathbf{P}$ \\
\hline \multirow{5}{*}{$\begin{array}{c}\mathrm{NC} \\
(\mathrm{N}=65)\end{array}$} & $\overline{\mathbf{G}_{2}}$ & 12 & $731,6(9)^{*}$ & $429,6(5)$ & 0,00386 & 0,00661 & 3,9632 & 3,7508 & 82,7 & 84,9 \\
\hline & $\mathbf{G}_{3}$ & 33 & $667,5(9)$ & $417,7(5)$ & 0,00403 & 0,00697 & 3,6960 & 3,6771 & 84,4 & 81,3 \\
\hline & $\mathbf{G}_{7}$ & 10 & $707,8(10)$ & $446,8(5)$ & 0,00403 & 0,00599 & 3,8932 & 3,3909 & 86,9 & 74,4 \\
\hline & $\mathbf{G}_{8}$ & 7 & $643,9(10)$ & $488,9(5)$ & 0,00461 & 0,00551 & 3,6763 & 3,2604 & 85,6 & 73,5 \\
\hline & $\mathbf{G}_{9}$ & 3 & $703,2(8)$ & $369,0(7)$ & 0,00404 & 0,00716 & 4,1605 & 3,4876 & 88,3 & 84,9 \\
\hline \multirow{9}{*}{$\begin{array}{c}\text { NA } \\
(\mathrm{N}=69)\end{array}$} & $G_{1}$ & 3 & $567,4(10)$ & $429,9(5)$ & 0,00557 & 0,00591 & 4,2165 & 3,1549 & 86,2 & 86,4 \\
\hline & $\mathbf{G}_{2}$ & 15 & 597,8 (11) & $462,3(5)$ & 0,00523 & 0,00598 & 3,9596 & 3,3647 & 89,0 & 84,4 \\
\hline & $\mathbf{G}_{3}$ & 14 & 636,5 (11) & $492,2(5)$ & 0,00464 & 0,00604 & 3,5674 & 3,3728 & 90,6 & 88,0 \\
\hline & $\mathbf{G}_{4}$ & 3 & 596,5 (11) & $468,0(8)$ & 0,00500 & 0,00741 & 3,7856 & 4,2694 & 89,2 & 97,3 \\
\hline & $\mathbf{G}_{5}$ & 8 & $617,6(9)$ & $454,8(6)$ & 0,00476 & 0,00714 & 3,8113 & 4,0263 & 89,9 & 88,8 \\
\hline & $\mathbf{G}_{6}$ & 8 & 615,7 (9) & $468,7(5)$ & 0,00476 & 0,00669 & 3,6231 & 3,5436 & 91,0 & 84,4 \\
\hline & $\mathbf{G}_{7}$ & 7 & $612,4(11)$ & $471,9(5)$ & 0,00503 & 0,00567 & 3,8428 & 3,2044 & 87,9 & 80,8 \\
\hline & $\mathbf{G}_{10}$ & 6 & $783,0(9)$ & $560,4(10)$ & 0,00402 & 0,00591 & 3,9230 & 3,9079 & 92,0 & 93,1 \\
\hline & $\mathbf{G}_{11}$ & 5 & $1035,8(5)$ & $795,3(6)$ & 0,00302 & 0,00397 & 4,0520 & 3,9085 & 91,7 & 94,1 \\
\hline \multirow{6}{*}{$\begin{array}{c}\text { NS } \\
(\mathrm{N}=\mathbf{5 9})\end{array}$} & $\mathbf{G}_{2}$ & 8 & $1524,8(7)$ & $538,9(5)$ & 0,00242 & 0,00519 & 4,5242 & 3,5562 & 95,7 & 77,9 \\
\hline & $\mathbf{G}_{3}$ & 26 & 1639,7 (6) & $485,4(5)$ & 0,00217 & 0,00608 & 4,4992 & 3,5461 & 91,9 & 84,6 \\
\hline & $\mathbf{G}_{4}$ & 11 & $3352,4(10)$ & $508,1(5)$ & 0,00166 & 0,00628 & 5,5408 & 3,8055 & 92,7 & 85,7 \\
\hline & $G_{5}$ & 5 & $1486,6(11)$ & $472,6(4)$ & 0,00237 & 0,00599 & 4,5051 & 3,5425 & 95,2 & 78,6 \\
\hline & $\mathbf{G}_{8}$ & 6 & $1365,5(6)$ & $512,5(4)$ & 0,00253 & 0,00567 & 4,1629 & 3,1427 & 92,3 & 84,3 \\
\hline & $\mathbf{G}_{11}$ & 3 & $1364,6(8)$ & $429,0(5)$ & 0,00252 & 0,00694 & 4,6795 & 3,5319 & 95,5 & 98,6 \\
\hline
\end{tabular}

* Número de iterações utilizadas para atingir a convergência.

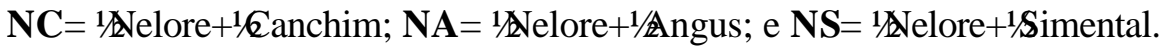

$\mathrm{G}_{1}=\mathrm{AALLAA} ; \mathrm{G}_{2}=\mathrm{AALLAB} ; \mathrm{G}_{3}=\mathrm{AALLBB} ; \mathrm{G}_{4}=\mathrm{AALVAB} ; \mathrm{G}_{5}=\mathrm{AALVBB} ; \mathrm{G}_{6}=$ ABLLAA; $\mathrm{G}_{7}=\mathrm{ABLLAB} ; \mathrm{G}_{8}=\mathrm{ABLLAB} ; \mathrm{G}_{9}=\mathrm{ABLLAB} ; \mathrm{G}_{10}=\mathrm{ABLVAB} ; \mathrm{e} \mathrm{G}_{11}=\mathrm{ABLVBB}$.

As estimativas do parâmetros $A, k$ e $m$ obtidas para cada animal, após transformadas pelo logaritmo natural, foram analisados pela técnica dos modelos lineares usando-se o PROC GLM (SAS, 2001), a fim de testar o efeito do genótipo. Os modelos utilizados incluíram os efeitos fixos de ano de nascimento, sexo, manejo alimentar e genótipo. O modelo linear descrito acima, foi utilizado para os rês conjunto de dados originais (grupos genéticos NC, NA e NS). 
A transformação logarítmica foi usada pois não foi atendida uma das suposições (linearidade) feitas em análises empregando-se os modelos lineares. Estas análises especificam que a média condicional $\mathrm{E}\left(\mathrm{y} \mid \mathrm{x}=\mathrm{x}_{0}\right)$ da variável resposta $\mathrm{y}$ dado $\mathrm{o}$ valor x do vetor preditor $x$, é linear em x. A aplicação dos modelos lineares pode ser estendida supondo-se que uma transformação apropriada da variável resposta dada por $t(y)$, em que $E\{t(y) \mid x\}$, seja linear em $x$, na função $t(y)=\beta_{0}+\beta^{T} x+\varepsilon$, para $\beta_{0}$ e $\beta^{T}$ desconhecidos. O termo $\varepsilon$ (erro aleatório) é independente de $\mathrm{x}$ e tem média zero (Cook \& Weisberg, 1994).

Não foi observado efeito significativo $(\mathrm{P}>0,05)$ do genótipo sobre os três parâmetros $(A, k$ e $m)$ do modelo Logístico, para os conjuntos de dados NA e NS.

Para os animais do grupo genético $\mathrm{NC}$, os genótipos influenciaram significativamente $(\mathrm{P}<0,01$ e $\mathrm{P}<0,05)$ as estimativas dos parâmetros $A$ e $k$, respectivamente, porém não influenciaram $(\mathrm{P}>0,05)$ o parâmetro $m$. $\mathrm{O}$ genótipo $\mathrm{G}_{3}$ apresentou valor inferior para o peso assintótico $(A)$ e maior taxa de maturação por unidade de tempo $(k)$, em relação aos genótipos $\mathrm{G}_{7}$ e $\mathrm{G}_{8}$. Os valores do parâmetro $A$ para o genótipo $\mathrm{G}$ foram 6,5\% e 14,5\% inferiores ao mesmo parâmetro para os genótipos $\mathrm{G}$ e $\mathrm{G}_{8}$, respectivamente e as diferenças quanto a taxa de maturação $(k)$ foram de $14 \%$ e $21 \%$ superiores para $\mathrm{G}_{3}$ em relação aos genótipos $\mathrm{G}_{7}$ e $\mathrm{G}_{8}$, respectivamente. A apesar de não significativa a diferença entre $\mathrm{G}_{2}$ e $\mathrm{G}_{7}$, o valor de $A$ para o genótipo $\mathrm{G}_{2}$, foi $4 \%$ inferior em relação ao $\mathrm{G}_{7}$, e de $k$ foi $10 \%$ superior para $\mathrm{G}_{2}$ em relação ao $\mathrm{G}$. Estes resultados indicam possíveis efeitos dos genes CSN3 e LGB, devido à tendência do genótipo $\mathrm{G}_{3}$ apresentar menor valor de $A$ e maior de $k$, em relação aos outros dois genótipos. Provavelmente, os alelos A do gene CSN3 e o B do gene LGB exerceram influência favorável sobre os parâmetros $A$ e $k$.

Estas diferenças podem ser visualizadas na Figura 3, que apresenta as estimativas dos pesos (pré-corrigidos e não corrigidos para sexo, manejo alimentar e ano de nascimento) em função da idade, para cada genótipo $\left(G_{1}, G_{2}, G_{3}, G_{4}, G_{5}, G_{6}, G_{7}, G_{8}\right.$, $\mathrm{G}_{9}, \mathrm{G}_{10}$ e $\mathrm{G}_{11}$ ), formados pelos genes CSN3, GH e LGB, de animais cruzados NC, NA e NS. 


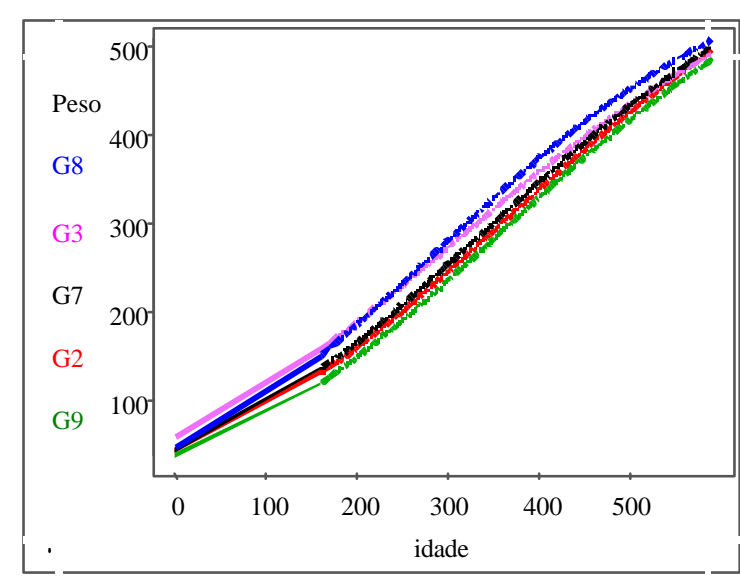

1/20lore + 1/6anchim $\left(\mathrm{P}_{\mathrm{Cor}}\right)$

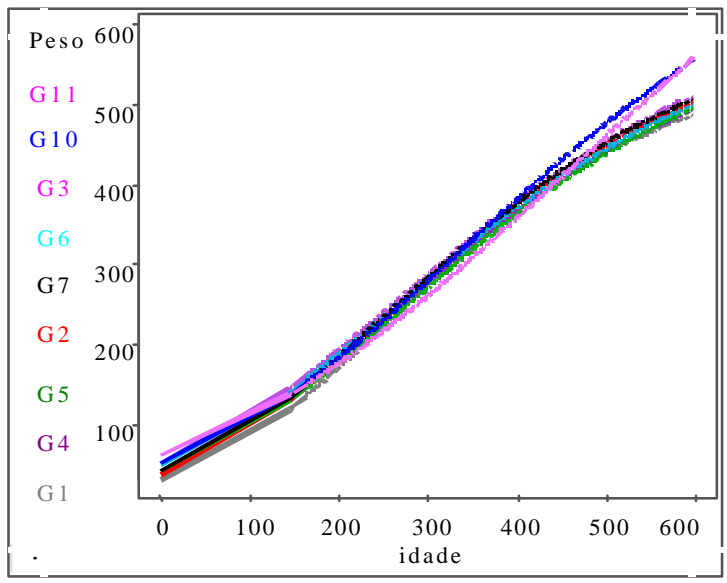

$1 / 2$ elore $+1 / 2$ Angus $\left(\mathrm{P}_{\mathrm{Cor}}\right)$

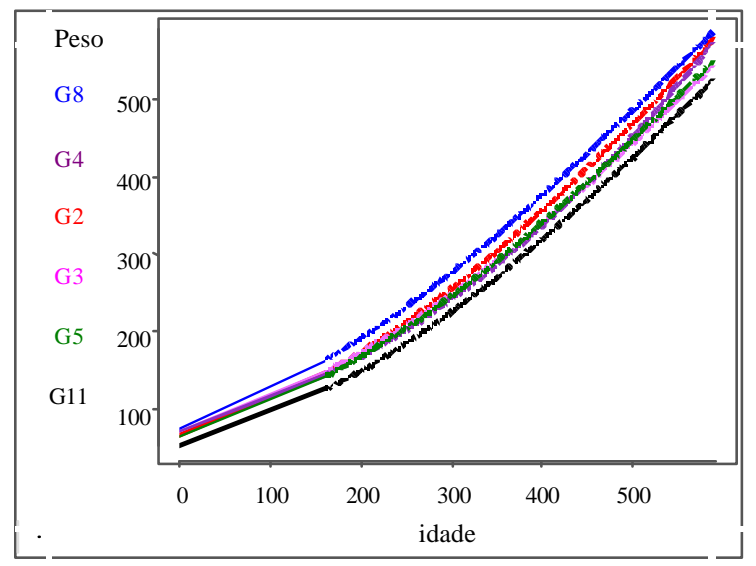

1/2 Eelore $+{ }^{1}$ Simental $\left(\mathrm{P}_{\mathrm{Cor}}\right)$

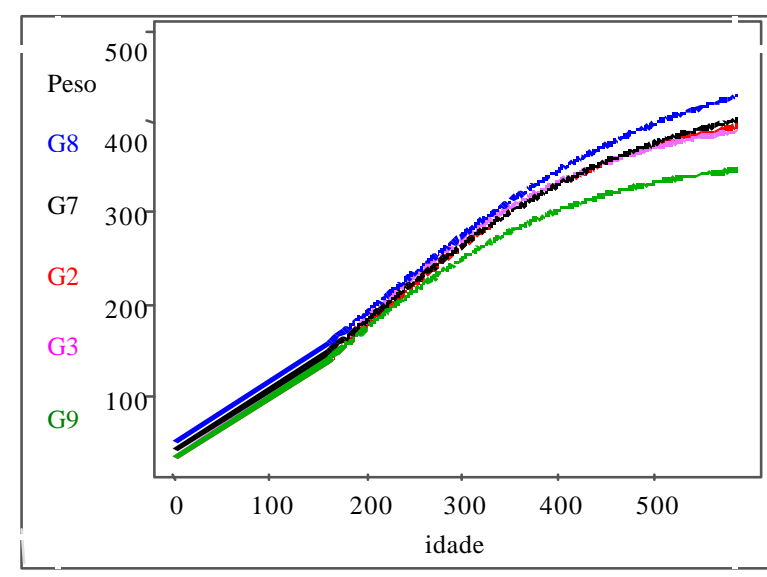

1/2elore + 16anchim (P)

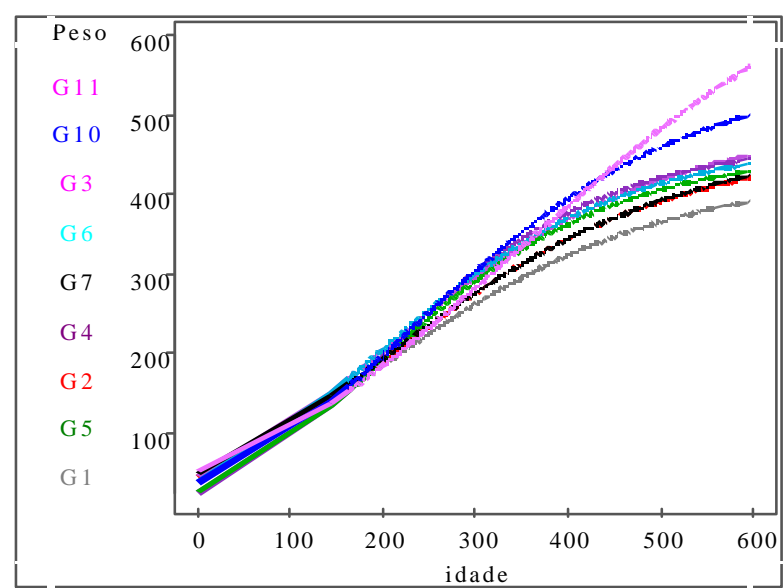

1/2elore +1/2ngus (P)

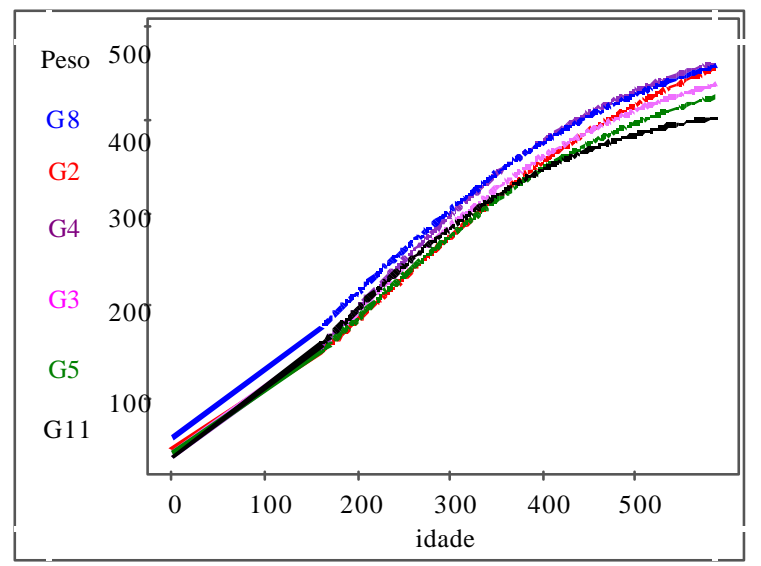

1/Eelore + ${ }^{1}$ Simental (P)

$\mathrm{G}_{1}=\mathrm{AALLAA} ; \mathrm{G}_{2}=\mathrm{AALLAB} ; \mathrm{G}_{3}=\mathrm{AALLBB} ; \mathrm{G}_{4}=\mathrm{AALVAB} ; \mathrm{G}_{5}=\mathrm{AALVBB} ; \mathrm{G}_{6}=\mathrm{ABLLAA} ;$

$\mathrm{G}_{7}=\mathrm{ABLLAB} ; \mathrm{G}_{8}=\mathrm{ABLLAB} ; \mathrm{G}_{9}=\mathrm{ABLLAB} ; \mathrm{G}_{10}=\mathrm{ABLVAB} ; \mathrm{e} \mathrm{G}_{11}=\mathrm{ABLVBB}$.

Figura 3 - Estimativa do peso $(\mathrm{kg})$ considerando-se dados pré-corrigidos $\left(\mathrm{P}_{\mathrm{Cor}}\right)$ para sexo, manejo alimentar e ano de nascimento e dados originais (P), em função da idade (dias), ajustada pelo modelo Logístico para os polimorfismos dos genes CSN3, GH e LGB, de animais cruzados. 
Mesmo o genótipo não tendo apresentado efeito significativo sobre os parâmetros da curva de crescimento dos grupos genéticos NA e NS, empregando-se o modelo de análise proposto, pode-se observar algumas diferenças entres as classes de genótipos.

Fazendo-se algumas comparações com relação aos genótipos observados no grupo genético NS, pode-se verificar possível efeito do gene CSN3 sobre os parâmetros da curva de crescimento. $\mathrm{O}$ valor do parâmetro $A$ do genótipos $\mathrm{G}_{3}$ em relação ao $\mathrm{G}_{8}$ foi $5 \%$ inferior e do $k$ foi $7 \%$ superior; para o genótipo $\mathrm{G}_{1}$ o parâmetro $A$ foi $9 \%$ inferior e o $k$ foi $14 \%$ superior em relação ao $G_{5}$. Os genótipos $G_{3}$ e $G_{8}$ são homozigotos (LL) para o gene $\mathrm{GH}$, enquanto o $\mathrm{G}_{5}$ e o $\mathrm{G}_{11}$ são heterozigotos (LV) para este gene.

Pode-se observar também a possibilidade do gene LGB influenciar o crescimento dos animais. Para o grupo genético NA, o genótipo $\mathrm{G}_{1}$ apresentou valores para o parâmetro $A$, em torno de $7 \%$ e $12,5 \%$ inferiores ao mesmo parâmetro para $\mathrm{G}_{2}$ e $\mathrm{G}_{3}$, respectivamente, e para $\mathrm{G}_{2}$ foi $6 \%$ inferior em relação ao $\mathrm{G}_{3}$. Os valores do parâmetro $k$, para o genótipo $\mathrm{G}_{1}$, foram $1 \%$ e $2 \%$ inferiores em relação aos genótipos $\mathrm{G}_{2}$ e $\mathrm{G}_{3}$, respectivamente, e o valor para $\mathrm{G}_{3}$ foi apenas $1 \%$ superior em relação ao $\mathrm{G}_{2}$. Considerando-se os mesmos critérios de comparação, o genótipo $\mathrm{G}_{4}$ apresentou valores de $3 \%$ e $4 \%$ superiores em relação ao $\mathrm{G}_{5}$ quanto aos parâmetro $A$ e $k$, respectivamente. A única exceção ocorreu quando estas comparações foram realizadas dentro dos genótipos em que CSN3 apresentava-se em heterozigose.

Para os animais NS, o valor de $A$ para o genótipo $\mathrm{G}_{3}$ foi $10 \%$ inferior em relação ao $\mathrm{G}_{2}$ e para o $\mathrm{G}_{5}$ foi $7 \%$ inferior em relação ao $\mathrm{G}$. Com relação a taxa de maturação, o valor de $k$ para $\mathrm{G}_{3}$ foi $14,5 \%$ superior em relação ao $\mathrm{G}_{2}$, e entretanto, para $\mathrm{G}_{5}$ foi de $4,5 \%$ inferior em relação ao $\mathrm{G}_{4}$.

Em geral, houve tendência dos genes CSN3 e LGB apresentarem efeito sobre os parâmetros $A$ e $k$, conforme descrito anteriormente. Lin et al. (1987) encontraram associação de CSN3 e LGB com o peso ao nascimento, peso aos 350 dias de idade e com o peso ao primeiro parto, e Moody et al. (1996) encontraram associação de CSN3 com características de crescimento (valor genético do peso ao nascimento, 
ganho do nascimento ao desmame, ganho do desmame ao ano e valor genético materno do peso ao nascimento e ganho do nascimento ao desmame).

Quanto ao efeito do polimorfismo do $\mathrm{GH}$, para o grupo genético NS, o valor do parâmetro $A$ do genótipo $\mathrm{G}_{4}$ foi apenas $5,5 \%$ inferior ao valor do mesmo parâmetro do $\mathrm{G}_{2}$, enquanto a diferença entre os dois genótipos quanto ao parâmetro $k$ foi de $17 \%$ superior para $\mathrm{G}_{4}$; os valores dos parâmetros de $A$ e $k$ do genótipo $\mathrm{G}_{4}$ foram respectivamente $4,5 \%$ e $3 \%$ superiores em relação ao $\mathrm{G}_{3}$. Houve evidências de efeito dos polimorfismos do GH sobre os parâmetros da curva de crescimento, concordando-se com resultados literatura (Rocha et al., 1992; Unaniam et al, 2000; Tambasco et al., 2002), os quais sugerem possível associação de GH com características de crescimento em bovinos de corte.

Nas análises de características quantitativas usando-se o modelo infinitesimal, a interação entre locos (epistasia) não é considerada devido às dificuldades como os modelos matemáticos para estimar este efeito, além das dificuldades computacionais. Outro fator que justifica a não inclusão do efeito de epistasia nos modelos, é a falta de evidências de que este efeito possa influenciar as características quantitativas. Entretanto, recentemente a interação entre locos (epistasia) foi relatada na literatura (Casas et al., 2000; Tambasco et al., 2002).

Possivelmente, pode estar ocorrendo interação entre os locos dos genes estudados ou ainda com locos de outros genes que estão muito próximos à localização destes genes, e portanto, estão segregando ligados. Em geral, os genótipos AB e BB para LGB, apresentaram forma da curva de crescimento mais desejável que os genótipos AA, na presença do genótipo LL para GH, e o genótipo BB para LGB apresentou forma da curva mais desejável que o $\mathrm{AB}$, na presença do genótipo LV para $\mathrm{GH}$, em conformidade com os resultados de Tambasco et al. (2002). Estes pesquisadores encontraram evidências de interação entre GH e LGB e associação de GH com o ganho de peso do nascimento ao desmame e do desmame aos 12 meses de idade, em animais cruzados. Os genótipos $\mathrm{AB}$ e $\mathrm{BB}$ para LGB na presença de LL para $\mathrm{GH}$, apresentaram maior ganho de 
peso que o genótipo AA, enquanto o genótipos AA apresentou maior ganho de peso que o BB na presença do genótipo LV para GH.

A aplicação da técnica dos modelos não lineares em estudos de associação entre polimorfismos genéticos e o crescimento animal, proporcionou uma análise detalhada do desenvolvimento dos animais dos diferentes genótipos (genes: CSN3, GH e LGB). Entretanto, mais estudos são necessários para confirmar a possível associação destes e outros genes com o crescimento de bovinos de corte e as possíveis interações entre genes.

\subsection{Conclusões}

O modelo Logístico forneceu uma estimação adequada da curva de crescimento para os polimorfismos dos genes kappa-caseína (CSN3), hormônio do

crescimento $(\mathrm{GH})$ e $\beta$-lactoglobulina (LGB) de animais dos grupos genéticos: 10lore

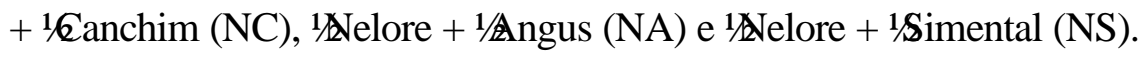

Foram constatados efeitos dos polimorfismos dos genes da kappa-caseínaHinfI (CSN3), do hormônio do crescimento-AluI e da $\beta$-lactoglobulina-HaeIII (LGB), sobre as estimativas dos parâmetros da curva de crescimento, ajustada pelo modelo Logístico, para bovinos de três grupos genéticos. 


\section{INFLUÊNCIA DOS POLIMORFISMOS GENÉTICOS SOBRE OS PARÂMETROS DA CURVA DE CRESCIMENTO EM BOVINOS DE CORTE}

\section{Resumo}

Registros de pesos ao nascimento, ao desmame e mensais dos 8 aos 19 meses de idade referentes à animais dos grupos genéticos: Nelore+1/Angus (NA) e elore+1/Simental (NS), pertencentes à Embrapa Pecuária Sudeste, São Carlos, SP, foram analisados pela técnica dos modelos não lineares incluindo, no modelo Logístico, os efeitos fixos de grupo contemporâneo e das classes de genótipos dos genes da kappa-caseína-Hinf (CSN3): AA e AB, do hormônio do crescimento-AluI (GH): LL e LV e da $\beta$-lactoglobulina-HaeIII (LGB): AA, AB e BB, com o objetivo de verificar a influência destes genes sobre a curva de crescimento destes animais. Os resultados sugerem que, os parâmetros $A$ e $k$, da função Logística utilizada para descrever o crescimento dos grupos genéticos NC, NA e NS, foram influenciados pelos polimorfimos dos genes CSN3, GH e LGB. As maiores diferenças entre os genótipos para os genes CSN3, GH e LGB foram observadas a partir dos 12-13 meses de idade. O genótipo AA para CSN3 apresentou maior taxa de maturação $k$ ) que o genótipo $\mathrm{AB}$ nos grupos genéticos NC, NA e NS. Quanto ao valor assintótico $(A)$, a diferença entre $\mathrm{AA}$ e $\mathrm{AB}$, foi pequena nos grupos genéticos $\mathrm{NC}$ e NS. Para o polimorfismo do GH no grupo genético NA, a curva que descreve o crescimento dos animais do genótipo LL mostrou-se mais desejável, do ponto de vista de produção de bovinos de corte. Entretanto, ocorreu inversão desta tendência no grupo genético NS. O mesmo ocorreu para o LGB, em que os genótipos $\mathrm{AA}$ e $\mathrm{AB}$ apresentaram estimativas do parâmetro $k$ superiores em relação ao genótipo $\mathrm{BB}$ no grupo genético NA, enquanto o 
genótipo $\mathrm{AB}$ apresentou estimativa de $k$ inferior em relação ao genótipo $\mathrm{BB}$, no grupo genético NS. Evidências de que os polimorfismos dos genes CSN3, GH e LGB estejam ligados à QTL ("Quantitative Trait Locus”) influenciando a curva de crescimento de bovinos, indicam que no futuro, os genótipos destes genes podem ser usados em programas de seleção assistida por marcadores.

Palavras-chaves: bovinos de corte, curvas de crescimento, marcadores genéticos, modelo Logístico.

\section{Summary}

Records of the weights at birth, weaning and monthly from 8 to 19 months of age from three genetic groups: $1 / 2$ elore+1/Eanchim (NC), $1 / 2$ elore+1/2berdeen Angus (NA) e 1Selore+1Simmental (NS), born in 1998 and 1999 in Southeast Brazil, were used to fit a Logistic nonlinear model that included the fixed effects of the contemporary group and genotype of the genes kappa-casein-Hinf I (CSN3): AA and $\mathrm{AB}$, growth hormone-AluI (GH): LL and LV, and $\beta$-lactoglobulin-HaeIII (LGB): AA, $\mathrm{AB}$ and $\mathrm{BB}$, to examine the effect of these markers on the growth curve. The Logistic model used by explain of growth of the NC, NA and NS genetic groups, was influenced by genotypes of the CSN3, GH e LGB markers The major differences started at 12-13 months of age. The value of the maturing rate $(k)$ of the AA genotype for CSN3 was superior in relation to $\mathrm{AB}$ genotype in the NC, NA and NS genetic groups. However, there was observed small difference in estimate of the asymptotic value $(A)$ for the AA and $\mathrm{AB}$ genotypes in $\mathrm{NC}$ and $\mathrm{NS}$ genetic groups. For the $\mathrm{GH}$ polymorphism in NA genetic group the growth curve of the LL genotype showed more desirable to production of the beef cattle. The same was observed for the LGB, there were superior values of the parameter $k$ of the $\mathrm{AA}$ and $\mathrm{AB}$ genotypes in relation to the $\mathrm{BB}$ for the NA genetic group, however, there was inferior value of the parameter $k$ of the $\mathrm{AB}$ genotype in relation to the $\mathrm{BB}$, for the NS genetic group. Evidences that CSN3, GH and LGB polymorphism 
are linked to QTL influencing growth curve in beef cattle, indicates these genotypes may be a useful marker in future maker-assisted selection programs.

Key-words: Beef cattle, genetic marker, growth curves, Logistic model.

\subsection{Introdução}

Os marcadores moleculares constituem ferramenta importante para identificação de animais portadores de doenças genéticas, determinação de parentesco e associação com características de interesse econômico. Características de produção, particularmente por sua importância, têm propiciado vários estudos com a finalidade de gerar metodologias que permitam maior acurácia na avaliação e seleção de animais.

Genes candidatos para uma determinada característica são seqüências de genes de ação biológica conhecida que estão envolvidas no desenvolvimento ou fisiologia da característica. Os polimorfismos da kappa-caseína-Hinf $\mathrm{I}$ (CSN3), do hormônio do crescimento-AluI (GH) e da $\beta$-lactoglobulina-HaeIII (LGB) são considerados genes candidatos e têm sido utilizados com o propósito de associação com características de produção.

Estruturalmente o gene do hormônio do crescimento bovino (GH), apresenta alto grau de polimorfismo, com vários sítios polimórficos (Lucy et al., 1991; Kirkpatric, 1992; Zhang et al., 1992 e 1993; Unanian et al., 1994). Este gene exerce importantes funções biológicas na regulação do crescimento animal (Gluckman et al., 1987) e nos processos envolvidos na resistência a doenças (Arkins et al., 1993). Os polimorfismos do GH foram associados à produção (Hoj et al., 1993, Moody et al., 1996) e quantidade de gordura do leite (Yao et al., 1996), ao peso ao nascimento (Rocha et al., 1992) e também a composição e qualidade da carne (Taylor et al., 1998).

A kappa-caseína descrita por Medrano \& Aguilar-Cordova (1990a) e a $\beta$ lactoglobulina, descrita por Medrano \& Aguilar-Cordova, (1990b), são proteínas presentes no leite e a princípio foram associadas à características produção de leite $(\mathrm{Ng}$ - 
Kwai-Hang et al., 1884 e 1991; Ron et al., 1994). A kappa-caseína faz parte do grupo estrutural das caseínas, as quais são as únicas proteínas passíveis de coagulação no leite, que está relacionado com o rendimento e qualidade do queijo (Lin et al., 1992). A $\beta$ lactoglobulina faz parte da fração globulina das proteínas do soro do leite e é considerada como importante fonte de imunidade para os organismos. Estas duas proteínas apresentaram relação importante ente si (Hines et al., 1981; Bovenhuis et al., 1992). A $\beta$-lactoglobulina parece ainda estar associada à porcentagem de gordura do leite e a porcentagem de kappa-caseína presente no leite (Lin et al., 1992).

Com relação à características de crescimento, os genes que codificam estas proteínas (kappa-caseína e $\beta$-lactoglobulina) foram associados ao valor genético do peso ao nascimento, do ganho do nascimento ao desmame, do ganho do desmame ao ano e o valor genético materno do peso ao nascimento e do ganho do nascimento ao desmame (Moody et al., 1996), e também com o peso ao nascimento, peso aos 350 dias de idade e com o peso ao primeiro parto (Lin et al., 1987).

Análises prévias (Paz et al. $^{2}$ ), em que os parâmetros $A$ e $k$ foram analisados pela técnica dos modelos lineares usando-se o PROC GLM (SAS, 2001), detectaram efeito significativo $(\mathrm{P}<0,01$ e $\mathrm{P}<0,05)$ dos polimorfismos dos genes CSN3, GH e LGB, respectivamente, sobre os parâmetros $A$ e $k$ da curva Logística ajustada ao conjunto de dados de peso em função da idade, de animais do grupo genético 1/Nelore + 1⁄Canchim. Entretanto, análises que consideram os parâmetros das funções não lineares e os efeitos fixos e/ou covariáveis simultaneamente no modelo, parecem ser mais adequadas. Schabenberger (2001), apresentou um exemplo de análise de variância, usando um modelo não linear Log-Logístico, com quatro parâmetros a serem estimados e y (variável resposta) em função da taxa de crescimento $(\mathrm{kg} / \mathrm{ha})$, com dois tratamentos. Nesta análise, as estimativas dos parâmetros do modelo Log-Logístico foram obtidas por um modelo que incluiu o efeito dos tratamentos, de maneira que a influência deste efeito sobre os parâmetros da função Log-Logística também foram consideradas.

2 PAZ, C.C.P.; PACKER, I.U.; FREITAS, A.R.; TAMBASCO-TALHARI, D.; REGITANO, L.C.A.; ALENCAR, M.M. Ajuste dos modelos não lineares no estudo da associação entre polimorfismos genéticos e crescimento em bovinos de corte. (Trabalho não publicado). 
Desta forma, no presente trabalho, a modelagem dos dados de peso em função da idade, de animais dos grupos genéticos 1/Nelore + 1/Eanchim, 1/Nelore + 1/Aberdeen Angus e 1/Eelore + ${ }^{1}$ Simental, foi realizada pela técnica dos modelos não lineares usando-se o procedimento NLIN (SAS, 2001). O modelo não linear Logístico, incluiu os efeitos fixos de grupo contemporâneo e dos genótipos dos genes da kappacaseína-HinfI (CSN3): AA e AB, do hormônio do crescimento-AluI (GH): LL e LV e da $\beta$-lactoglobulina-HaeIII (LGB): $\mathrm{AA}, \mathrm{AB}$ e $\mathrm{BB}$, com o objetivo de verificar a influência destes genes sobre a curva de crescimento dos animais e estimar os parâmetros da função Logística, simultaneamente.

\subsection{Material e Métodos}

\subsubsection{Descrição dos dados}

Foram utilizadas informações de 230 animais, dos grupos genéticos

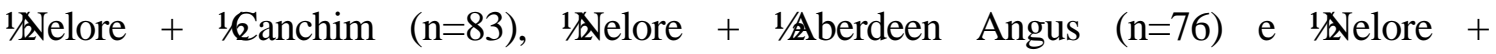
1Simental (n=71), pertencentes à Embrapa Pecuária Sudeste, São Carlos, SP.

Anualmente, foram usados 2, 5 e 4 touros das raças Canchim, Aberdeen Angus e Simental respectivamente cruzados com 57, 57 e 53 fêmeas Nelore. Os cruzamentos foram feitos em dois ciclos (anos de 1998 e 1999).

$\mathrm{Na}$ edição dos dados, as variáveis fenotípicas foram obtidas do arquivo que continha a identificação do animal, touro e vaca, os pesos ao nascimento, ao desmame (7 meses de idade em média), e mensalmente dos 8 aos 19 meses de idade, além de sexo, dia, mês e ano de nascimento do animal (1998 ou 1999) e da vaca, manejo alimentar (CS $=$ com suplementação ou $\mathbf{S S}=$ sem suplementação $)$ e grupo genético $(\mathbf{N C}=\mathbf{1}$ - Velore

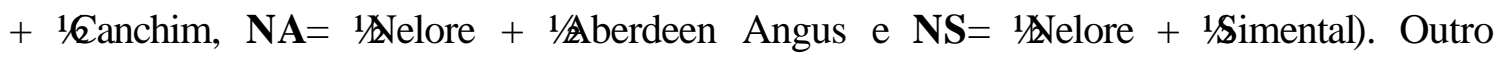
arquivo continha a identificação dos animais e as variáveis genotípicas que compreendiam os polimorfismos de restrição dos genes da kappa-caseína-Hinf $\mathrm{I}$ (Barendse et al., 1997), do hormônio do crescimento-AluI (Taylor et al., 1998), e $\beta$ - 
lactoglobulina-HaeIII (Barendse et al. 1997), que são do tipo RFLP-PCR e estão distribuídos nos cromossomos 19, 6 e 11 de bovinos, às distâncias de 72,7 cM, 103 cM e $150 \mathrm{cM}$, respectivamente, cujas classes genotípicas observadas foram LL e LV para o GH e AA, AB e BB para CSN3 e LGB.

A partir das informações do primeiro arquivo, foram formados 8 grupos contemporâneos pela concatenação das variáveis, sexo, ano de nascimento e grupo de manejo alimentar.

Ainda durante a edição dos dados, foram eliminadas as observações dos animais que pertenciam à classe de polimorfismos genéticos (para os genes CSN3, GH e LGB) desconhecida, ou com menos de 5 animais, e à classe de grupo manejo alimentar desconhecido, além de eliminar os genótipos BB do gene CSN3 dos animais NC e NA, e AA do gene LGB dos animais NS. Desta forma, restaram 66, 68 e 52 informações, respectivamente para os grupos genéticos NC, NA e NS, do total de 230 animais.

\subsubsection{Análises estatísticas}

O conjunto de dados peso-idade foi ajustado pelo modelo Logístico (Nelder, 1961). As estimativas dos parâmetros dos modelos Logísticos ajustados para os grupos genético foram descritas por Paz et al. $^{2}$. A estimação dos parâmetros de cada

modelo foi realizada por meio da técnica dos modelos não lineares usando-se o procedimento NLIN (SAS, 2001), utilizando-se o método de Gauss Newton descrito por Hartley (1961).

Modelo Logístico é representado pela seguinte equação:

$$
y_{t}=A\left(1+e^{-k t}\right)^{-m}
$$




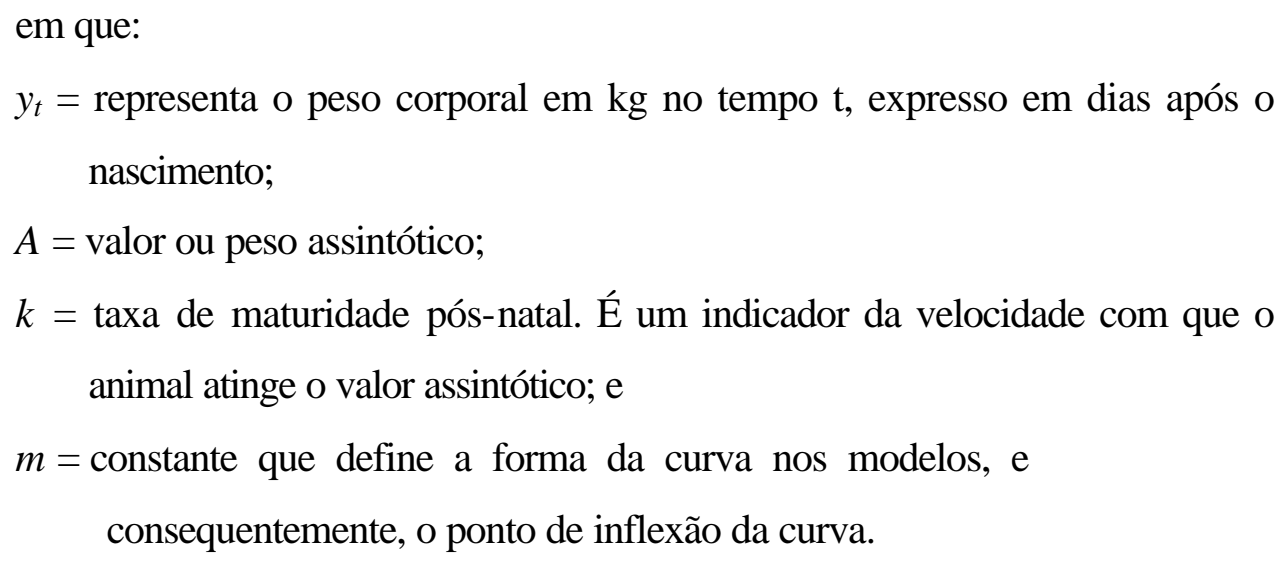

\subsubsection{Erro de Predição}

Para as curvas médias, ajustadas pelo modelo Logístico, para cada grupo genético (Paz et al. $^{2}$ ), foi calculado o erro de predição (EP), em porcentagem (Goonewardene et al., 1981), para cada observação peso-idade, como um desvio do peso estimado $(\hat{\mathrm{Y}})$ em relação ao peso observado (Y), dividido pelo peso observado e multiplicado por $100(\mathrm{EP}=100(\mathrm{Y}-\hat{\mathrm{Y}}) / \mathrm{Y})$ e consequentemente foi obtida a estimativa do erro de predição médio (EPM), para cada grupo genético. O sinal que este valor apresenta, designa se a função subestimou (+) ou superestimou (-) o peso observado.

\subsubsection{Comparação entre os genótipos}

Neste estudo, foi utilizada a proposta de Schabenberger (2001), considerando-se no modelo de análise os polimorfismos dos genes CNS3, GH e LGB e o grupo contemporâneo (GC), como efeitos fixos.

Inicialmente, verificou-se o efeito do GC sobre resposta ajustada pelo modelo Logístico considerando o conjunto de dados peso-idade. A influência do GC sobre a curva de crescimento foi verificada pela técnica dos modelos não lineares (SAS, 
2001), considerando-se dois modelos. O primeiro, denominado Completo, considera diferentes conjuntos de estimativas de parâmetros $(A, k$ e $m)$ em função dos GC, para definir a resposta ajustada pelo modelo Logístico. O segundo modelo, denominado Reduzido considera que não existem diferenças entre os GC, então a curva de crescimento dos animais pode ser definida por um único conjunto de estimativas de parâmetros $(A, k$ e $m)$.

Da mesma forma que na análise anterior, foi verificada a influência dos genótipos dos animais para os genes CSN3, GH e LGB, sobre a curva de crescimento. Neste caso, o modelo Completo considera diferentes conjuntos de estimativas de parâmetros $(A, k$ e $m)$ em função dos genotípos e dos $\mathrm{GC}$, para definir a resposta por meio do modelo Logístico e o modelo Reduzido considera que não existem diferenças entre os genótipos, ajustando o conjunto de dados peso-idade por meio de um modelo com número reduzido de parâmetros $(A, k$ e $m)$ definido em função dos grupos contemporâneos. Para cada gene estudado foi definido um modelo Completo, que incluiu apenas o efeito principal do gene.

\section{Modelo Completo:}

$$
y_{j t}=A_{j}\left(1+e^{-k_{j} t}\right)^{-m_{j}}
$$

Para verificar o efeito do grupo contemporâneo sobre a curva de crescimento foi utilizado o modelo Completo que apresenta $\mathrm{n} \times 3$ parâmetros, em que o subscrito $j$ identifica o $\mathrm{GC}, \mathrm{n}_{\mathbb{l}}$ é o número de classes formadas pelos $\mathrm{GC}$ e 3 é o número de parâmetros do modelo Logístico utilizado ( $\mathrm{n}_{1}$ conjuntos de 3 parâmetros, um para cada classe de GC).

$\mathrm{Na}$ segunda análise, o nodelo Completo apresenta $\mathrm{n}_{2} \times 3$ parâmetros, em que o subscrito $j$ identifica o conjunto 'genótipo $+\mathrm{GC}$ ', $\mathrm{n}_{2}$ é o número de classes formadas pelo conjunto 'genótipo + GC', e 3 é o número de parâmetros do modelo Logístico ( $\mathrm{n}_{2}$ conjuntos de 3 parâmetros, um para cada classe identificada pelo conjunto 'genótipo + GC'). 
$\mathrm{O}$ modelo Completo define a hipótese alternativa $\left(\mathrm{H}_{\mathrm{A}}\right)$, ou seja, que existe diferença na resposta ajustada pelo modelo Logístico, entre os GC ou entre os polimorfismos genéticos de cada gene estudado, respectivamente para a primeira e segunda análise.

\section{Modelo Reduzido:}

$$
y_{t}=A\left(1+e^{-k t}\right)^{-m}
$$

Utilizando-se o modelo Logístico, se não existe influência do GC sobre a curva de crescimento, então os $\mathrm{n}_{1}$ grupos contemporâneos terão os mesmos parâmetros $A, k$ e $m$, no caso da primeira análise.

Entretanto, se não existe influência do genótipo e existe efeito do GC sobre os parâmetros do modelo Logístico, então os $\mathrm{n}_{2}$ grupos definidos por 'genótipo + GC' terão os mesmos conjuntos de estimativas de parâmetros $(A, k$ e $m)$ dos $\mathrm{n}_{1} \mathrm{GC}$.

O modelo Reduzido define como hipótese de nulidade $\left(\mathrm{H}_{\mathrm{o}}\right)$, que não há diferença na resposta ajustada pelo modelo Logístico, entre os GC ou entre os polimorfismos genéticos de cada gene estudado.

\section{Valor observado do teste $F$ :}

$$
\mathrm{F}_{\mathrm{obs}}=\frac{\left(\mathrm{SQR}_{\text {Re duzido }}-\mathrm{SQR}_{\text {Completo }}\right) /\left(\mathrm{GLR}_{\text {Reduzido }}-\mathrm{GLR}_{\text {Completo }}\right)}{\mathrm{QME}_{\text {Completo }}}
$$

utilizado para testar as diferentes hipóteses. 


\section{Probabilidade do valor observado de $F$ :}

$$
\operatorname{Pr} \mathrm{ob}>\mathrm{F}=1-\operatorname{Prob}_{\mathrm{F}}\left\{\mathrm{F}_{\mathrm{obs}},\left[\mathrm{GLR}_{\text {Re duzido }}-\mathrm{GLR}_{\text {Completo }}\right],\left[\mathrm{GLR}_{\text {Completo }}\right]\right\}
$$

em que:

$\mathrm{SQR}_{\text {Reduzido }}=$ soma de quadrados do resíduo do modelo Reduzido;

$\mathrm{SQR}_{\text {Completo }}=$ soma de quadrados do resíduo do modelo Completo;

$\mathrm{QME}_{\text {Completo }}=$ quadrado médio do erro do modelo Completo;

$\mathrm{GLR}_{\text {Reduzido }}=$ graus de liberdade do resíduo do modelo Reduzido; e

$\mathrm{GLR}_{\text {Completo }}=$ graus de liberdade do resíduo do modelo Completo.

Para calcular a probabilidade do valor observado de $F$, foi usada a função PROBF (SAS, 2001), a qual retorna a probabilidade de uma distribuição $F$, com os graus de liberdade do numerador igual a GLR $_{\text {Reduzido }}-$ GLR $_{\text {Completo }}$ e os graus de liberdade do denominador igual a GLR Completo.

\subsection{Resultados e Discussão}

\subsubsection{Frequências alélica e genotípica}

Com o objetivo de caracterizar os rebanhos estudados quanto à frequência dos genes, na Tabela 1 estão apresentadas as frequências genotípica e alélica dos polimorfismos dos genes candidatos, CSN3, GH e LGB dos animais cruzados NC, NA e NS.

Os polimorfismos identificados para kappa-caseína-HinfI, hormônio do crescimento-AluI e $\beta$-lactoglobulina-HaeIII apresentaram dois alelos conforme descritos por Lucy et al. (1991), Medrano \& Aguilar-Cordova (1990a ) e Medrano \& AguilarCordova (1990b), respectivamente. 
Tabela 1. Frequiências genotípica e alélica dos polimorfismos dos genes candidatos, kappa-caseína-HinfI (CSN3), hormônio do crescimento-AluI (GH) e $\beta$ lactoglobulina-HaeIII (LGB) em bovinos cruzados.

\begin{tabular}{|c|c|c|c|c|c|c|}
\hline \multirow{2}{*}{$\begin{array}{c}\text { Gene Candidato } \\
\text { CSN3 }\end{array}$} & \multirow{2}{*}{$\begin{array}{c}\text { Grupo Genético } \\
\text { 1/Nelore + } 1 / \text { Canchim }\end{array}$} & \multicolumn{3}{|c|}{ Frequência Genotípica* } & \multicolumn{2}{|c|}{ Frequência Alélica*** } \\
\hline & & $\begin{array}{c}\text { AA } \\
(n=50) \\
0,724\end{array}$ & $\begin{array}{c}\mathrm{AB} \\
(\mathrm{n}=18) \\
0,261\end{array}$ & $\begin{array}{c}\mathrm{BB} \\
(\mathrm{n}=1) \\
0,015\end{array}$ & $\begin{array}{c}\mathrm{A} \\
(\mathrm{n}=118) \\
0,855\end{array}$ & $\begin{array}{c}\mathrm{B} \\
(\mathrm{n}=20) \\
0,145\end{array}$ \\
\hline CSN3 & 1/Nelore + 1/Angus & $\underset{(\mathrm{n}=41)}{\mathrm{AA}}$ & $\begin{array}{c}\mathrm{AB} \\
(\mathrm{n}=27)\end{array}$ & $\begin{array}{c}\text { BB } \\
(n=2)\end{array}$ & $\underset{(n=109)}{\mathrm{A}}$ & $\begin{array}{c}\mathrm{B} \\
(\mathrm{n}=31)\end{array}$ \\
\hline & & $\begin{array}{c}0,586 \\
\text { AA }\end{array}$ & $\begin{array}{c}0,386 \\
\mathrm{AB}\end{array}$ & $\begin{array}{c}0,028 \\
\text { BB }\end{array}$ & $\begin{array}{c}0,779 \\
\text { A }\end{array}$ & $\begin{array}{c}0,221 \\
\mathrm{~B}\end{array}$ \\
\hline CSN3 & 1/Nelore + ${ }^{1}$ Simental & $\begin{array}{c}(\mathrm{n}=46) \\
0,821\end{array}$ & $\begin{array}{c}(\mathrm{n}=10) \\
0,178\end{array}$ & $\begin{array}{c}(\mathrm{n}=0) \\
0\end{array}$ & $\begin{array}{c}(\mathrm{n}=102) \\
0,911\end{array}$ & $\begin{array}{c}(\mathrm{n}=10) \\
0,089\end{array}$ \\
\hline GH & 1/Nelore + 1 Canchim & $\begin{array}{c}\mathrm{LL} \\
(\mathrm{n}=60) \\
0,886\end{array}$ & $\begin{array}{c}\mathrm{LV} \\
(\mathrm{n}=7) \\
0,114\end{array}$ & $\begin{array}{c}\mathrm{VV} \\
(\mathrm{n}=0) \\
0\end{array}$ & $\begin{array}{c}\mathrm{L} \\
(\mathrm{n}=127) \\
0,948\end{array}$ & $\begin{array}{c}\mathrm{V} \\
(\mathrm{n}=7) \\
0,052\end{array}$ \\
\hline GH & $1 / \mathbb{N}$ elore + $1 /$ Angus & $\begin{array}{c}\mathrm{LL} \\
(\mathrm{n}=45) \\
0,643\end{array}$ & $\begin{array}{c}\mathrm{LV} \\
(\mathrm{n}=25) \\
0,357\end{array}$ & $\begin{array}{c}\mathrm{VV} \\
(\mathrm{n}=0) \\
0\end{array}$ & $\begin{array}{c}\mathrm{L} \\
(\mathrm{n}=115) \\
0,821\end{array}$ & $\begin{array}{c}\mathrm{V} \\
(\mathrm{n}=25) \\
0,179\end{array}$ \\
\hline GH & 1/Nelore + ${ }^{1}$ Simental & $\begin{array}{c}\mathrm{LL} \\
(\mathrm{n}=39) \\
0,709\end{array}$ & $\begin{array}{c}\mathrm{LV} \\
(\mathrm{n}=16) \\
0,291\end{array}$ & $\begin{array}{c}\mathrm{VV} \\
(\mathrm{n}=0) \\
0\end{array}$ & $\begin{array}{c}\mathrm{L} \\
(\mathrm{n}=94) \\
0,855\end{array}$ & $\begin{array}{c}\mathrm{V} \\
(\mathrm{n}=16) \\
0,145\end{array}$ \\
\hline LGB & 1/Nelore + ${ }^{1 / C a n c h i m ~}$ & $\begin{array}{c}\text { AA } \\
(n=6) \\
0,087\end{array}$ & $\begin{array}{c}\mathrm{AB} \\
(\mathrm{n}=27) \\
0,391\end{array}$ & $\begin{array}{c}\text { BB } \\
(\mathrm{n}=36) \\
0,522\end{array}$ & $\begin{array}{c}A \\
(n=39) \\
0,283\end{array}$ & $\begin{array}{c}B \\
(n=99) \\
0,717\end{array}$ \\
\hline LGB & $1 /$ Nelore + $1 / \mathbf{\Delta n g u s}$ & $\begin{array}{c}\text { AA } \\
(n=12) \\
0,169\end{array}$ & $\begin{array}{c}\text { AB } \\
(\mathrm{n}=31) \\
0,437\end{array}$ & $\begin{array}{c}\mathrm{BB} \\
(\mathrm{n}=28) \\
0,394\end{array}$ & $\begin{array}{c}\mathrm{A} \\
(\mathrm{n}=55) \\
0,387\end{array}$ & $\begin{array}{c}B \\
(n=87) \\
0,613\end{array}$ \\
\hline LGB & 1/Nelore + ${ }^{1}$ Simental & $\begin{array}{c}\text { AA } \\
(\mathrm{n}=1) \\
0,018\end{array}$ & $\begin{array}{c}\mathrm{AB} \\
(\mathrm{n}=19) \\
0,346\end{array}$ & $\begin{array}{c}\mathrm{BB} \\
(\mathrm{n}=35) \\
0,636\end{array}$ & $\begin{array}{c}\mathrm{A} \\
(\mathrm{n}=21) \\
0,191\end{array}$ & $\begin{array}{c}\mathrm{B} \\
(\mathrm{n}=89) \\
0,809\end{array}$ \\
\hline
\end{tabular}

* $\mathrm{n}=$ número de animais.

** $\mathrm{n}=$ número total dos alelos.

As frequências do alelo $\mathrm{L}$ do $\mathrm{GH}$ foram 0,95, 0,82 e 0,85, respectivamente para os grupos genéticos NC, NA e NS. A predominância destes alelo está de acordo com os resultados encontrados na literatura, tanto nos zebuínos quanto nos taurinos (Lucy et al., 1991; Schlee et al., 1994a, Borges, 1997).

$\mathrm{O}$ alelo A de LGB apresentou frequência alélica de 0,28, 0,39 e 0,19 para os cruzamentos NC, NA e NS, respectivamente, e portanto não foi o alelo predominante, concordando com o resultado de uma das populações do estudo de Moody et al. (1996). 
$\mathrm{O}$ alelo A do gene CSN3 foi predominante, apresentando frequências de 0,85, 0,78 e 0,91, respectivamente para NC, NA e NS.

As frequências dos alelos A e B dos genes CSN3 e LGB e dos alelos L e V do $\mathrm{GH}$, nos animais cruzados neste estudo, foram semelhantes às descritas na literatura (Zhang et al.,1993; Schlee et al., 1994b; Moody et al., 1996; Kemenes, 1996; Unaniam et al., 2000). Animais da raça Hereford apresentaram diferenças significativas nas frequências alélicas de três populações para os locos GH e LGB, apenas o CSN3 não apresentou diferenças significativas entre as populações (Moody et al., 1996). Os autores observaram que o alelo A de CSN3 apresentou frequência em torno de 0,60 nas três populações, enquanto o alelo A de LGB variou de 0,02 a 0,70 e o alelo L de GH, variou de 0,30 a 0,75 .

\subsubsection{Análises estatísticas- modelos não lineares}

\subsubsection{Erro de predição}

Os erros de predição médios (EPM), em \%, e respectivos erros-padrão (\%), para animais dos grupos genéticos 1/20lore + 1/Canchim (NC), 1/2elore + 1/Angus (NA) e 1 Eelore $+{ }^{1}$ Simental (NS), estão apresentados na Tabela 2.

O EPM foi considerado como critério adicional para verificar a qualidade do ajuste do modelo Logístico, pelo método de Gauss-Newton, aos conjuntos de dados peso-idade de animais cruzados NC, NA e NS (Paz et al. ${ }^{2}$ ). 
Tabela 2. Erros de predição médios (EPM) e respectivos erros-padrão para animais de três grupos genéticos.

\begin{tabular}{ccc}
\hline Grupo Genético & EPM (\%) & Erro-padrão (\%) \\
\hline 1/Nelore+1/Canchim & $-3,0663577$ & 0,5689609 \\
1/Nelore+1/Angus & $-3,4129238$ & 0,5585633 \\
1/Nelore+1Simental & $-3,8202408$ & 0,6502210 \\
\hline
\end{tabular}

Com base nestes valores médios, que apresentaram sinais negativos, constata-se que o modelo Logístico superestimou os pesos observados nos três conjuntos de dados (NC, NA e NS) em que foram realizadas as análises. A Figura 1 apresenta a distribuição dos valores de EPM em função da idade (meses), para os animais dos três grupos genéticos. Uma distribuição aleatória dos valores abaixo e acima de zero indica ajuste adequado do modelo aos dados; maior concentração de pontos acima e abaixo do zero indica, respectivamente, subestimatição e superestimatição das estimativas dos pesos obtidas pelo modelo com relação aos dados observados.

$\mathrm{Na}$ literatura, alguns trabalhos têm relatado estimativas negativas do erro de predição médio (superestimação dos valores observados) para diversos modelos não lineares ajustados aos dados peso-idade de bovinos (Goonewardene et al., 1981; Elias, 1998). Os erros de predição médios do presente estudo (Tabela 2 e Figura 1) estão de acordo com os valores de $-3,97 \%$ e $-2,96 \%$, respectivamente para os modelos Brody e Richards ajustados por Elias (1998), aos conjuntos de dados peso-idade de animais Nelore, Guzerá e Gir. 


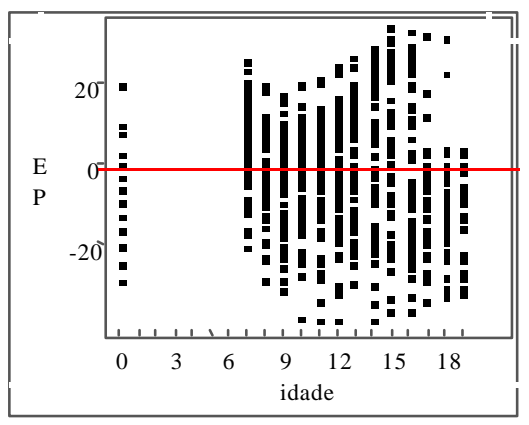

1/2elore+1/6anchim

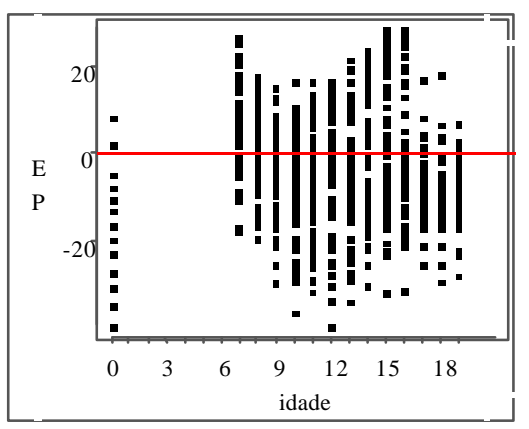

1/2elore +1/2Angus

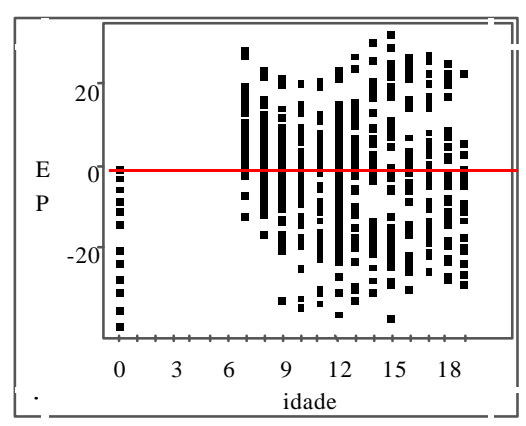

1/2Nelore+1/Simental

Figura 1 - Estimativas dos erros de predição médios (\%), em função da idade (meses) obtidas pelo ajuste das curvas de crescimento usando-se o modelo Logístico, para animais cruzados.

\subsubsection{Efeito dos polimorfismos genéticos sobre a curva de crescimento}

O conceito de grupo contemporâneo (GC) têm importância no melhoramento animal, identificando os grupos de animais que realmente podem ser comparados entre si, já que é impossível fornecer uma padronização para todos os animais.

Assim, inicialmente foi testado o efeito do grupo contemporâneo (GC) sobre a curva de crescimento dos animais NC, NA e NS. A comparação das curvas de crescimento dos animais em função dos GC foi realizada pela técnica dos modelos não lineares incluindo este efeito no modelo. Para efetuar esta análise, foram definidos dois modelos, o Completo e o Reduzido. O modelo Completo, nesta análise, proporcionou 8 conjuntos de estimativas dos parâmetros $(A, k$ e $m)$ para definir a resposta ajustada pelo modelo Logístico, um conjunto para cada GC. 
O modelo Reduzido considera que não existem diferenças entre os GC, portanto o crescimento dos animais pode ser descrito por uma curva média - um único conjunto de estimativas dos parâmetros da função Logística.

A soma de quadrado e graus de liberdade do resíduo dos modelos Completo ( $\left.\mathrm{SQR}_{\text {Completo}}\right)$, (GLR $\left.\mathrm{Gompleto}_{\text {o }}\right)$ e Reduzido $\left(\mathrm{SQR}_{\text {Reduzido }}\right)$ e $\left(\mathrm{GLR}_{\text {Reduzido }}\right)$, e o

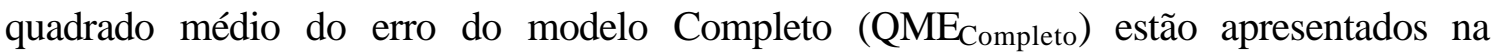
Tabela 3. Estes valores são utilizados para calcular o valor observado de $F$ ( $\left.F_{\text {obs }}\right)$ e probabilidade do valor observado de $F$ (Prob $>F$ ) para distribuição:

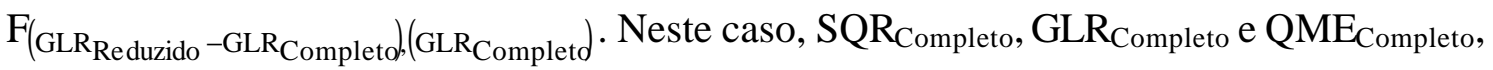
são resultados da análise que incluiu o efeito de $\mathrm{GC}$ e $S Q R_{\text {Reduzido }}$ e $\mathrm{GLR}_{\text {Reduzido, foram }}$ obtidos da análise que determina a curva média para cada grupo genético, usando-se os modelos descritos anteriormente.

Tabela 3. Soma de quadrados do resíduo (SQR), graus de liberdade do resíduo (GLR), quadrado médio do erro (QME), dos modelos Comple to e Reduzido, coeficiente de determinação $\left(\mathrm{R}^{2}\right)$ do modelo Completo, valor observado de $F\left(\mathrm{~F}_{\mathrm{obs}}\right)$ e probabilidade do valor observado de $F$ (Prob $>F$ ), para bovinos cruzados.

\begin{tabular}{ccccccccc}
\hline Grupo & \multicolumn{9}{c}{ Modelo Completo* } & \multicolumn{2}{c}{ Modelo Reduzido** } & & & \\
Genético & SQR & GLR & QME & SQR & GLR & R $^{2}(\%)$ & Fobs $_{\text {obrob }}$ P \\
\hline NC & 525.468 & 760 & 691,4 & 2.008 .141 & 781 & 94,5 & 102,1 & $<0,0001$ \\
NA & 495.993 & 772 & 642,5 & 1.665 .412 & 793 & 95,5 & 86,7 & $<0,0001$ \\
NS & 384.921 & 621 & 619,8 & 1.549 .345 & 642 & 95,7 & 89,5 & $<0,0001$ \\
\hline
\end{tabular}

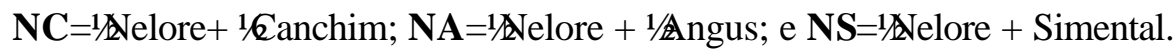

* Modelo Completo: 8 conjuntos (um para cada GC) de estimativas dos parâmetros A, k e m.

** Modelo Reduzido: um único conjunto de parâmetros $(A, k$ e $m)$ foi estimado. 
De acordo com estas estatísticas, o grupo contemporâneo influenciou $(\mathrm{P}<0,0001)$ a curva de crescimento, descrita pela função não linear Logística, dos bovinos NC, NA e NS. Estes resultados sugerem que uma única curva média (um único conjunto de parâmetro para função Logística, para cada grupo genético) não é adequada para descrever o crescimento destes animais. Assim, deve-se considerar na descrição destas curvas, os 8 conjuntos (um conjunto para cada GC) de estimativas de parâmetros $(A, k$ e $m)$ obtidos para cada grupo genético.

A análise dos efeitos dos genes CSN3, GH e LGB sobre a curva de crescimento foram realizadas da mesma maneira que a anterior. O modelo Completo considerou $\left(\mathrm{n}_{1} \times \mathrm{n}_{2}\right)$ conjuntos de estimativas de parâmetros $(A, k$ e $m)$ formados por $\mathrm{n}_{1}$ GC $\left(n_{1}=8\right)$ e $n_{2}$ genótipos para os genes CSN3, GH e LGB. Para cada gene estudado foi definido um modelo Completo, que incluiu apenas o efeito principal dos genes. Para os genes CSN3 e GH o valor de $\mathrm{m}_{2}$ foi igual a 2 (AA e AB para CSN3 e LL e LV para GH) nos três grupos genéticos NC, NA e NS. Quanto ao gene LGB, n e BB) para a análise dos animais NC e NA e igual a 2 (AB e BB) para os animais NS. O modelo Reduzido nesta análise, foi definido por 8 conjuntos (um para cada GC) de estimativas dos parâmetros $A, k$ e $m$ da função Logística.

As distribuições dos polimorfismos dos genes CSN3, GH e LGB, para os grupos genéticos NC, NA e NS, nas classes de grupo contemporâneo, foram razoáveis (Anexo C), com exceção do genes GH e LGB do grupo genético NC.

Os resultados de associação entre os polimorfismos dos genes da kappacaseína-Hinf I (CSN3), do hormônio do crescimento-AluI (GH) e da $\beta$-lactoglobulinaHaeIII (LGB) e a curva de crescimento ajustada pelo modelo Logístico para bovinos

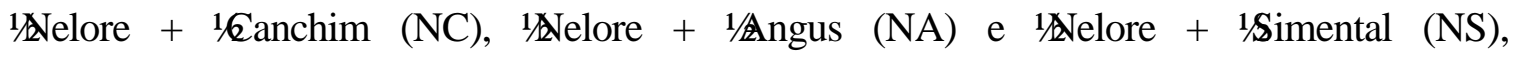
estão apresentados na Tabela 4. 
Tabela 4. Soma de quadrados do resíduo (SQR), graus de liberdade do resíduo (GLR), quadrado médio do erro (QME), dos modelos Completo e Reduzido, número dos conjuntos de parâmetros estimados (NP) e coeficiente de determinação $\left(\mathrm{R}^{2}\right)$ do modelo Completo, valor observado de $F\left(\mathrm{~F}_{\text {obs }}\right)$ e probabilidade do valor observado de $F(\operatorname{Prob}>F)$, para bovinos cruzados.

\begin{tabular}{|c|c|c|c|c|c|c|c|c|c|c|}
\hline \multirow{2}{*}{$\begin{array}{c}\text { Grupo } \\
\text { Genético }\end{array}$} & \multirow[b]{2}{*}{ Gene } & \multirow[b]{2}{*}{$\mathbf{N P}$} & \multicolumn{3}{|c|}{ Modelo Completo* } & \multicolumn{2}{|c|}{ Modelo Reduzido*** } & \multirow[b]{2}{*}{$\mathbf{R}^{2}(\%)$} & \multirow[b]{2}{*}{$\mathbf{F}_{\text {obs }}$} & \multirow[b]{2}{*}{ Prob $>F$} \\
\hline & & & SQR & GLR & QME & SQR & GLR & & & \\
\hline \multirow{3}{*}{ NC } & CSN3 & 14 & 496.071 & 742 & 668,6 & 525.468 & 760 & 94,8 & 2,443 & 0,0007 \\
\hline & GH & 11 & 519.239 & 751 & 691.4 & 525.468 & 760 & 94,6 & 1,001 & 0,4375 \\
\hline & LGB & 20 & 490.756 & 724 & 677,8 & 525.468 & 760 & 94,8 & 1,423 & 0,0536 \\
\hline \multirow{3}{*}{ NA } & CSN3 & 16 & 462.736 & 748 & 618,6 & 495.993 & 772 & 95,7 & 2,240 & 0,0006 \\
\hline & GH & 13 & 469.505 & 757 & 620,2 & 495.993 & 772 & 95,6 & 2,847 & 0,0002 \\
\hline & LGB & 21 & 455.017 & 733 & 620,8 & 495.993 & 772 & 95,8 & 1,692 & 0,0059 \\
\hline \multirow{3}{*}{ NS } & CSN3 & 14 & 358.920 & 603 & 595,2 & 384.921 & 621 & 96,2 & 2,413 & 0,0009 \\
\hline & GH & 14 & 359.053 & 603 & 595,4 & 384.921 & 621 & 96,1 & 2,433 & 0,0008 \\
\hline & LGB & 16 & 324.021 & 597 & 542,7 & 384.921 & 621 & 96,6 & 4,675 & $<0,0001$ \\
\hline
\end{tabular}

NC = 1/Nelore+1/Eanchim; NA = 1/Nelore+1/Angus; NS = 1/Nelore+Simental; CSN3 = gene da kappa-caseína-HinfI; GH = gene do hormônio do crescimento-AluI; e LGB = gene da $\beta$ lactoglobulina-HaeIII.

* Modelo Completo: definido por $\left(\mathrm{n}_{1} \times \mathrm{n}_{2}\right)$ conjuntos (um para cada grupo identificado pela concatenação de GC com os genes kappa-caseína-HinfI (CSN3), hormônio do crescimento-AluI (GH) e $\beta$-lactoglobulina-HaeIII (LGB)), de estimativas dos parâmetros $A, k$ e $m$. Neste modelo $n_{1}$ é o número de classes de GC e $\mathrm{n}_{2}$ é o número de genótipos para cada gene estudado.

** Modelo Reduzido: considerou-se 8 conjuntos (um para cada GC) de estimativas dos parâmetros $A, k$ e $m$, para definir a resposta ajustada pelo modelo Logístico.

Os genótipos do gene da kappa-caseína-HinfI (CSN3) influenciaram $(\mathrm{P}<0,001)$ a curva de crescimento dos animais dos três grupos genéticos (Tabela 4). Com exceção dos animais do grupo genético NC, os genes do hormônio do crescimento-AluI 
(GH) e da $\beta$-lactoglobulina-HaeIII (LGB) também influenciaram significativamente a função Logística ajustada às curvas de crescimento destes bovinos.

$\mathrm{O}$ efeito de touro também influenciou $(\mathrm{P}<0,0001)$ a curva de crescimento dos animais dos grupos genéticos NC, NA e NS, quando se utilizou um modelo que incluiu os efeitos fixos de GC e touro. Está análise foi realizada com o objetivo de verificar se os efeitos de touro e genótipos estavam confundidos. Entretanto, verificou-se que os touros estão razoavelmente bem representados nas classes dos genótipos dos genes CSN3, GH e LGB, principalmente nos grupos genéticos NA e NS (as distribuições dos touros nas classes de genótipos, não foram apresentadas).

Lin et al. (1987) e Moody et al. (1996) encontraram associação do gene CSN3 e LGB com características de crescimento no período do nascimento aos 350 dias de idade, em bovinos de corte. Tambasco et al. (2002) utilizaram os mesmos animais envolvidos no presente estudo e encontraram efeito significativo dos polimorfismos do gene GH e da interação entre os genes GH e LGB, sobre o ganho de peso do nascimento ao desmame e do desmame aos 12 meses de idade.

Os polimorfismos do GH foram associados à produção (Hoj et al., 1993), à quantidade de gordura do leite (Yao et al., 1996), ao peso no nascimento (Rocha et al., 1992), à composição e à qualidade da carcaça (Schlee et al., 1994a e1994b; Taylor et al., 1998). Estes polimorfismos também foram associados à características de tipo, como circunferência torácica em animais cruzados Piemontês x Chianina (Pilla et al., 1994).

Sartore \& Di Stasio (2000) sugerem que existe associação dos genótipos de GH com peso de bezerros Piemontês. Entretanto, estudo posterior de Di Stasio et al. (2002), não encontrou evidências de associação do GH com características de produção de carne nestes mesmos animais.

$\mathrm{Na}$ Tabela 5 estão apresentados as estimativas dos parâmetros $(A, k$ e $m)$, o número de animais que atingiram a convergência para cada modelo Logístico considerando-se os genótipos dos genes CSN3, GH e LGB de bovinos dos grupos genéticos NC, NA e NS. 
Tabela 5. Estimativas dos parâmetros $(A, k$ e $m)$ e respectivos erros-padrão (s) obtidas pelo modelo Logístico e número de animais $(\mathrm{N})$ que atingiram a convergência, para os polimorfismos genéticos de animais de três grupos genéticos (GG).

\begin{tabular}{|c|c|c|c|c|c|c|c|c|c|}
\hline GG & Gene & Genótipo & $\mathbf{N}$ & $\mathbf{A}(\mathbf{k g})$ & s (kg) & $k\left(\operatorname{dia}^{-1}\right)$ & $\mathbf{s}\left(\mathrm{dia}^{-1}\right)$ & $\mathbf{m}$ & $\mathbf{s}$ \\
\hline \multirow{7}{*}{$\mathrm{NC}$} & CSN3 & $\overline{\mathrm{AA}}$ & 48 & 449,4 & 13,2 & 0,00621 & 0,000388 & 3,5616 & 0,1979 \\
\hline & CSN3 & $A B$ & 18 & 437,5 & 23,3 & 0,00611 & 0,000706 & 3,3404 & 0,3252 \\
\hline & GH & LL & 59 & 432,8 & 10,7 & 0,00648 & 0,000363 & 3,5459 & 0,1892 \\
\hline & GH & LV & 7 & 668,1 & 157,9 & 0,00384 & 0,001040 & 3,4675 & 0,2920 \\
\hline & LGB & AA & 5 & 458,8 & 50,7 & 0,00592 & 0,001350 & 3,5165 & 0,6793 \\
\hline & LGB & $A B$ & 25 & 475,8 & 23,9 & 0,00552 & 0,000521 & 3,4152 & 0,2320 \\
\hline & LGB & $\mathrm{BB}$ & 36 & 425,5 & 13,1 & 0,00677 & 0,000487 & 3,5943 & 0,2601 \\
\hline \multirow{7}{*}{ NA } & CSN3 & $\overline{\mathrm{AA}}$ & 41 & 455,5 & 11,1 & 0,00649 & 0,000358 & 3,4940 & 0,1812 \\
\hline & CSN3 & $\mathrm{AB}$ & 27 & 518,1 & 19,9 & 0,00579 & 0,000435 & 3,5445 & 0,2150 \\
\hline & GH & LL & 45 & 461,6 & 11,7 & 0,00619 & 0,000343 & 3,3314 & 0,1590 \\
\hline & GH & LV & 23 & 514,7 & 17,8 & 0,00630 & 0,000454 & 3,9564 & 0,2747 \\
\hline & LGB & AA & 11 & 448,5 & 19,5 & 0,00673 & 0,000738 & 3,5311 & 0,4226 \\
\hline & LGB & $\mathrm{AB}$ & 31 & 481,9 & 15,9 & 0,00597 & 0,000419 & 3,4647 & 0,2104 \\
\hline & LGB & BB & 26 & 513,4 & 19,8 & 0,00591 & 0,000415 & 3,5606 & 0,1816 \\
\hline \multirow{6}{*}{ NS } & CSN3 & $\overline{\mathrm{AA}}$ & 42 & 501,8 & 15,3 & 0,00595 & 0,000376 & 3,5766 & 0,1923 \\
\hline & CSN3 & $A B$ & 10 & 494,4 & 14,1 & 0,00534 & 0,000667 & 3,0536 & 0,2215 \\
\hline & GH & LL & 36 & 510,1 & 18,6 & 0,00557 & 0,000369 & 3,3992 & 0,1568 \\
\hline & GH & LV & 16 & 471,5 & 20,7 & 0,00628 & 0,000585 & 3,5884 & 0,3198 \\
\hline & LGB & $\mathrm{AB}$ & 18 & 550,4 & 15,6 & 0,00507 & 0,000546 & 3,4562 & 0,2255 \\
\hline & LGB & BB & 34 & 476,1 & 14,9 & 0,00607 & 0,000404 & 3,4402 & 0,1950 \\
\hline
\end{tabular}

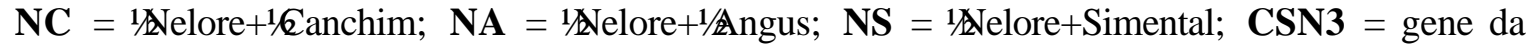
kappa-caseína-HinfI; GH = gene do hormônio do crescimento-AluI; e LGB = gene da $\beta$ lactoglobulina-HaeIII.

Os valores das estimativas dos parâmetros $A, k$ e $m$, obtidos pelo modelo Logístico, foram adequados, com exceção das estimativas obtidas para os genótipos LV (GH) e AA (LGB) do grupo genético NC, cujas estimativas dos erros-padrão do parâmetro $A$ foram altas e de magnitude média, respectivamente e as do parâmetro $k$ 
foram altas para os dois polimorfismos genéticos. O número limitado de informações destas duas classes de genótipos pode ter sido determinante na não constatação de efeito significativo dos genótipos sobre a curva de crescimento.

Alguns resultados da literatura foram comparados com os obtidos no presente estudo. $\mathrm{O}$ valores estimados pelo modelo Von Bertalanffy, ajustado para fêmeas da raça Guzerá, para os parâmetros $A$ e $k$, foram 453,9 $\mathrm{kg}$ e 0,00231 dia ${ }^{-1}$, respectivamente (Oliveira, 1995). Para fêmeas Guzerá e Gir, foi ajustado o modelo Richards e estimados os valores 441,4 kg e 383,0 kg, 0,00217 $\mathrm{dia}^{-1}$ e 0,00217 $\mathrm{dia}^{-1}$ e 3,8416 e 3,1329, respectivamente, para os parâmetros $A, k$ e $m$ (Perotto et al., 1997).

Considerando-se os parâmetros $A$ e $k$, o genótipo AA para CSN3 apresentou valores superiores para o parâmetro $k$ em relação ao genótipo $\mathrm{AB}$ nos três grupos genéticos. $\mathrm{O}$ tamanho à maturidade $(A)$ do animais do genótipo AA apresentou pequena diferença em relação ao genótipo $\mathrm{AB}$ nos grupos genéticos $\mathrm{NC}$, NA e NS.

Para o polimorfismo do GH no grupo genético NA, a curva que descreve o crescimento dos animais do genótipo LL mostrou-se mais desejável, do ponto de vista de produção de bovinos de corte, apesar de apresentar taxa de maturação menor que o genótipo LV. Entretanto, ocorreu uma inversão desta tendência no grupo genético NS. O mesmo ocorreu para o LGB, em que os genótipos AA e AB apresentaram estimativas do parâmetro $k$ superiores em relação ao genótipo $\mathrm{BB}$ no grupo genético $\mathrm{NA}$, enquanto o genótipo $\mathrm{AB}$ apresentou estimativa de $k$ inferior em relação ao genótipo $\mathrm{BB}$, no grupo genético NS.

Existem evidências de que os genes CSN3 e LGB tenham relação importante ente si (Hines et al., 1981; Bovenhuis et al., 1992). Os resultados encontrados na literatura com relação à associação de marcadores com características produtivas são conflitantes. Por exemplo, o alelo A do gene CSN3 que foi associado com a maior produção de leite (Bovenhuis et al., 1992; Moody et al., 1996), enquanto Lin et al. (1989) e Cowan et al.(1992) observaram que o alelo B, deste mesmo gene, estava associado ao aumento de produção de leite. Estudos anteriores não detectaram diferenças dos efeitos dos genes CSN3 e LGB sobre características quantitativas. O genótipo LL do gene GH foi associado ao maior ganho de peso por Unanian et al. (2000) 
em animais da raça Nelore, enquanto Moody et al. (1996) verificaram que o alelo V estava associado com maior ganho de peso no período do nascimento ao desmame em bovinos da raça Hereford. Estas contradições podem ser explicadas por diferenças no desequilíbrio de ligação entre marcadores e QTL ("Quantitative Trait Locus") nas diferentes populações estudadas, além de diferenças na base genética destas populações, também influenciarem o efeito dos QTL (Moody et al., 1996).

Na Figura 2 estão representadas as curvas do peso $(\mathrm{kg})$ em função da idade, ajustadas pelo modelo Logístico, para os genótipos dos genes da kappa-caseína-HinfI (CSN3), do hormônio do crescimento-AluI (GH) e da $\beta$-lactoglobulina-HaeIII (LGB) dos grupos genéticos 1/Nelore + 1/Canchim (NC), 1/2Nelore + 1/Angus (NA) e 1/20lore $+{ }_{1}^{1}$ Simental (NS).

Observa-se por meio das estimativas de parâmetros da função Logística (Tabelas 4 e 5) e também pelo formato da curva (Figura 2), que o crescimento corporal nos três grupos genéticos NC, NA e NS, foi influenciado pelos genótipos dos genes CSN3, GH e LGB.

As maiores diferenças entre os genótipos para os genes CSN3, GH e LGB foram encontradas a partir dos 12-13 meses de idade, concordando com os resultados encontrados por Unanian et al. (2000), que usando o modelo Von Bertallanffy para descrever o crescimento de animais Nelore, encontraram tendência de associação do ganho de peso com os polimorfismos GH-AluI e GH-MspI, a partir dos 12-13 meses de idade. Borges (1997) e Taylor et al. (1998) que não encontraram diferenças significativas com relação ao genótipo do GH sobre o PN.

Análises inadequadas podem negligenciar aspectos importantes no padrão de desenvolvimento dos animais, portanto, é relevante considerar que os pesos obtidos ao longo da vida do animal são correlacionados entre si, que a variância no peso é crescente em função da idade e que o custo de obtenção das análises laboratoriais utilizadas para determinação de polimorfismos genéticos é elevado, limitando o tamanho amostral. 


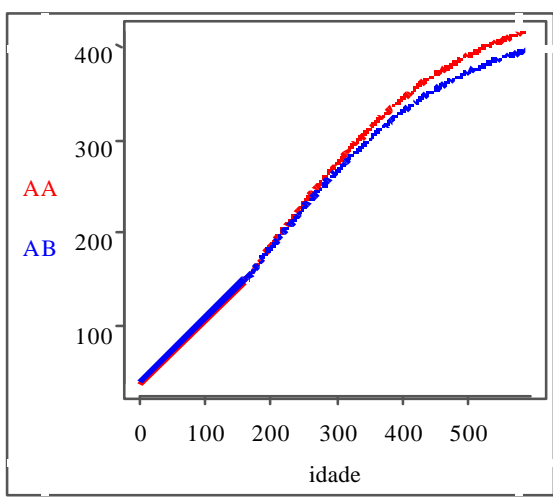

1/2elore+1/Eanchim - CSN3

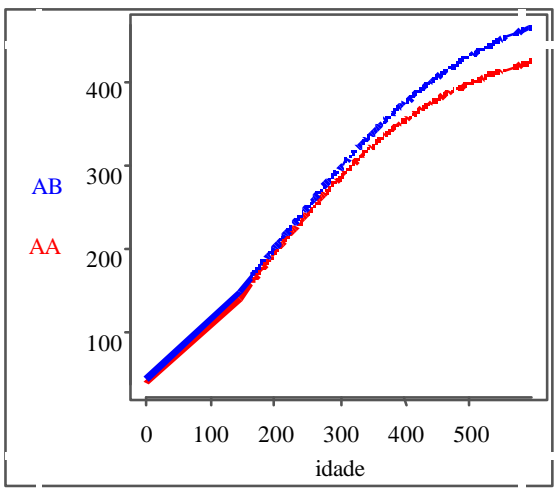

1/2elore+1/2ngus - CSN3

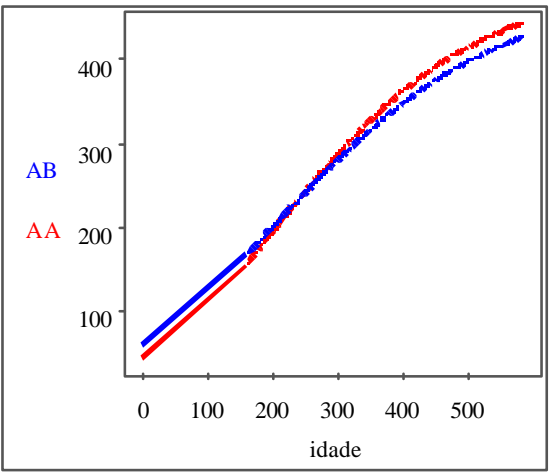

1/Nelore+ ${ }^{1}$ Simental - CSN3
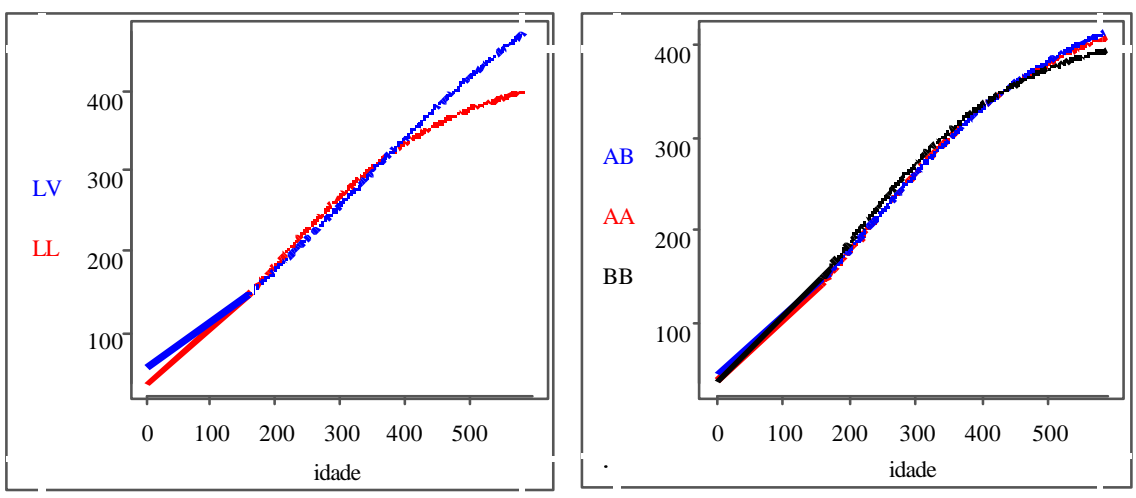

1/2elore+16anchim - GH

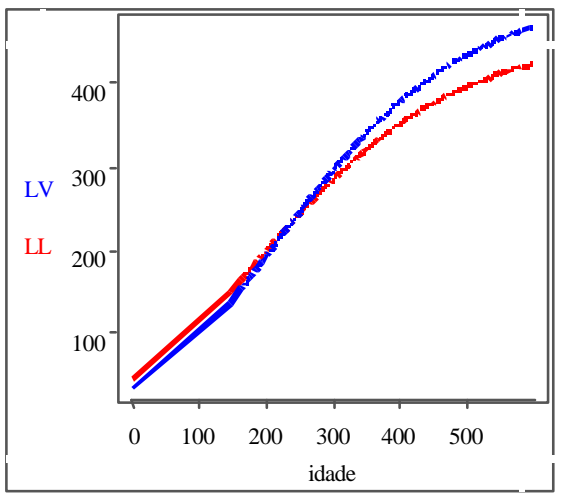

1/2elore+ 1/20ngus - GH

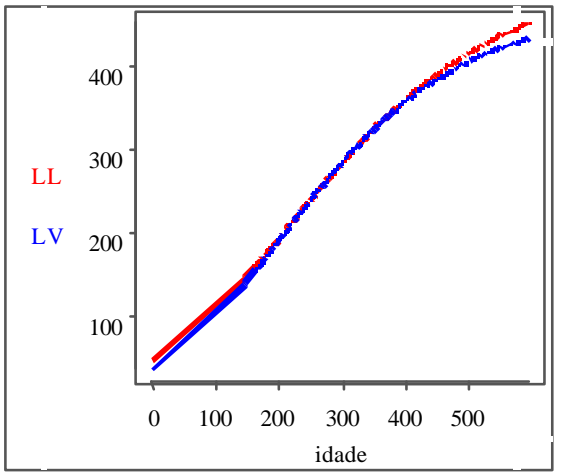

12Nelore+ ${ }^{1}$ Simental - GH 1/2elore+16anchim - LGB

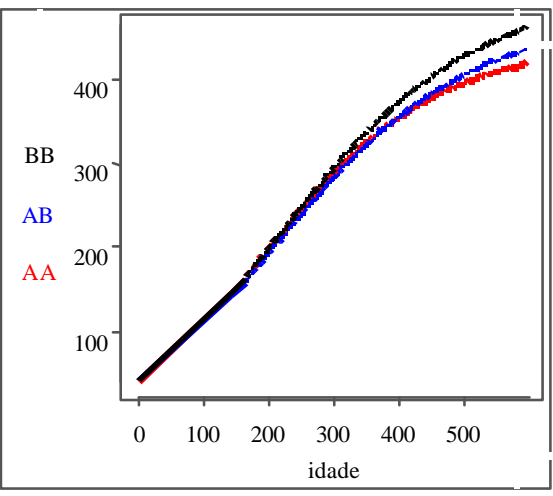

1/2elore+ 1/2/Angus - LGB

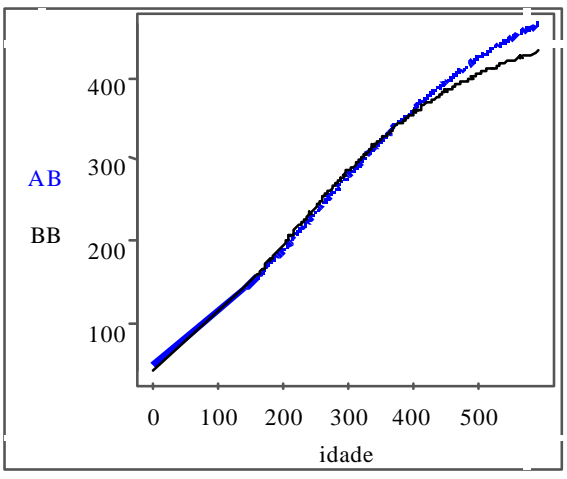

1/2elore+ 1SBimental - LGB

Figura 2 - Estimativa do peso $(\mathrm{kg})$ em função da idade (dias), ajustado pelo modelo Logístico para os genótipos dos genes da kappa-caseína-HinfI (CSN3), do hormônio do crescimento-AluI (GH) e da $\beta$-lactoglobulina-HaeIII (LGB), de animais cruzados. 
Nas condições em que foi realizado o presente estudo, é pertinente fazer algumas considerações sobre as análises realizadas com o objetivo de verificar possíveis associações entre os polimorfismos genéticos e a curva de crescimento de bovinos cruzados.

Tanto na primeira abordagem de análise (Paz et al. ${ }^{2}$ ), na qual os parâmetros $A, k$ e $m$, estimados para cada animal, foram analisados por meio dos modelos lineares a fim de verificar o efeito dos polimorfismos genéticos sobre estes parâmetros, quanto na presente análise, que considerou os parâmetros e os efeitos fixos de ambiente e de polimorfismo genético simultaneamente, pode-se admitir que o os resultados foram prejudicados pelo reduzido número de informações, por fatores ambientais pouco controlados, além do fato de que os animais não apresentavam registros completos dos pesos ao longo de suas vidas produtivas.

Apesar das considerações anteriores, os problemas associados à segunda abordagem de análise podem ter sido superados ou pelo menos minimizados, pelo fato de ter-se usado uma metodologia inédita. Desta forma, podemos considerar que a segunda abordagem, proporcionou uma análise mais adequada do que a primeira (Paz et $\mathrm{al}^{2}{ }^{2}$ ). Principalmente, porque na primeira abordagem, a pré-correção para os efeitos fixos de ambiente, não proporcionou estimativas coerentes para os parâmetros das funções não lineares aplicadas neste estudo e porque, na segunda abordagem, foi possível considerar os efeitos fixos (genótipo e grupo contemporâneo) no modelo e estimar os parâmetros da função Logística, simultaneamente.

Entretanto, é relevante recomendar análises adicionais em populações maiores e com fatores ambientais mais controlados, uma vez que os experimentos de associação de polimorfismos genéticos à características de interesse econômico geralmente são realizados em conjunto com experimentos de outras áreas científicas, pois o custo de obtenção destes polimorfismos é elevado, além de que esta metodologia foi aplicada a dados de associação entre polimorfismos genéticos e parâmetros da curva de crescimento animal, pela primeira vez. 


\subsection{Conclusões}

A abordagem proposta de incluir no modelo de análise, simultaneamente, os parâmetros da curva de crescimento, os efeitos fixos de ambiente e dos polimorfismos genéticos, pode ser considerada preliminar, mais abrangente e adequada que a usualmente empregada nos estudos de crescimento, nos quais os parâmetros estimados para a curva de cada animal, são analisados por meio dos modelos lineares. Áreas científicas que utilizem dados de peso em função da idade com o propósito de estudar os fatores que estejam influenciando os parâmetros da curva de crescimento, além dos polimorfismos genéticos estudados, também podem usar esta nova abordagem.

A possível aplicação dos resultados deste estudo em programa de seleção assistida por marcadores (MAS) ainda é prematura. Entretanto, evidências de que os polimorfismos dos genes da kappa-caseína-HinfI, do hormônio do crescimento-AluI e da $\beta$-lactoglobulina-HaeIII estejam influenciando a curva de crescimento dos bovinos

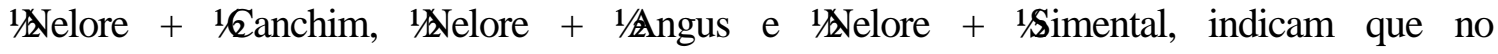
futuro os genótipos destes genes podem ser usados em programas de seleção assistida por marcadores. 


\section{CONCLUSÕES GERAIS}

O modelo Logístico de regressão não linear forneceu uma estimação adequada da curva de crescimento dos animais pertencentes aos grupos genéticos

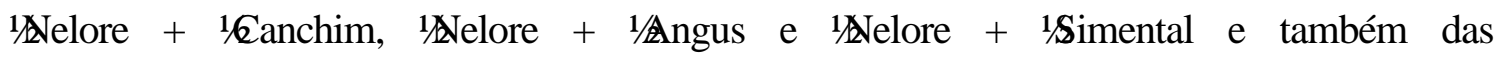
classes de genótipos dos genes da kappa-caseína-HinfI (CSN3): AA e AB, do hormônio do crescimento-AluI (GH): LL e LV e da $\beta$-lactoglobulina-HaeIII (LGB): AA, AB e BB.

De maneira geral, ambas abordagens de análises, podem ser consideradas preliminares nos estudos de associação entre polimorfismos genéticos e crescimento de bovinos. No entanto, aquela que incluiu no modelo de análise, simultaneamente, os parâmetros da curva de crescimento, os efeitos fixos de ambiente e dos polimorfismos genéticos, foi mais abrangente e adequada que a usualmente empregada nos estudos de crescimento, nos quais os parâmetros estimados para a curva de cada animal, são analisados por modelos lineares. Áreas científicas que utilizem dados de peso em função da idade com o propósito de estudar os fatores que estejam influenciando os parâmetros da curva de crescimento, além dos polimorfismos genéticos estudados, também podem usar esta nova abordagem.

A possível aplicação dos resultados deste estudo em programa de seleção assistida por marcadores (MAS) ainda é prematura. Entretanto evidências de que os polimorfismos dos genes da kappa-caseína-HinfI, do hormônio do crescimento-AluI e da $\beta$-lactoglobulina-HaeIII estejam influenciando a curva de crescimento dos bovinos

1/2elore +1/Eanchim, 1/2elore $+1 /$ Angus e 1/2elore +1 Simental, indicam que, no 
futuro os genótipos destes genes podem ser usados em programas de seleção assistida por marcadores. 
ANEXOS 
Anexo A - Elipse com $95 \%$ de confiança da distribuição dos pesos observados ao desmame (7 meses de idade), e mensalmente dos 8 aos 19 meses, em função das idades.
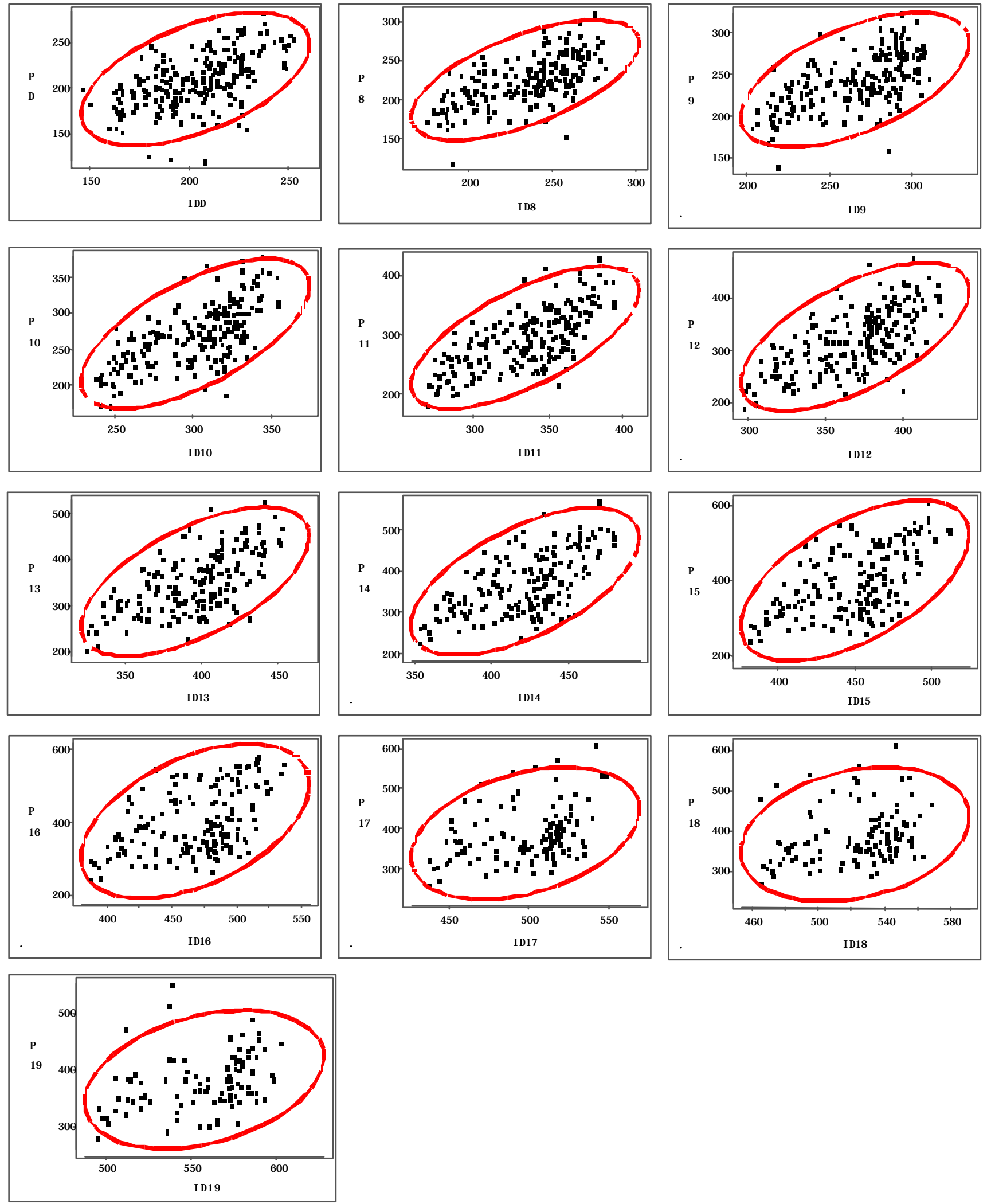
Anexo B - Médias das 14 mensurações de pesos, ao nascer, ao desmame (7 meses), e pesos mensais dos 8 aos 19 meses de idade, em função dos polimorfismos genéticos em bovinos cruzados.

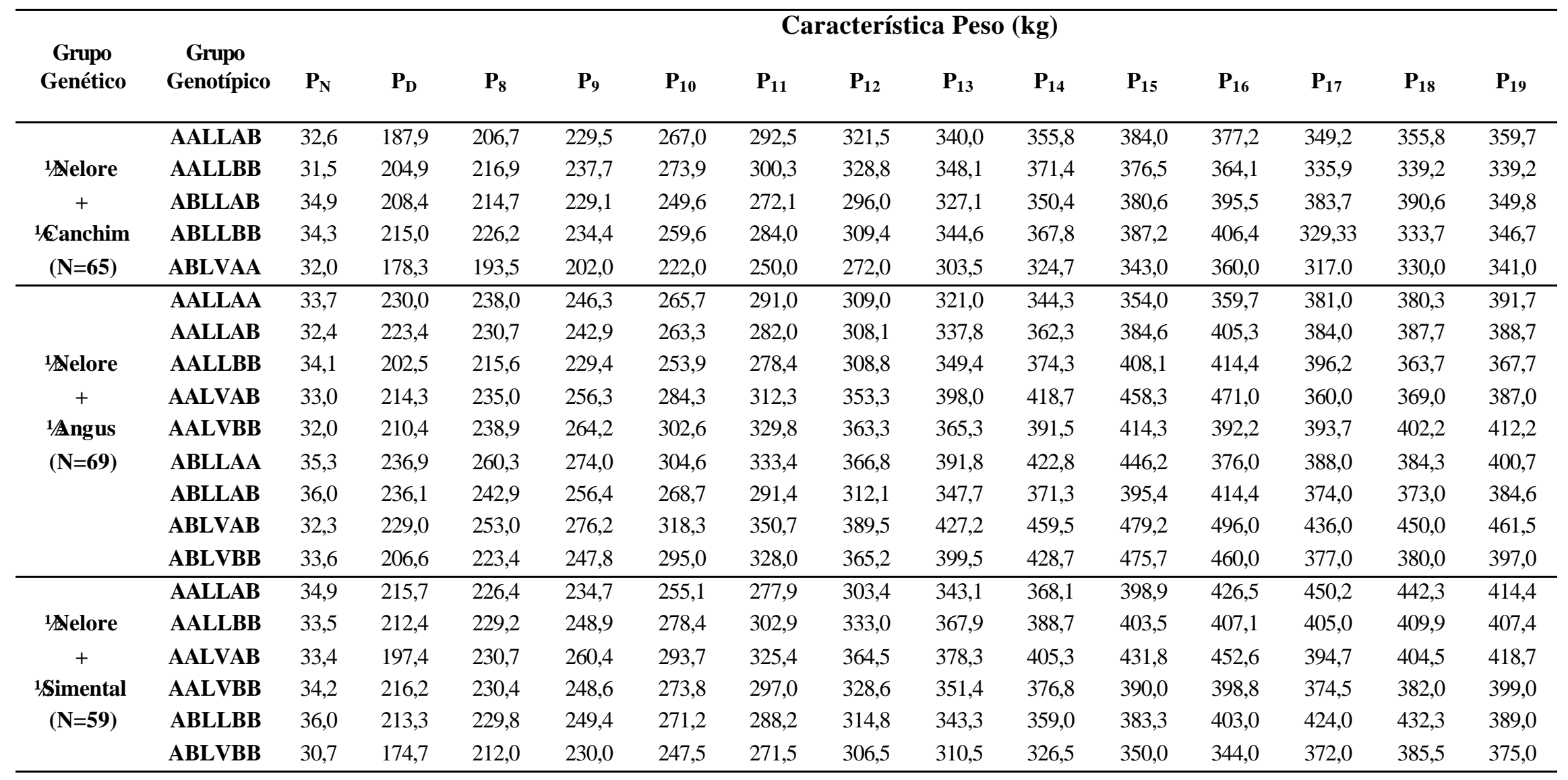

$\mathrm{P}_{\mathrm{N}}, \mathrm{P}_{\mathrm{D}}, \mathrm{P}_{8} ; \mathrm{P}_{9}, \mathrm{P}_{10}, \mathrm{P}_{11}, \mathrm{P}_{12}, \mathrm{P}_{13}, \mathrm{P}_{14}, \mathrm{P}_{15}, \mathrm{P}_{16}, \mathrm{P}_{17}, \mathrm{P}_{18}$ e $\mathrm{P}_{19}$, pesos ao nascimento, desmame, aos 8, 9, 10, 11, 12, 13, 14, 15,16, 17,

18 , e 19 meses de idade, respectivamente. 
Anexo C - Número de animais observados nas classes de grupo contemporâneo (GC) por classe de genótipo dos genes da kappa-caseína-HinfI (CSN3), do hormônio do crescimento-AluI (GH) e da $\beta$-lactoglobulina-HaeIII (LGB), para bovinos 1/2elore+1/Canchim (NC), 1/Nelore+1/Angus (NA) e 1/Nelore+ 1Simental (NS).

\begin{tabular}{|c|c|c|c|c|c|c|c|c|c|c|c|c|c|c|c|c|c|c|c|c|}
\hline \multirow{4}{*}{$\begin{array}{c}\text { Classes de } \\
\text { Genótipo }\end{array}$} & \multicolumn{7}{|c|}{$\mathbf{N C}$} & \multicolumn{7}{|c|}{$\mathbf{N A}$} & \multicolumn{6}{|c|}{ NS } \\
\hline & \multicolumn{2}{|c|}{ CSN3 } & \multicolumn{2}{|c|}{ GH } & \multicolumn{3}{|c|}{ LGB } & \multicolumn{2}{|c|}{ CSN3 } & \multicolumn{2}{|c|}{ GH } & \multicolumn{3}{|c|}{ LGB } & \multicolumn{2}{|c|}{ CSN3 } & \multicolumn{2}{|c|}{ GH } & \multicolumn{2}{|c|}{ LGB } \\
\hline & $\mathbf{A}$ & $\mathbf{A}$ & $\mathbf{L}$ & $\mathbf{L}$ & $\mathbf{A}$ & $\mathbf{A}$ & $\bar{B}$ & $\overline{\mathrm{A}}$ & $\mathbf{A}$ & $\mathbf{L}$ & $\mathbf{L}$ & $\overline{\mathbf{A}}$ & $\overline{\mathbf{A}}$ & B & $\mathbf{A}$ & $\overline{\mathbf{A}}$ & $\mathbf{L}$ & $\mathbf{L}$ & $\mathbf{A}$ & B \\
\hline & $\mathbf{A}$ & B & $\mathbf{L}$ & $\mathbf{V}$ & $\mathbf{A}$ & B & B & A & B & $\mathbf{L}$ & $\mathbf{V}$ & $\mathbf{A}$ & B & B & $\mathbf{A}$ & B & $\mathbf{L}$ & $\mathbf{V}$ & B & B \\
\hline $\mathbf{G C}_{1}$ & 7 & 1 & 8 & -- & -- & 3 & 5 & 6 & 2 & 3 & 5 & -- & 4 & 4 & 7 & 1 & 4 & 4 & 3 & 5 \\
\hline $\mathbf{G C}_{2}$ & 7 & -- & 7 & -- & -- & 2 & 5 & 6 & 2 & 5 & 3 & 1 & 4 & 3 & 5 & 2 & 4 & 3 & 1 & 6 \\
\hline $\mathbf{G C}_{3}$ & 10 & -- & 10 & -- & -- & 2 & 8 & 3 & 5 & 4 & 4 & 2 & 1 & 5 & 5 & -- & 2 & 3 & 3 & 2 \\
\hline $\mathbf{G C}_{4}$ & 9 & 1 & 10 & -- & -- & 4 & 6 & 3 & 7 & 1 & 9 & 1 & 3 & 6 & $J$ & -- & 3 & 2 & 1 & 4 \\
\hline $\mathbf{G C}_{5}$ & 4 & 4 & 8 & -- & 1 & 3 & 4 & 4 & 4 & 8 & -- & 3 & 4 & 1 & 0 & 1 & 5 & 2 & 1 & 6 \\
\hline $\mathbf{G C}_{6}$ & 2 & 5 & 5 & 2 & 1 & 4 & 2 & 5 & 3 & 8 & -- & 2 & 6 & -- & 5 & 1 & 4 & 2 & 4 & 2 \\
\hline $\mathbf{G C}_{7}$ & 3 & 6 & 7 & 2 & 2 & 3 & 4 & 6 & 3 & 7 & 2 & 2 & 4 & 3 & 6 & 2 & 8 & -- & 2 & 6 \\
\hline $\mathbf{G C}_{8}$ & 6 & 1 & 4 & 3 & 1 & 4 & 2 & 8 & 1 & 9 & -- & -- & 5 & 4 & 3 & 3 & 6 & -- & 3 & 3 \\
\hline
\end{tabular}

\begin{tabular}{cccc}
\hline $\begin{array}{c}\text { Grupo } \\
\text { Contemporâneo }\end{array}$ & $\begin{array}{c}\text { Ano de } \\
\text { Nascimento }\end{array}$ & Sexo & $\begin{array}{c}\text { Manejo } \\
\text { Alimentar* }\end{array}$ \\
\hline $\mathbf{G C}_{\mathbf{1}}$ & 1998 & Fêmea & $\mathrm{CS}$ \\
$\mathbf{G C}_{\mathbf{2}}$ & 1998 & Fêmea & $\mathrm{SS}$ \\
$\mathbf{G C}_{\mathbf{3}}$ & 1998 & Macho & $\mathrm{CS}$ \\
$\mathbf{G C}_{\mathbf{4}}$ & 1998 & Macho & $\mathrm{SS}$ \\
$\mathbf{G C}_{\mathbf{5}}$ & 1999 & Fêmea & $\mathrm{CS}$ \\
$\mathbf{G C}_{\mathbf{6}}$ & 1999 & Fêmea & $\mathrm{SS}$ \\
$\mathbf{G C}_{\mathbf{7}}$ & 1999 & Macho & $\mathrm{CS}$ \\
$\mathbf{G C}_{\mathbf{8}}$ & 1999 & Macho & $\mathrm{SS}$ \\
\hline
\end{tabular}

* CS = Com Suplementação; e SS = Sem Suplementação 


\section{REFERÊNCIAS BIBLIOGRÁFICAS}

ARKINS, S.; DANTZER, R.; KELLEY, K.W. Somatolactogens, somatomedins, and immunity. Journal of Dairy Science, v.76, p.2437-2442, 1993.

BARENDSE, W.; ARMITAGE, S.M.; KOSSAREK, L.M. et al. A genetic linkage map of the bovine genome. Nature Genetics, v.6, p.227-244, 1994.

BARENDSE, W.; VAIMAN, D.; KEMP, S.J. et al. A medium-density genetic linkage map of the bovine genome. Mammalian Genome, v.8, p.21-28, 1997.

BERTALANFFY, L. Von. Quantitative laws in metabolism and growth. The Quarterly Review of Biology, v.32, p.217-230, 1957.

BISHOP, M.D.; KAPPES, S.M.; KEELE, J.W. et al. A genetic linkage map for cattle. Genetics, v.136, p.619-639, 1994.

BLAXTER, K.L. Relative efficiencies of farm animals in using crops and by products production of foods. Animal Production, v.10, p.31-40, 1968.

BORGES, M. Marcadores moleculares seus efeitos sobre características quantitativas de bovinos de corte. Uberlândia, 1997. 119p. Dissertação (Mestrado) - Universidade Federal de Uberlândia. 
BOVENHUIS, H.; VAN ARENDONK, J.A.M.; KORVER, S. Associations between milk protein polymorphisms and milk production traits. Journal of Dairy Science, v.75, n.9, p.2549-2599, 1992.

BRINKS, J.S.; CLARK, R.T.; KIEFFER, N.M. et al. Estimates of genetic, environmental and phenotypic parameters in range Hereford females. Journal of Animal Science, v.23, n.3, p.711-716, 1964.

BRODY, S. Bioenergetics and growth. New York: Reinhold Publ., 1945. 1023p.

BROWN, J.E.; BROWN, C.J.; BUTTS, W.T. Evaluation relationships among immature measures of size, shape and performance of beef bulls. I. Principal components as measures of size and shape in young Hereford and Angus bulls. Journal of Animal Science, v.36, p.1010-1020, 1973a.

BROWN, J.E.; BROWN, C.J.; BUTTS, W.T. Evaluation relationships among immature measures of size, shape and performance of beef bulls. III The relations between postweaning test performance and size and shape at twelve months. Journal of Animal Science, v.37, p.11-17, 1973 b.

BROWN, J.E.; FITZHUGH JUNIOR H.A.; CARTWRIGHT, T.C.A. A comparision of nonlinear models for describing weight-age relationships in cattle. Journal of Animal Science, v.42, p.810-818, 1976.

BRYNE, P.F.; McMULLEN, M.D. Defining genes for agricultural traits: QTL analysis and the candidate gene approach. Probe, v.7, n.24-27, 1996.

CARTWRIGHT, T.C. Selection criteria for beef cattle for the future. Journal of Animal Science, v.30, p.706-711, 1970. 
CASAS, E.; KEELE, J.W.; SHACKELFORD, S.D. et al. Association of the muscle hypertrophy locus with carcass traits in beef cattle. Journal of Animal Science, v.76, p.468-473, 1998.

CASAS, E.; SHACKELFORD, S.D.; KEELE, J.W. et al. Quantitative trait loci affecting growth and carcass composition of cattle segregating alternate forms of myostatin. Journal of Animal Science, v.78, p.560-569, 2000.

CASTANHO, M.J.P. Estimativa da função logística para dados de crescimento de bovinos. Londrina, 1994. 117p. Dissertação (Mestrado) - Universidade Estadual de Londrina.

COOK, R.D.; WEISBERG, S. Transforming a response variable for linearity. Biometrika, v.81, n.4, p.731-737, 1994.

CORTARELLI, A. Estudo da curva de crescimento de machos da raça Nelore, através de quatro modelos estocásticos. Jaboticabal, 1973. 179p. Tese (Doutorado)Faculdade de Ciências Agrárias e Veterinárias, Universidade Estadual Paulista "Júlio de Mesquita Filho".

COUTINHO, L.L.; REGITANO, L.C.A. O uso de marcadores moleculares na indústria animal. In: CONGRESSO BRASILEIRO DE REPRODUÇÃO ANIMAL, 11., Belo Horizonte, 1995. Anais. Belo Horizonte: Colégio Brasileiro de Reprodução Animal, 1995. p.195-205.

COWAN, C.M.; DENTINE, M.R.; COYLE, T. Chromosome substitution effects associated with $\kappa$-casein and $\beta$-lactoglobulin in Holstein Cattle. Journal of Dairy Science, v.75, n.4, p.1097-1104, 1991. 
DeNISE, R.S.K.; BRINKS, J.S. Genetic and environmental aspects of the growth curve parameters in beef cows. Journal of Animal Science, v.61, n.6, p.1431-1440, 1985.

DI STASIO, L.; SARTORE, S.; ALBERA,A. Lack of association of GH1 and POU1F1 gene variants with meat production traits in Piemontese cattle. Animal Genetics, v.33, p.61-64, 2002.

DUARTE, F.A.M. Estudo da curva de crescimento de animais da raça Nelore, através de cinco modelos estocásticos. Ribeirão Preto, 1975. 284p. Tese (Livre Docência) Faculdade de Medicina de Ribeirão Preto, Universidade de São Paulo.

EDWARDS, M.D.; STUBER, C.V.; WENDEL, J.F. Molecular-marker-facilitated investigations of Quantitative-Trait Loci in maize. I. Numbers, genomic distribution and types of gene action. Genetics, v.116, p.113-125, 1987.

ELIAS, A.M. Análise de curvas de crescimento de vacas das raças Nelore, Guzerá e Gir. Piracicaba, 1998. 128p. Dissertação (Mestrado) - Escola Superior de Agricultura “Luiz de Queiroz”, Universidade de São Paulo.

FALCONER, D.S.; MACKAY, T.F.C. Introduction to quantitative genetics. Essex: Longman, 1996, 464p.

FERREIRA, M.E.; GRATTAPAGLIA, D. Introdução ao uso de marcadores moleculares em análise genética. Brasília: Embrapa-Cenargen, 1998, 220p.

FITZHUGH JUNIOR, H.A. Analysis of growth curves and strategies for altering their shape. Journal of Animal Science, v.42, p.1036-1051, 1976.

FITZHUGH JUNIOR, H.A.; TAYLOR, S.C.S. Genetic analysis of degree of maturity. Journal of Animal Science, v.33, n.4, p.717-725, 1971. 
FREITAS, A.R.; ALENCAR, M.M.; SILVA, A.S. Ajuste de modelos não lineares em bovinos de corte. I. Padrão da população. In: REUNIÃO ANUAL DA SOCIEDADE BRASILEIRA DE ZOOTECNIA, 35., Botucatu, 1998a. Anais. Botucatu: Sociedade Brasileira de Zootecnia, 1998a. p.341-343.

FREITAS, A. R.; ALENCAR, M.M; SILVAL, A.M. Ajuste de modelos não lineares em bovinos de corte. II. Influência do mês de nascimento. In: REUNIÃO ANUAL DA SOCIEDADE BRASILEIRA DE ZOOTECNIA, 35., Botucatu, 1998b. Anais. Botucatu: Sociedade Brasileira de Zootecnia, 1998b. p.344-346.

FREITAS, A.R.; DURÃES, M.C.; TEIXEIRA, N.M. Funções de crescimento de animais da raça Holandesa, mantidos em regime de confinamento. In: REUNIÃO ANUAL DA SOCIEDADE BRASILEIRA DE ZOOTECNIA, 32., Brasília, 1995. Anais. Brasília: Sociedade Brasileira de Zootecnia, 1995. p.662-665.

FREITAS, A.R.; DURÃES, M.C.; TEIXEIRA, N.M. Curvas de crescimento de novilhas da raça Holandesa mantidas em regime de confinamento. Arquivos Brasileiros de Medicina Veterinária e Zootecnia, v.49, n.1, p.85-93, 1997.

FREITAS, A. R.; SILVA, L.O.C.; EUCLIDES FILHO, K. et al. Análise bivariada e elipses de confiança obtidos de dados de desenvolvimento ponderal de bovinos da raça gir (compact disc). In: REUNIÃO ANUAL DA SOCIEDADE BRASILEIRA DE ZOOTECNIA., 39., Recife, 2002. Anais. Recife: Sociedade Brasileira de Zootecnia, 2002.

GLUCKMAN, P.D.; BREIER, B.G.; DAVIS, S.R. Physiology of somatotropic axis with particular reference to the ruminant. Journal of Dairy Science, v.70, p.442-466, 1987. 
GOONEWARDENE, L.A.; BERG, R.T.; HARDIN, R.T. A growth study of beef cattle. Canadian Journal of Animal Science, v.61, p.1041-1048, 1981.

GORDON, D.F.; QUICK, D.P.; ERWIN, R.C. et al. Nucleotide sequence of the bovine growth hormone chromosomal gene. Molecular and Cellular Endocrinology, v.33, p.81-95, 1983.

GRIFFITHS, A.J.F.; MILLER, J.H.; SUZUKI, D.T. et al. Introdução à genética. Rio de Janeiro: Koogan, 1998, 856p.

HARTLEY, H.O. The modified Gauss-Newton method for the fitting of nonlinear regression functions by least squares. Thechnometrics, v.3, p.269-280, 1961.

HINES, H.C.; ZIKAKIS, J.P.; HAENLEIN, C.A. et al. Linkage relationships among loci of polymorphism in blood and milk of cattle. Journal of Dairy Science, v.64, n.1, p.71-76, 1981.

HOJ, S.; FREDHOLM, M; LARSEN, N. J. et al. Growth hormone gene polymorphism associated with selection or milk fat production in lines of cattle. Animal Genetics, v.24, p.91-96, 1993.

HUGHES, T.E.; PITCHFORD, W.S. Heterosis effects on efficiency of post-weaning growth. In: WORLD CONGRESS ON GENETICS APPLIED TO LIVESTOCK PRODUCTION, 5., Guelph, 1994. Proceedings. Guelph: WCGALP, 1994.v.19, p.197-200.

KEMENES, P.A. Quantificação das frequências dos alelos 'A' e 'B' dos genes da kappa-caseína e $\beta$-lactoglobulina em algumas raças bovinas. Piracicaba, 1996. 85p. Dissertação (Mestrado) - Escola Superior de Agricultura "Luiz de Queiroz", Universidade de São Paulo. 
KIRKPATRIC, B.W. Detection of a three-allele single strand conformation polymorphism (SSCP) in the fourth intron of the bovine growth hormone gene. Animal Genetics, v.23, p.179-181, 1992.

LAIRD, A.K. Dynamics of relative growth. Growth, v.29, p.249-263, 1965.

LIN, C.Y.; McALLISTER, J.; NG-KWAI-HANG, K.F. et al. Association of milk protein with growth and reproductive performance of dairy heifers. Journal of Dairy Science, v.70, p.29-39, 1987.

LIN, C.Y.; McALLISTER, J.; NG-KWAI-HANG, K.F. et al. Relationships of milk protein types to lifetime performance. Journal of Dairy Science, v.72, n.11, p.30853090, 1989.

LIN, C.Y.; SABOUR, M.P.; LEE, A.J. Direct typing of milk proteins as an aid genetic improvement of dairy bulls and cows: a review. Animal Breeding Abstracts, v.60, p.1-10, 1992.

LUCY, M.C.; HAUSER, S.D.; EPPARD, P.J. et al. Genetic polymorphism within the bovine somatotropin (bST) gene detected by polymerase chain reaction and endonuclease digestion. Journal of Dairy Science, v.74, suppl.1, p.284, 1991.

MANSOUR, H.; JENSEN, E.L.; JOHNSON, L.P. Analysis of covariance structure of repeated measurements in holstein conformation traits. Journal of Dairy Science, v.74, n.8, p.2757-2766, 1991.

MEDRANO, J.F.; AGUILAR-CORDOVA. E. Genotyping of bovine kappa-casein loci following DNA sequence amplification. Bio/Technology, v.8, p.144-146, 1990a. 
MEDRANO, J.F.; AGUILAR-CORDOVA. E. Polymerase chain reaction amplification of bovine $\beta$-lactoglobulin genomic sequences and identification de genetic variants by RFLP analysis. Animal Biotechnology, v.1, p.73-77, 1990b.

MEZZADRA, C.A.; MIQUEL, M.C. Heterosis and breed transmitted effects in growth curve parameters in Angus Criollo and reciprocal crossbred cows. In: WORLD CONGRESS ON GENETICS APPLIED TO LIVESTOCK PRODUCTION, 5., Guelph, 1994. Proceedings. Guelph: WCGALP, 1994. v.17, p.276-279.

MOODY, D.E.; POMP, D.; NEWMAN, S. et al. Characterization of DNA polymorphisms in three populations of Hereford cattle and their associations with growth and maternal EPD in line 1 Herefords. Journal of Animal Science, v.74, p.1784-1793, 1996.

NADARAJAH, K.; MARLOWE, T.J.; NOTTER, D.R. Growth patterns of Angus, Charolais, Charolais $\mathrm{x}$ Angus and Holstein $\mathrm{x}$ Angus cows from birth to maturity. Journal of Animal Science, v.59, p.957-966, 1984.

NEIMANN-SORENSEN, A.; ROBERTSON, A. The associations between blood groups and several production characteristics in three Danish cattle breeds. Acta Agricultura Scandinavica, v.11, p.163-196, 1961.

NELDER, J.A. The fitting of a generalization of the logistic curve. Biometrics, v.17, p.89-110, 1961.

NG-KWAI-HANG, K.F.; HAYES, J.F.; MOXLEY, J.E. et al. Association of genetic variants of casein and milk serum protein with milk, fat and protein production by dairy cattle. Journal of Dairy Science, v.67, p.835-840, 1984. 
NG-KWAI-HANG, K.F.; ZADWORNY, D.; HAYES, J.F. et al. Identification of kappacasein genotype in Holstein sires: a comparison between analysis of milk samples from daughters and directed analysis of semen samples from sires by polymerase chain reaction. Journal of Dairy Science, v.74, p.2410-2415, 1991.

OLIVEIRA, H.N. Análise genético-quantitativa da curva de crescimento de fêmeas da raça Guzerá. Ribeirão Preto, 1995. 73p. Tese (Doutorado) - Faculdade de Medicina de Ribeirão Preto, Universidade de São Paulo.

OLIVEIRA, H.N.; LÔBO, R.B.; PEREIRA, C.S. Relationships among growth curve parameters, weights and reproductive traits in Guzerá beef cows. In: WORLD CONGRESS ON GENETICS APPLIED TO LIVESTOCK PRODUCTION, 5., Guelph, 1994. Proceedings. Guelph: WCGALP, 1994. v.19, p.189-192.

PEROTTO, D.; CASTANHO, M.J.P.; ROCHA, J.L et al. Descrição das curvas de crescimento de fêmeas bovinas Guzerá, Gir, Holandês x Guzerá e Holandês x Gir. Revista Brasileira de Zootecnia, v.26, p.283-288, 1997.

PEROTTO, D.; CUE, R.I.; LEE, A.J. Comparison of nonlinear functions for describing the growth curve of three genotypes of dairy cattle. Canadian Journal of Animal Science, v.72, p.773-782, 1992.

PILLA, A.M.; NAPOLITANO, F.; MOIOLI, B.M. et al. Association between restriction fragment length polymorphisms and quantitative traits in Piemontese $x$ Chianina crossbred. In: WORLD CONGRESS ON GENETICS APPLIED TO LIVESTOCK PRODUCTION, 5., Guelph, 1994. Proceedings. Guelph: WCGALP, 1994. v.21, p.284-287.

RAPLEY, E.; McDONALD, B. Microsatellites: the genomic road map. Today's Life Science, v.1, p.62-65, 1992. 
RASMUSSON, J.M. A contribution to the theory of quantitative character inheritance. Hereditas, v.18, n.245-261, 1933.

RATKOSWKY, D.A. Nonlinear regression modeling. New York: Marcel Dekker, 1983. 297p.

RICHARDS, F.J. A flexible growth function for empirical use. Journal of Experimental Botany, v.10, p.290-300, 1959.

ROCHA, J.L.; BAKER, J.F.; WOMACK, J.E. et al., Statistical associations between restriction fragment length polymorphisms and quantitative traits in beef cattle. Journal of Animal Science, v.70, p.3360-3370, 1992.

RON, M.; YOFFE, O.; MEDARANO, J.F. et al. Determination of effects of milk protein genotype on production traits of Israeli Holsteins. Journal of Dairy Science, v.77, p.1106-1113, 1994.

ROTHSCHILD, M.F.; SOLLER, M. Candidate gene analysis to detect genes controlling traits of economic importance in domestic livestock. In: INTERNATIONAL SYMPOSIUM ON ANIMAL BREEDING AND GENETICS, Viçosa, 1999. Proceedings. Viçosa: Universidade Federal de Viçosa, 1999. p.219-242.

SAS INSTITUTE. SAS/STAT 2001: user's guide: statistics version 8.2, (compact disc). Cary, 2001.

SARTORI, S.; DI STASIO, L. Analisi genetica del locus GH (ormone della crescita) nella razza bovina Piemontesa. In: CONVEGNO SOCIETÀ ITALIANA DELLE SCIENZE VETERINARIE LIV, 54. 2000. Proceedings. s.1.: s.ed., 2000. p. 411-412. 
SAX, K. The association of size differences with seed-coat pattern and pigmentation in Phaseolus vulgaris. Genetics, v.8, p.552-560, 1923.

SCHABENBERGER, O. Nonlinear regression with the SAS system. http://www.cas.vt.edu/schabenb/SASNlin.htm. (14 nov. 2001).

SCHLEE, P.; GRAML, R.; ROTTMANNN,O. et al. Influence of growth-hormone genotypes on breeding values Simmental bulls. Journal of Animal Breeding and Genetics, v.111, p.253-256,1994a.

SCHLEE, P.; GRAML, R.; SCHALLEMBERGER, E. et al. Growth hormone AND insulin-like growth factor-I concentrations in bull of various growth hormone genotypes. Theoretical and Applied Genetics, v.88, p.497-500, 1994b.

SOLLER, M. Marker assisted selection - an overview. Animal Biotechnology, v.5, p.193-207, 1994.

SOLLER, M.; BRODY, T. On the power of experimental designs for the detection of linkage between marker loci and quantitative loci in crosses between inbred lines. Theoretical and Applied Genetics, v.47, p.35-39, 1976.

SOLLER, M.; MEDJUGORAC, I. A successful marriage: making the transition from quantitative trait locus mapping to maker-assisted selection. In: JAY LUSH TO GENOMICS: VISIONS FOR ANIMAL BREEDING AND GENETICS, Ames, 1999. Proceedings. Ames: Iowa State University, 1999.

TAMBASCO, .D.D.; PAZ, C.C.P.; TAMBASCO-STUDART, M. et al. Candidate genes for growth traits in beef cattle crosses Bos taurus $x$ Bos indicus (compact disc). In: WORLD CONGRESS ON GENETICS APPLIED TO LIVESTOCK PRODUCTION, 7., Montpellier, 2002. Proceedings. Montpellier: WCGALP, 2002. 
TAYLOR, S.C.S., CRAIG, J. Genetic correlation during growth of twin cattle. Animal Production, v.7, p.83-102, 1965.

TAYLOR, S.C.S., YOUNG, G.B. Variation in growth efficiency in twin cattle with live weight and food intake controlled. Journal of Agricultural Science, v.66, p.67-85, 1966.

TAYLOR, J.F.; COUTINHO, L.L.; HERRING, K.L. et al. Candidate gene analysis of GH1 for effects on growth and carcass composition of cattle. Animal Genetics, v.29, p.194-201, 1998.

THODAY, J.M. Location of polygenes. Nature, v.191, p.368-370, 1961.

UNANIAN, M.M.; BARRETO, C.C.; FREITAS, A.R. et al. Associação do polimorfismo do gene do hormônio do crescimento com a caraterística peso em bovinos da raça Nelore. Revista Brasileira de Zootecnia, v.29, n.5, p.1380-1386, 2000.

UNANIAN, M.M.; DeNISE, S.K.; ZHANG, H.M. et al. Rapid communication: polymerase chain reaction-restriction fragment length polymorphism in the bovine growth hormone gene. Journal of Animal Science, v.72, p.2203, 1994.

WEBSTER, A.J.F. Bioenergetics, bioengineering and growth. Animal Production, v.48, n.1, p.249-269, 1989.

WOYCHIK, R.P.; CAMPER, S.A.; LYONS, R.H. et al. Cloning and nucleotide sequencing of the bovine growth hormone gene. Nucleic Acid Research, v.10, n.22, p.7197-7210, 1982. 
YAO, J.; AGGREY, S.E.; ZADWORNY, D. et al. Sequence variations inthe bovine growth hormone gene characterized by single-strand conformation polymorphism (SSCP) analysis and their association with milk production traits in Holsteins. Genetics, v.144, p.1809-1816, 1996.

ZHANG, H.M.; BROWN, D.R.; DeNISE, S.K. et al. Nucleotide sequence determination of a bovine somatotropin allele. Animal Genetic, v.23, p.578, 1992.

ZHANG, H.M.; BROWN, D.R.; DeNISE, S.K. et al. Rapid communication: polymerase chain reaction-restriction fragment length polymorphism analysis of the bovine somatotropin gene. Journal of Animal Science, v.71,n.8, p.2276, 1993. 
APÊNDICES 


\title{
Apêndice 1 - TAMANHO AMOSTRAL PARA PESO CORPORAL DE BOVINOS DE CORTE EM EXPERIMENTOS DE MEDIDAS REPETIDAS
}

\section{SAMPLE SIZE FOR BODY WEIGHT IN BEEF CATTLE IN REPEATED MEASUREMENTS EXPERIMENTS}

\author{
C.C.P. Paz ${ }^{1,2}$, A.R. Freitas ${ }^{3}$, I.U. Packer ${ }^{2}$, D.D. Tambasco ${ }^{4}$, L.C.A. Regitano $^{3}$ and \\ M.M. Alencar ${ }^{3}$ \\ ${ }^{1}$ Animal Science Institute of São Paulo, P. Box 60, 13460-000, Nova Odessa, SP, \\ Brazil \\ ${ }^{2}$ Animal Science Department - ESALQ/USP, P. Box 9, 13418-900 Piracicaba, SP, \\ Brazil \\ ${ }^{3}$ Embrapa Southeast Cattle Research Center, P.Box 339, 13560-970 São Carlos, \\ SP, Brazil \\ ${ }^{4}$ Federal University of São Carlos, São Carlos, SP, Brazil
}

\section{INTRODUCTION}

Animal production has been experimenting considerable genetic improvement in some performance traits. Further improvements of the animal breeding programs may require molecular marker-assisted selection, which requires a identification of candidate genes or anonymous genetic markers associated with the traits of interest. The use of 
candidate genes has been proposed to direct the search for QTL (Quantitative Trait Loci). There were reports associating growth traits with polymorphisms observed in the א-Casein (CSN3) and $\beta$-Lacglobulin (LGB) (Moody et al., 1996; Lin et al., 1987) and growth hormone (GH) genes (Rocha et al., 1992; Unanian et al., 2000). The latter has also been associated with carcass composition and meat quality (Taylor et al., 1998). The influence of candidate genes on performance traits of cattle has been analyzed considering each trait individually, which is a difficult way to detect significant effects. An alternative method is the use of repeated measurements (RM) that has increased substantially in beef cattle breeding studies in recent years. Jensen (1982) and Vonesh (1983) showed greater efficiency in the use of RM designs, confirmed by the results from Vonesh and Schork (1986) regarding the sample size. An important contribution of sample size in RM was given by Freitas et al. (1999) for scrotal circumference of Nellore catlle. Proper planning reduces the risks of conducting a study that will not produce useful results and determines the most sensitive design for the available resources. In studies of candidate genes or molecular markers associate with QTL, the cost of laboratory analyses is very important and need to be considered in the planning of the experiment. The aim of this study was to estimate sample size required for an experiment which associates candidate genes (CSN3, GH and LGB) with body weight in crossbred beef cattle, assuming the body weight of the animals at different ages during growth phase as repeated measurements. 


\section{MATERIAL AND METHODS}

This study used data collected of 213 animals (75 1/Canchim+1/20llore, 74 1/2 Aberdeen Angus+1/20llore and 64 1/Simental+1/Nellore) born in 1998 and 1999 in Southeast Brazil. The data were the weight, collected at birth, weaning ( 7 months of age) and thereafter monthly until to 19 months of age, totaling 14 measurements considered as RM.

The model used to determine sample size in repeated measurements analysis was as follow:

$$
\mathrm{Y}_{\mathrm{ijk}}=\mu+\varepsilon_{\mathrm{ijk}}(i=1, \ldots, n), \quad \varepsilon_{\mathrm{ijk}} \sim \operatorname{IID~N} \mathrm{N}_{\mathrm{p}}(\mathbf{0}, \boldsymbol{\Sigma}),
$$

where $\mathrm{Y}_{\mathrm{i}}^{\prime}=\left(\mathrm{Y}_{\mathrm{i} 1}, \ldots, \mathrm{Y}_{\mathrm{ip}}\right)$ is the response vector of the $i^{\text {th }}$ subject across $p$ repeated measurements, $\mu^{\prime}=\left(\mu_{1}, \ldots \mu_{\mathrm{p}}\right)$ is the mean response vector, $\varepsilon_{\mathrm{i}}=$ experimental error, and $\mathrm{N}_{\mathrm{p}}(\mathbf{0}, \mathbf{\Sigma})=p$-variate normal distribution with mean vector $\mathbf{0}$ and covariance matrix $\Sigma$.

Considering the standard model for repeated measure (Little et al., 1998), the $\mu$ effect in this case also included fixed effects such as contemporaneous and genotype group $\left(\tau_{\mathrm{i}}\right)$, random effect of animal within $\tau\left(\mathrm{d}_{\mathrm{ij}}\right)$, k times $\left(\mathrm{t}_{\mathrm{k}}\right)$ and interaction of $\tau_{\mathrm{i}}$ with $\mathrm{t}_{\mathrm{k}}$ $(\tau t)_{\text {ik }}$ effects. The test to reject or accept the null hypothesis of equal measurements effects $H_{0}=\mu_{1}=\ldots=\mu_{\mathrm{p}}$, is based on the statistic:

$$
\mathrm{T}^{2}=\mathrm{n} \overline{\mathrm{Y}}^{\prime} \mathrm{C}\left(\mathrm{C}^{\prime} \Sigma \mathrm{C}\right)^{-1} \mathrm{C}^{\prime} \overline{\mathrm{Y}}
$$




$$
\begin{aligned}
& \text { where } \overline{\mathrm{Y}}=\mathrm{n}^{-1} \sum_{\mathrm{i}=1}^{\mathrm{n}} \mathrm{Y}_{\mathrm{i}}, \\
& \mathrm{S}=(\mathrm{n}-1)^{-1} \sum_{\mathrm{i}=1}^{\mathrm{n}}\left(\mathrm{Y}_{\mathrm{i}}-\overline{\mathrm{Y}}\right)\left(\mathrm{Y}_{\mathrm{i}}-\overline{\mathrm{Y}}\right)^{\prime} \text { is the sample covariance matrix, positive } \\
& \text { defined, and } \\
& \mathrm{C}^{\prime}=\text { any }(p-1) \mathrm{x} p \text { orthogonal contrast matrix. }
\end{aligned}
$$

The $T^{2}$ statistic is distributed according to the Hotelling $T^{2}$ with $(p-1)$ and $(n-1)$ degrees of freedom (df) and noncentrality parameter $\delta^{2}=n \mu^{\prime} \mathrm{C}\left(\mathrm{C}^{\prime} \Sigma \mathrm{C}\right)^{-1} \mathrm{C}^{\prime} \mu$. Under true $\mathrm{H}_{0}$, $\mathrm{F}=(n-p+1)[(n-1)(p-1)]^{-1} \mathrm{~T}^{2}$ was obtained, which has distribution $\mathrm{F}$ with $(p-1)$ and $(n-p+1)$ df and noncentrality parameter $\delta^{2}$; for a particular $\alpha$, then it rejects $\mathrm{H}$ if $\mathrm{F}>\mathrm{F}(p-1, n$ $\left.p+1 ; \delta^{2}\right)$.

The sample size $(n)$ is determined by assuming several values of $\mu$ and $\Sigma$, in which $\mathrm{H}_{0}$ is rejected. It was specified for any pair of $\mathrm{RM}$ a minimum difference $(\Delta)$, subject to the restriction $\left|\mu_{j}-\mu_{\mathrm{k}}\right|=\Delta$ for any $\mathrm{j} \neq \mathrm{k}$ (Scheffé, 1959), whose significance should be detected, considering a level of probability $\alpha$ and power of test (1- $\beta$ ). The minimum value of $\delta^{2}$ subject to the restriction $\left|\mu_{j}-\mu_{k}\right|=\Delta$, defined by $\delta^{2}$, is equal to $n \Delta^{2} / \max _{\mathrm{j}<\mathrm{k}}\left\{\sigma_{\mathrm{j}}^{2}+\sigma^{2}{ }_{\mathrm{k}}-2 \sigma_{\mathrm{jk}}\right\}$ where $\sigma_{\mathrm{j}}^{2}$ and $\sigma_{\mathrm{k}}^{2}(\mathrm{j}<\mathrm{k})$ are the variances and $\sigma_{\mathrm{jk}}$ is the covariance associated to traits $\mathrm{j}$ and $\mathrm{k}$, respectively. Considering $\Sigma$, any variancecovariance matrix, defined positive satisfying $\rho_{\mathrm{jk}} \geq 0$, for all $\mathrm{j}<\mathrm{k}$, it can be demonstrated that $\mathrm{m}^{2} /\left[\left(2 \sigma_{\max }^{2}\left(1-\rho_{\min }\right)\right] \leq \delta^{2}{ }_{\Delta}\right.$ is appropriated for estimating sample size $n$ (Vonesh and Schork, 1986). In this expression, $\rho_{\min }$ is the lower correlation coefficient between 
repeated measures, $\sigma_{\max }^{2}=\operatorname{maximum}\left(\sigma_{\mathrm{j}}^{2}\right)$ and $\Delta$ is measured in units of $\sigma_{\max }$. Using this expression, the $n$ estimated for $p \geq 2 \mathrm{RM}$, in functions of $p-1$ and $n-p+1, \alpha$ and power of test $(1-\beta)$, were obtained by SAS program that considered an integral and a noncentral Fdistribution (Hardison et al., 1983; Vonesh and Schork, 1986). The main point of this study was based on the fact that repeated measures $(p=14)$ of body weight from birth to approximately 19 months of age were adequately described by a sigmoid growth curve, so, as $n$ increases, the confidence interval becomes lower and the closer the curve approximates the population growth curve.

\section{RESULTS AND DISCUSSION}

The maximum standard deviation $\left(\sigma_{\max }\right)$ obtained from sample variancecovariance matrix (Table 1$)$, positive defined, was $85.4235 \mathrm{~kg}$ and $\rho_{\min }=0.05\left(\sigma_{\max }\right.$ was based on $\sigma_{\text {max }}^{2}=\sigma^{2}{ }_{\mathrm{i}}+\sigma_{\mathrm{j}}^{2}-2 \sigma_{\mathrm{ij}}$, where $i$ and $j$ are couple body weight). So, the $n$ estimates showed in Figures 1 and 2, were obtained by evaluating the integral of a central and noncentral F-distribution in function of expression $0.0000685 n \Delta^{2} /\left(1-\rho_{\min }\right)$; power of test $(1-\beta)=0.80$ and 0.90 ; minimum correlation $\left(\rho_{\min }\right)=0,0.2,0.4$ and 0.6 , detectable difference $(\Delta)=1.0 \sigma, 1.5 \sigma$ and $2.0 \sigma$, and $\alpha=0.01$ and $\alpha=0.05$, respectively. For including $\rho_{\min }$, this expression takes on account the fact that the correlation between repeated measures decreases as the repeated measures become far apart; for considering $\sigma_{\max }^{2}$, it takes on account a common fact in growth studies, that is, the variance is linearly proportional to the increment in the response function. These properties, and the 
fact that the sample variance-covariance matrix is positive defined, assure reliability of the sample size estimate (Brownie et al., 1990; Cullis and McGilchrist, 1990). The minimum number of individuals necessary for detecting significant difference between repeated measure, increases in the following order: $(\Delta=2.0 \sigma$; Power $=0.80) ;(\Delta=2.0 \sigma$; Power=0.90); $(\Delta=1.5 \sigma ;$ Power=0.80); $(\Delta=1.5 \sigma ;$ Power $=0.90) ;(\Delta=1.0 \sigma ;$ Power $=0.80)$ and $(\Delta=1.0 \sigma ;$ Power $=0.90)$.

As an example, to detect a significant difference between any two of 14 measurements, considering a minimum difference of $1.0 \sigma$, power of test $=0.90$, minimum correlation equal to 0.4 , it would be necessary a minimum of 50 and 40 individuals for $\alpha=0.01$ and $\alpha=0.05$, respectively. At the same conditions, a minimum of 31 and 26 individuals are needed when $\Delta$ changes from $1.0 \sigma$ to $1.5 \sigma$, for $\alpha=0.01$ and $\alpha=0.05$ respectively. Vonesh and Schork (1986) studied the sample size from three to six $(p=3(1) 6)$ measurements, seven values of $\Delta(1.0 \sigma$ to $3.0 \sigma)$, power of test of 0.80 and 0.90, and minimum correlation from 0.1 to 0.9 . They observed greater reduction in the estimates of $n$ when $\Delta$ changed from $1.0 \sigma$ to $1.25 \sigma$. The determination of sample sizes as implemented in this study, plays an important role in the planning of the number of individuals requested in an experiment. Suppose a similar study is planned to evaluate the influence of candidate genes on body weight in cattle, from birth to two years of age. In this case, it is reasonable to estimate the sample size $n$ by $0.0000685 n \Delta^{2} /(1-0.05)$, where 0.05 is the estimated minimum correlation. Adequate planning reduces the risks of conducting a study that will not produce useful results, and provide a desired power for an effect of scientific interest. 


\section{CONCLUSION}

The number of animals necessary to detect significance between repeated monthly evaluations of body weight of cattle from birth to approximately 19 months of age is influenced by a minimum difference significative $(\Delta)$, correlation among the repeated measures, type I error $(\alpha)$ and power of test (1- $\beta)$. For a particular $\Delta$ value, it is necessary a bigger sample size $(n)$ to prove significant difference between repeated measures response, when $\alpha$ moves from 0.05 to 0.01 and the power goes from 0.80 to 0.90. Independently of the power of the test, $\rho_{\min }$ and $\Delta$, significant difference between mean of any two measurements at $\alpha=0.01$ requests a sample size about $30 \%$ greater than that for $\alpha=0.05$.

\section{ACKNOWLEDGMENTS}

This work had financial support from CNPq and FAPESP.

\section{SUMMARY}

The objective of this work was to estimate minimum sample size $(n)$ required for an experiment which associates candidate genes ( $\kappa$-Casein $(\mathrm{CSN} 3)$ and $\beta$-Lacglobulin (LGB) and growth hormone $(\mathrm{GH})$ ) with body weight in different phases of growth in crossbred beef cattle, assuming the body weight at different ages as repeated measures (14 measurements). The value of $n$ required to detect significative differences $(\Delta)$ 
between any two measurements of body weight was obtained by SAS program that considered a $p$-variate normal distribution $(p=14)$, F-distribution with noncentrality parameter $\delta^{2}{ }_{\Delta}$ and levels of type I error $(\alpha)$, power test $(1-\beta)$, correlation between repeated measures $\left(\rho_{\text {min }}\right)$ and $\Delta$. The calculated $n$ ranged from 6 to 74 being mostly affected by variation in $\Delta$.

\section{REFERENCES}

BROWNIE, C.; BOODS, D.D.; OLIVER, J.H. 1990: Modifuing the $t$ and ANOVA $F$ Tests when treatment is expected to increase variability relative to controls. Biometrics. 46: 259-266.

CULLIS, B.R.; MCGILCHRIST, C.A. 1990: A model for the analysis of growth data from designed experiments. Biometrics. 46: 131-142.

FREITAS, A.R.; SILVA, A.E.D.F.; UNANIAN, M. 1999: Estimativa de tamanho amostral em medidas repetidas de circunferência escrotal de bovinos de corte. Rev. Bras. Zootec. 28: 279-287.

HARDISON, C.D.; QUADE, D.; LANGSTON, R.E. 1983. In: SAS Institute Inc. SUGI Supplemental Library User's Guide. Cary: North Caroline, SAS Institute hc: 229236.

JENSEN, D.R. 1982: Efficiency and robustness in the use of repeated measurements. Biometrics. 38: 813-825. 
LIN, C.Y.; McALLISTER, J.; NG-KWAI-HANG, K.F. et al., 1987. Association of milk protein with growth and reproductive performance of dairy heifers. J. Dairy Sci., 70: 29-39.

LITTLE, R.C., HENRY, P.R.,AMMERMAN, C.B., 1998. Statistical analysis of repeated measures data using SAS procedures. J. Anim. Sci. 76: 1216-1231.

MOODY, D.E.; POMP, D.; NEWMAN, S.; McNEIL, M.D., 1996: Characterization of DNA polymorphisms in three populations of Hereford cattle and their associations with growth and maternal EPD in line 1 Herefords. J. Anim. Sci. 74: 1784-1793.

ROCHA, J.L.; BAKER, J.F.; WOMACK, J.E.; SANDERS, J.O.; TAYLOR, J.F., 1992:

Statistical associations between restriction fragment length polymorphisms and quantitaive traits in beef cattle. J. Anim. Sci. 70: 3360-3370.

SCHEFFÉ, A. (1959) The Analysis of Variance. ed. John Wiley, 477p.

TAYLOR, J.F.; COUTINHO, L.L.; HERRING, K.L., GALlAGHER Jr, D.S.; BRENNEMAN, R.A.; BURNEY, N.; SANDERS, J.O; TURNER, J.W.; SMITH, S.B.; MILLER, R.K.; SAVELL, J.W.; DAVIS, S.K., 1998: Candidate Gene Analysis of Gh1 for effects on growth and carcass composition of cattle. Anim. Genet. 29: 194-201.

UNANIAN, M.M.; BARRETO, C.C.; FREITAS, A. R.; CORDEIRO, C.M.T.; JOSAHKIAN, L.A., 2000: Associação do polimorfismo do gene do hormônio de crescimento com a característica peso em bovinos da raça Nelore. Rev. Bras. Zootec. 29: $1380-1386$. 
VONESH, E.F., 1983. Efficiency of repeated measures designs versus completely randomized designs based on multiple comparisons. Communication in StatisticsTheory and Methods 12: 289-301.

VONESH, E.F.; SCHORK, M.A., 1986: Sample Size in the multivariate analysis of repeated measurements. Biometrics. 42 : 601-610. 


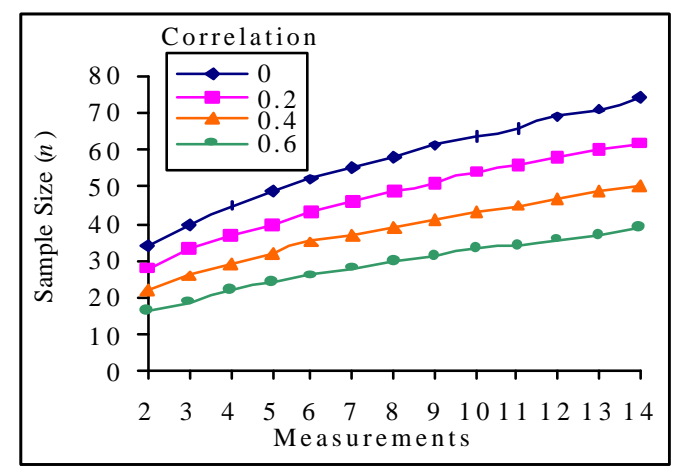

$\Delta=1.0 \sigma$ and Power $=0.90$

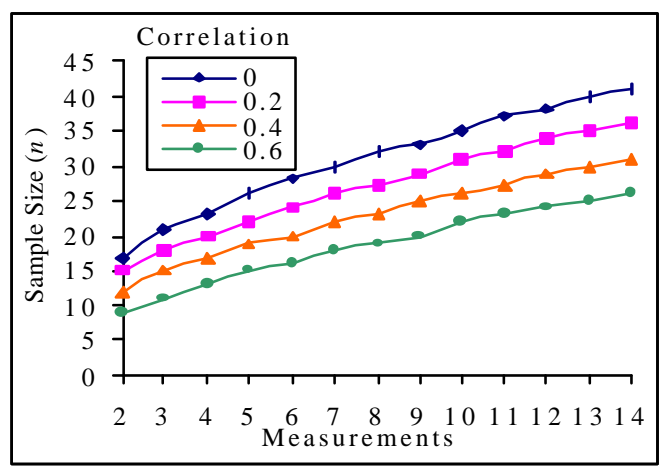

$\Delta=1.5 \sigma$ and Power $=0.90$

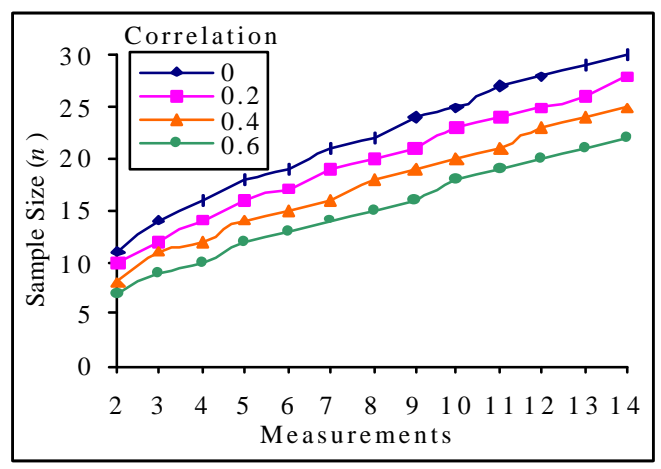

$\Delta=2.0 \sigma$ and Power $=0.90$

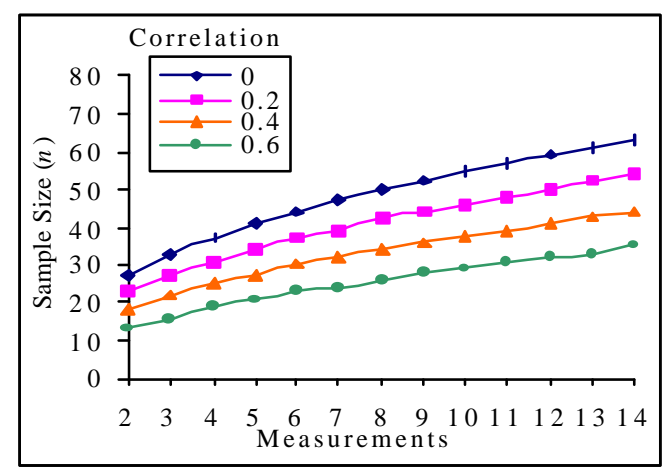

$\Delta=1.0 \sigma$ and Power $=0.80$

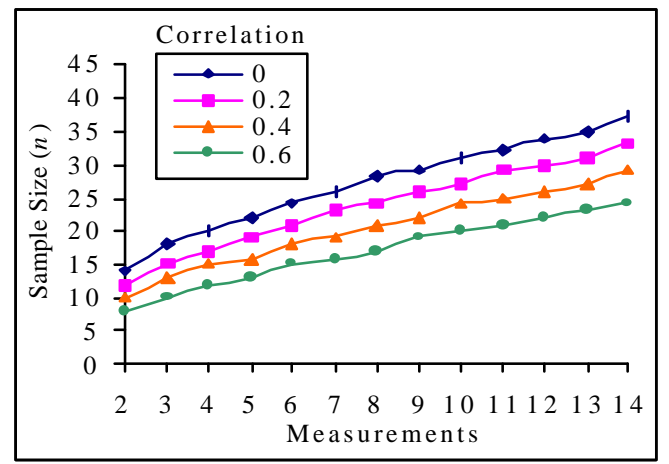

$\Delta=1.5 \sigma$ and Power $=0.80$

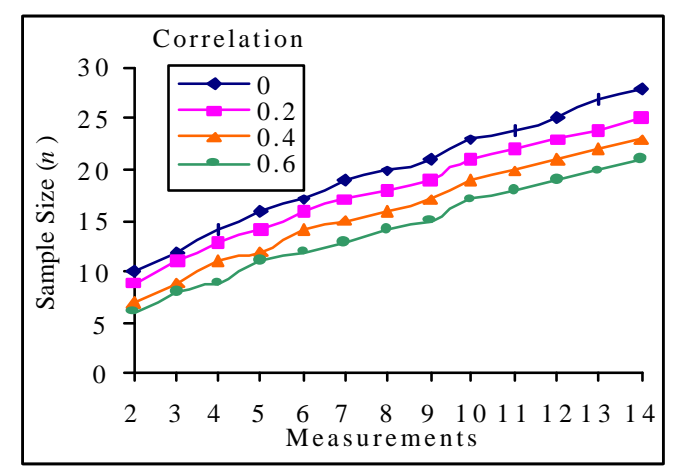

$\Delta=2.0 \sigma$ and Power $=0.80$

Figure 1. Estimates of sample size (n) in repeated measurements of body weight (BW) in beef cattle for $\alpha=0.01$; power of test $(1-\beta)=0.80$ and 0.90 ; minimum correlation $\left(\rho_{\min }\right)=0,0.2,0.4$ and 0.6 and detectable difference $(\Delta)=1.0 \sigma, 1.5 \sigma$ and 2.00. 


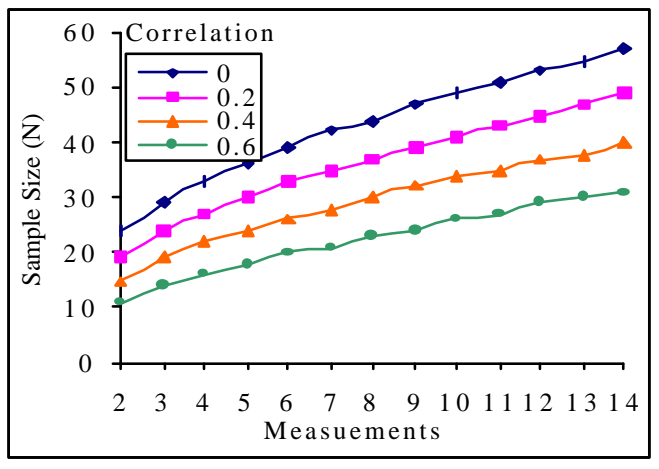

$\Delta=1.0 \sigma$ e Power $=0.90$

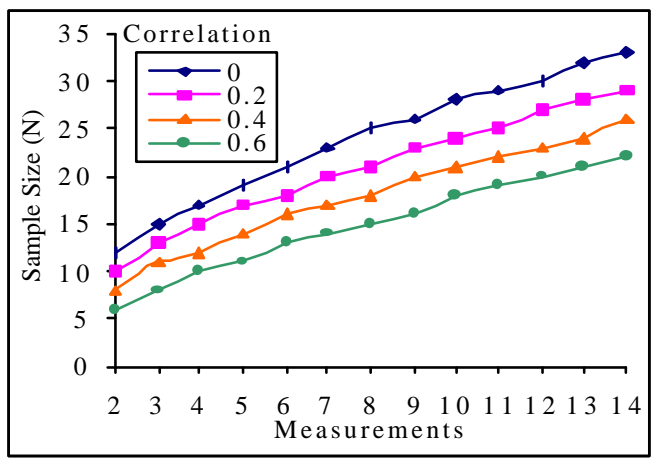

$\Delta=1.5 \sigma$ e Power $=0.90$

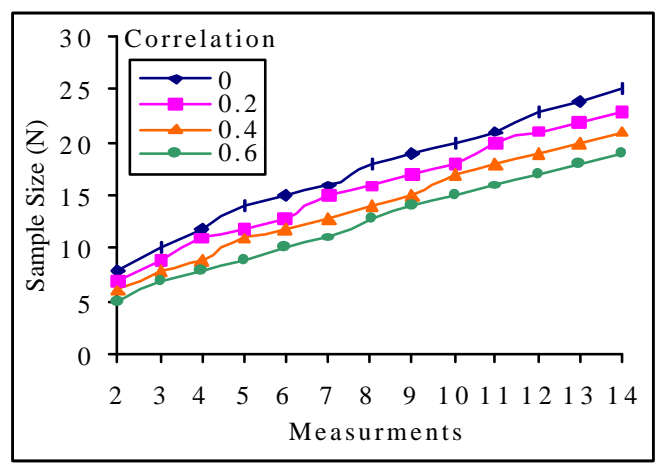

$\Delta=2.0 \sigma$ e Power $=0.90$

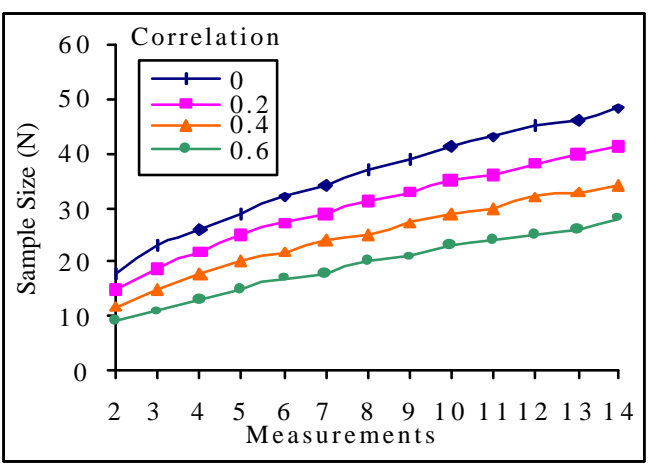

$\Delta=1.0 \sigma$ e Power $=0.80$

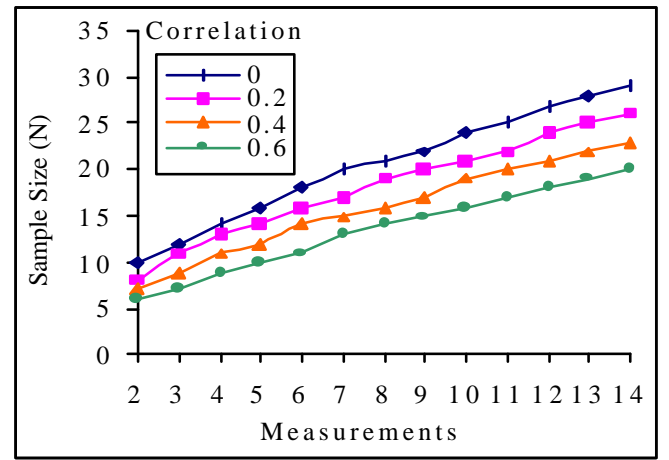

$\Delta=1.5 \sigma$ e Power $=0.80$

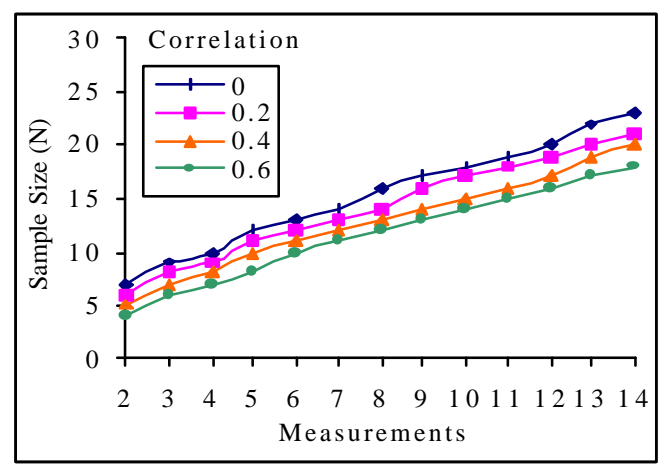

$\Delta=2.0 \sigma$ e Power $=0.80$

Figure 2. Estimates of sample size $(n)$ in repeated measurements of body weight (BW) in beef cattle for $\alpha=0.05$; power of test $(1-\beta)=0.80$ and 0.90 ; minimum correlation $\left(\rho_{\min }\right)=0,0.2,0.4$ and 0.6 and detectable difference $(\Delta)=1.0 \sigma, 1.5 \sigma$ and 
Table 1. Matrix of sample variances-covariances considering 14 repeated measures of body weight from beef cattle

\begin{tabular}{|c|c|c|c|c|c|c|c|c|c|c|c|c|c|c|}
\hline & BW & WW & W8 & W9 & W10 & W11 & W12 & W13 & W14 & W15 & W16 & W17 & W18 & W19 \\
\hline BW & 15.74 & 30.03 & 24.73 & 24.66 & 14.80 & 9.51 & 15.27 & 29.83 & 37.36 & 38.25 & 51.39 & 47.32 & 57.82 & 54.00 \\
\hline WW & & 895.17 & 731.74 & 666.2 & 646.50 & 657.10 & 664.07 & 775.82 & 845.96 & 838.46 & 603.12 & 518.06 & 484.57 & 513.16 \\
\hline W8 & & & 897.79 & 871.81 & 941.62 & 1008.17 & 1075.96 & 1230.33 & 1344.93 & 1388.75 & 1032.71 & 743.73 & 703.41 & 690.68 \\
\hline W9 & & & & 1001.42 & 1205.30 & 1338.05 & 1488.38 & 1628.57 & 1760.24 & 1802.27 & 1272.66 & 780.84 & 808.81 & 858.32 \\
\hline W10 & & & & & 1687.74 & 1947.17 & 2184.26 & 2338.83 & 2547.15 & 2671.20 & 1804.78 & 865.97 & 854.59 & 940.13 \\
\hline W11 & & & & & & 2332.44 & 2636.18 & 2842.04 & 3108.08 & 3304.52 & 2293.61 & 1118.50 & 1075.25 & 1043.49 \\
\hline W12 & & & & & & & 3126.02 & 3397.73 & 3702.03 & 3954.01 & 2861.16 & 1374.13 & 1336.85 & 1273.06 \\
\hline W13 & & & & & & & & 4054.05 & 4499.38 & 5049.70 & 4068.05 & 2157.98 & 2006.29 & 1434.57 \\
\hline W14 & & & & & & & & & 5128.68 & 5873.77 & 4866.17 & 2477.24 & 2291.06 & 1546.32 \\
\hline W15 & & & & & & & & & & 7357.94 & 6391.95 & 3165.24 & 2909.19 & 1726.48 \\
\hline W16 & & & & & & & & & & & 7133.51 & 3810.11 & 3507.61 & 1959.42 \\
\hline W17 & & & & & & & & & & & & 3956.20 & 3691.66 & 2031.52 \\
\hline W18 & & & & & & & & & & & & & 3843.44 & 2222.13 \\
\hline W19 & & & & & & & & & & & & & & 2384.02 \\
\hline
\end{tabular}

$\mathrm{BW}=$ Birth Weight ;WW=Weaning Weight; W8=Weight at 8 months; W9=Weight at 9 months; W10=Weight at 10 months; W11=Weight at 11 months; W12=Weight at 12 months; W13=Weight at 13 months; W14=Weight at 14 months; W15=Weight at 15 months; W16=Weight at 16 months; W17=Weight at 17 months; W18=Weight at 18 months; W19=Weight at 19 months. 
Apêndice 2 - Rotina de Análise: Modelos Não Lineares - PROC NLIN (SAS, 2001)

\section{Modelo Completo (inclui as classes de grupo contemporâneo)}

Titlel ' Ful I Mdel gr upo cont empor aneo' ;

dat a ful I gc; set d;

PROC NLI N naxi ter $=500$ METHOD = GAUSS;

PARIS $\mathrm{A} 1=500 \mathrm{kl}=0.005 \mathrm{ml}=3$

$\mathrm{A} 2=500 \mathrm{k} 2=0.005 \mathrm{~m} 2=3$

$\mathrm{A} 3=500 \mathrm{k} 3=0.005 \mathrm{mB}=3$

$\mathrm{A} 4=500 \mathrm{k} 4=0.005 \mathrm{~m} 4 \mathrm{H}=3$

$\mathrm{A} 5=500 \mathrm{k} 5=0.005 \mathrm{~m} 5=3$

$\mathrm{A} 6=500 \mathrm{k} 6=0.005 \mathrm{~m} 6=3$

$\mathrm{A} 7=500 \mathrm{k} 7=0.005 \mathrm{~m}=3$

$\mathrm{A} 8=500 \mathrm{k} 8=0.005 \mathrm{~m} 8=3$;

$\mathrm{CO}=1+\mathrm{EXP}(-\mathrm{K} 1 * \mathrm{i}$ dade $)$

$\mathrm{CO} 2=1+\mathrm{EXP}(-\mathrm{K} 2 * \mathrm{i}$ dade)

$\mathrm{CO}=1+\mathrm{EXP}(-\mathrm{K} 3 * \mathrm{i}$ dade $)$

$\mathrm{CO} 4=1+\mathrm{EXP}(-\mathrm{K} 4 * \mathrm{i}$ dade)

$\mathrm{CO5}=1+\mathrm{EXP}(-\mathrm{K} 5 * \mathrm{i}$ dade)

CO6 $=1+E X P(-K 6 * i$ dade $) ;$

$\mathrm{CO}=1+\mathrm{EXP}(-\mathrm{K} 7 * \mathrm{i}$ dade)

$\mathrm{COB}=1+\mathrm{EXP}(-\mathrm{K} 8 * \mathrm{i}$ dade $)$;

MDDEL peso $=\left(\mathrm{Al}^{*} \mathrm{CO}^{*} *(-\mathrm{m} 1)\right) *(\mathrm{NGC}=1)+(\mathrm{A2} * \mathrm{CO} 2 * *(-\mathrm{m} 2)) *(\mathrm{NGC}=2)+$ $\left(\mathrm{A}^{*} * \mathrm{CO}^{*} *(-\mathrm{mB})\right) *(\mathrm{NGC}=3)+\left(\mathrm{A} 4 * \mathrm{CO}^{*} *(-\mathrm{m} 4)\right) *(\mathrm{NGC}=4)+$ $\left(\mathrm{A}^{*} \mathrm{CO}^{* * *}(-\mathrm{n} D)\right) *(\mathrm{NGC}=5)+(\mathrm{A} 6 * \mathrm{CO} * *(-\mathrm{n} 6)) *(\mathrm{NGC}=6)+$ $\left(\mathrm{A} 7 * \mathrm{CO}^{*} *(-\mathrm{m} 7)\right) *(\mathrm{NGC}=7)+(\mathrm{A} 8 * \mathrm{CO} * *(-\mathrm{n} 8)) *(\mathrm{NGC}=8)$;

out put out =outful gc predi ct ed=Ppred I 95m Ci nf u95m\# Csup;

RUN; 
Modelo Completo (inclui as classes de grupo contemporâneo e de genótipos para o GH)

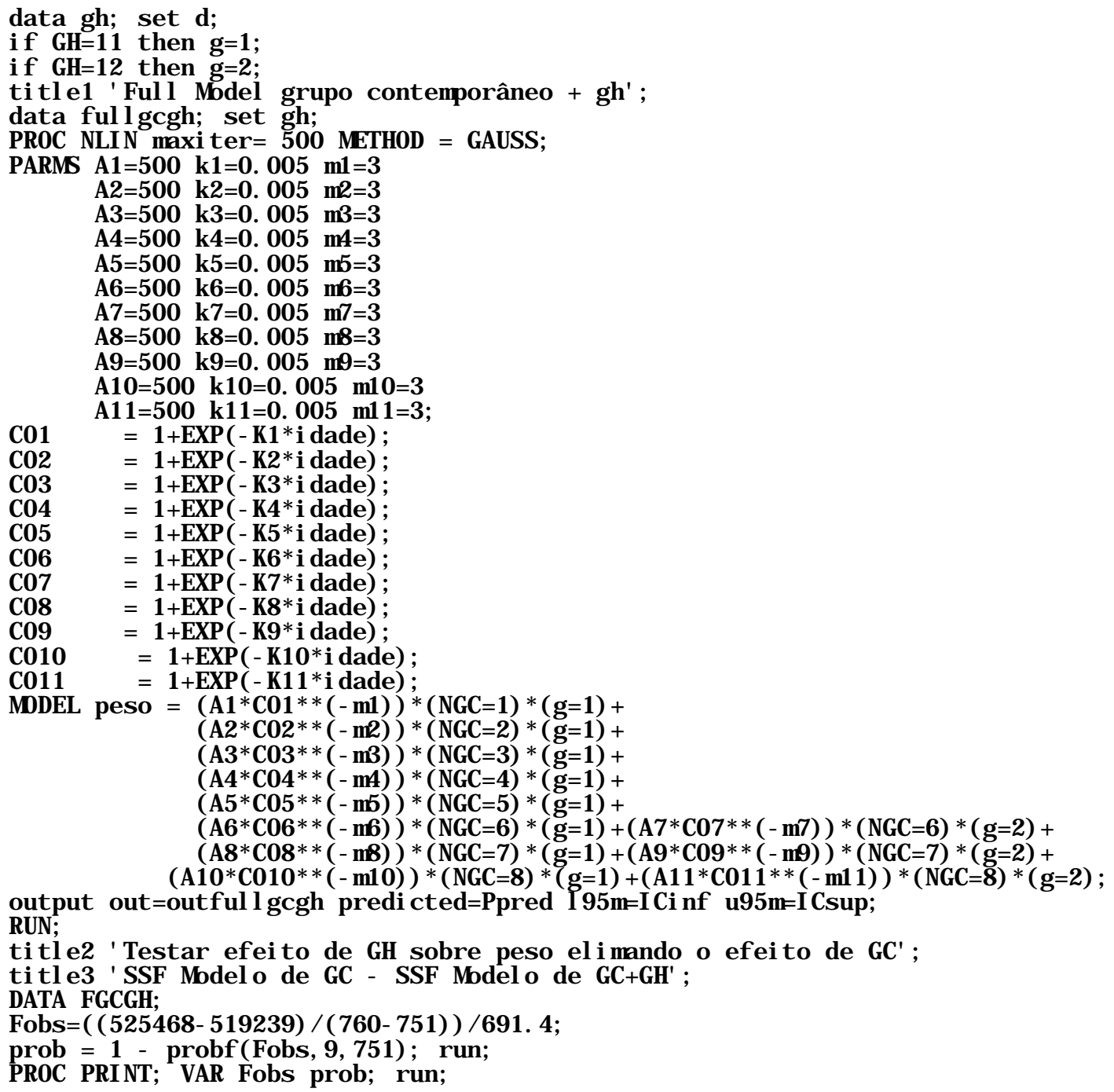

Modelo Completo (inclui as classes de grupo contemporâneo e de genótipos para o CSN3)

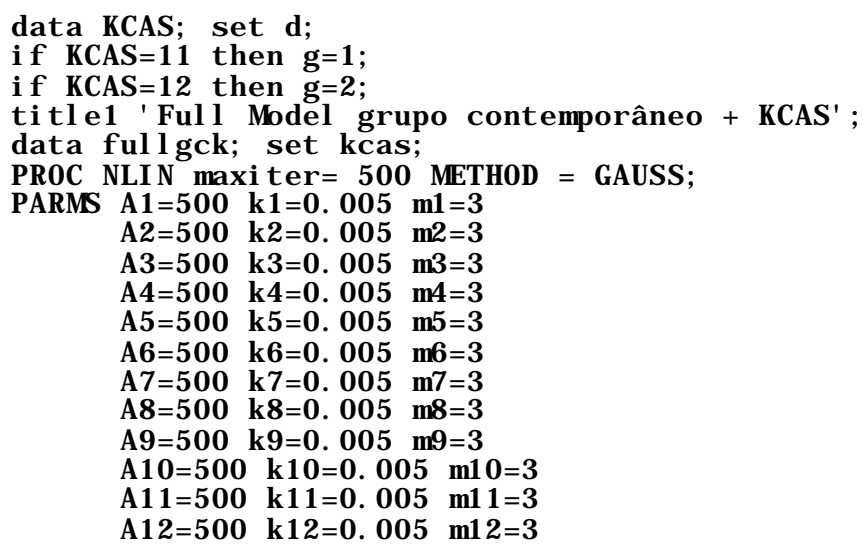




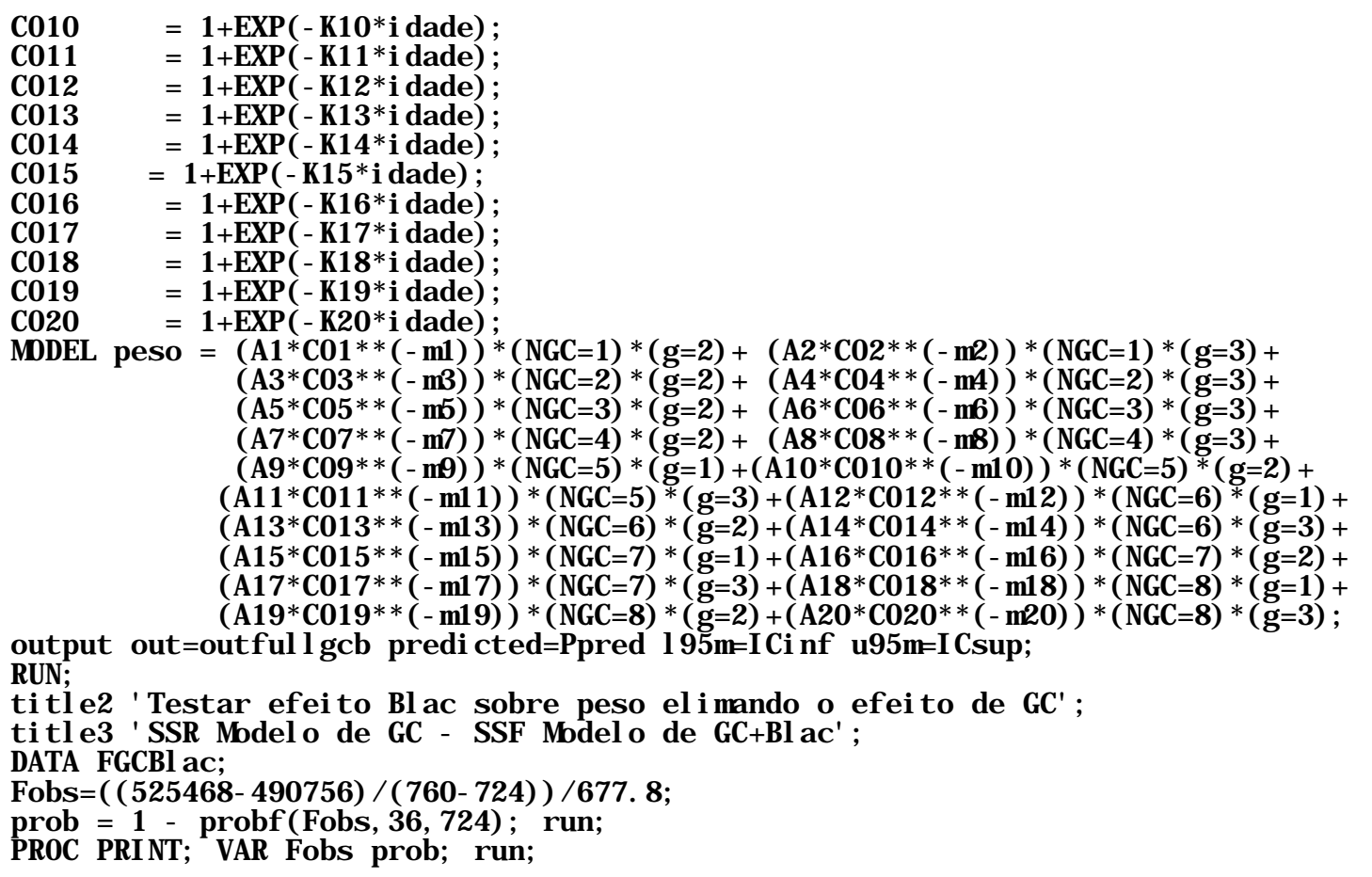

\section{Modelo Reduzido}

dat a red; set d;

PROC NLI N maxi ter $=500$ METHOD = GAUSS;

PARMS $A=500$ to 2000 by 500

$\mathrm{k}=0.001$ to 0.005 by 0.001 $\mathrm{m}=2$. 8 to 5.8 by 0.5 ;

MDDEL peso $=A^{*}\left(1+E X P\left(-K^{*} \mathrm{i}\right.\right.$ dade $) * *(-m)$;

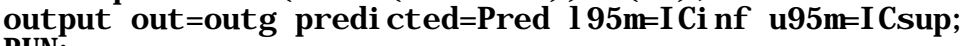
RUN;

titlel ' Nel ore $x$ Canchi $m$;

title2 'Testar ef ei to de 'GC sobre Peso '.

ti tl e3 ' SS Mbdel o Reduzi do - SSF Mbdel o de GC';

DATA FGC:

Fobs $=($ ( 2008141- 525468) / ( 781- 760) $) / 691.4$;

prob = 1 - probf (Fobs, 21, 760); run;

PROC PRI NT; VAR Fobs prob; run; 